NISTIR 7459

\title{
Design of the HLPR Chair
}

Home Lift Position and Rehabilitation Chair

\author{
Roger Bostelman \\ James Albus \\ Intelligent Systems Division \\ Manufacturing Engineering Laboratory \\ National Institute of Standards and Technology
}

June 19, 2007 


\section{Table Contents}

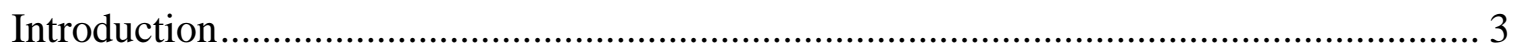

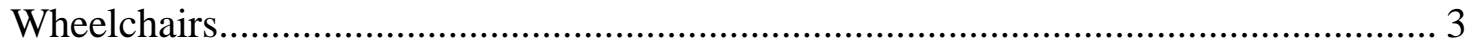

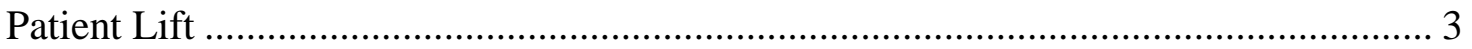

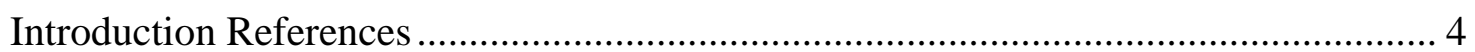

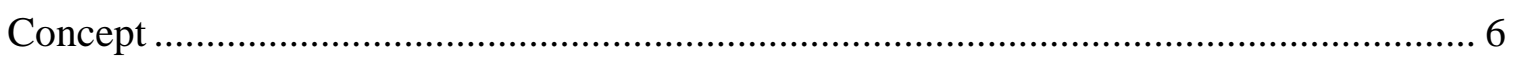

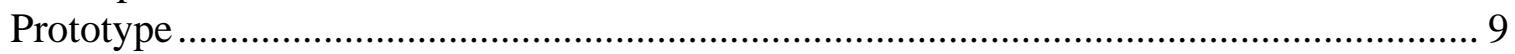

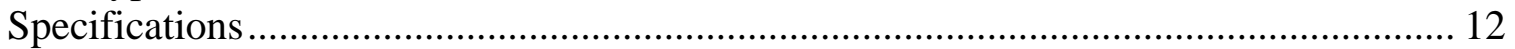

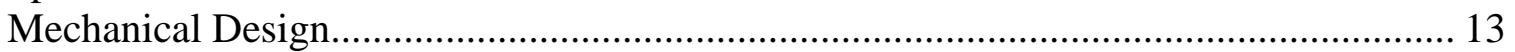

HLPR Chair Component Labels ....................................................................... 17

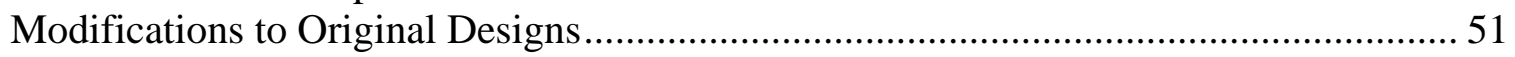

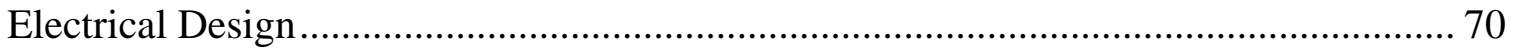

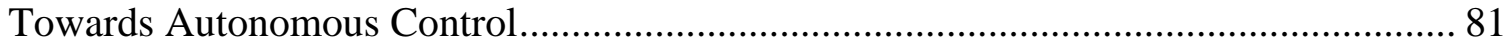

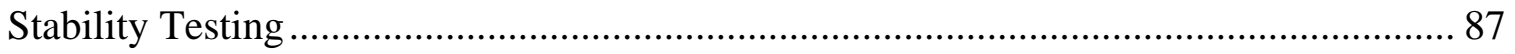

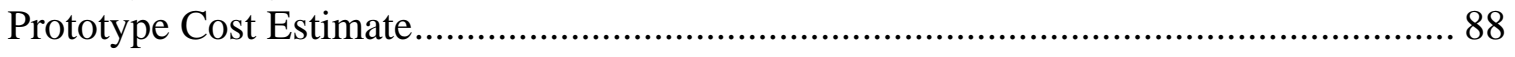




\section{Introduction}

Reference [1] says "today, approximately 10 percent of the world's population is over 60; by 2050 this proportion will have more than doubled" and "the greatest rate of increase is amongst the oldest old, people aged 85 and older.” She follows by adding that this group is subject to both physical and cognitive impairments more than younger people. These facts have a profound impact on how the world will maintain the elderly independent as long as possible from caregivers. Both physical and cognitive diminishing abilities address the body and the mental process of knowing, including aspects such as awareness, perception, reasoning, intuition and judgment. Assistive technology for the mobility impaired includes the wheelchair, lift aids and other devices, all of which have been around for decades. However, the patient typically or eventually requires assistance to use the device; whether it's someone to push them in a wheelchair, to lift them from the bed to a chair or to the toilet or for guiding them through cluttered areas. With fewer caregivers and more elderly, there is a need for improving these devices to provide them independent assistance.

\section{Wheelchairs}

There has been an increasing need for wheelchairs over time. L.H.V. van der Woude [2] states that mobility is fundamental to health, social integration and individual wellbeing of the humans. Henceforth, mobility must be viewed as being essential to the outcome of the rehabilitation process of wheelchair dependent persons and to their successful (re-)integration into society and to a productive and active life. Thrun [3] said that, if possible, rehabilitation to relieve the dependence on the wheelchair is ideal for this type of patient to live a longer, healthier life. Van der Woude continues stating that many lower limb disabled subjects depend upon a wheelchair for their mobility. Estimated numbers for Europe and USA are respectively 2.5 million and 1.25 million. The quality of the wheelchair, the individual work capacity, the functionality of the wheelchair/user combination, and the effectiveness of the rehabilitation program do indeed determine the freedom of mobility.

\section{Patient Lift}

Just as important as wheelchairs are the lift devices and people who lift patients into wheelchairs and other seats, beds, automobiles, etc. The need for patient lift devices will also increase as generations get older. When considering if there is a need for patient lift devices, several references state the positive, for example:

- "The question is, what does it cost not to buy this equipment? A back injury can cost as much as $\$ 50,000$, and that's not even including all the indirect costs. If a nursing home can buy these lifting devices for $\$ 1,000$ to $\$ 2,000$, and eliminate a back injury that costs tens of thousands of dollars, that's a good deal," [4]

- 1 in every 3 nurses become injured from the physical exertion put forth while moving non-ambulatory patients; costing their employers \$35,000 per injured nurse. [5]

- 1 in 2 non-ambulatory patients fall to the floor and become injured when being transferred from a bed to a wheelchair. - [6]

- "Nursing and personal care facilities are a growing industry where hazards are known 
and effective controls are available," said OSHA Administrator John Henshaw. "The industry also ranks among the highest in terms of injuries and illnesses, with rates about 2 1/2 times that of all other general industries..." [7]

- "Already today there are over 400,000 unfilled nursing positions causing healthcare providers across the country to close wings or risk negative outcomes. Over the coming years, the declining ratio of working age adults to elderly will further exacerbate the shortage. In 1950 there were 8 adults available to support each elder $65+$, today the ratio is $5: 1$ and by 2020 the ratio will drop to 3 working age adults per elder person.” [8]

In 2005, NIST ISD began the Healthcare Mobility Project to target this staggering healthcare issue of patient lift and mobility. ISD researchers looked at currently available technology through a survey of patient lift and mobility devices [9]. That report showed that there is need for technology that includes mobility devices that can lift and maneuver patients to other seats and technology that can provide for rehabilitation to help the patient become independent of the wheelchair.

An additional area investigated in the survey was intelligent wheelchairs. NIST has been studying intelligent mobility for the military, transportation, and the manufacturing industry for nearly 30 years through the Intelligent Control of Mobility Systems (ICMS) Program. [10] Toward a standard control system architecture and advanced 3D imaging technologies, as being researched within the ICMS Program, and applying them to intelligent wheelchairs, NIST has begun outfitting the HLPR Chair with computer controls. Although throughout the world there are or have been many research efforts in intelligent wheelchairs, including: $[11,12,13,14]$ and many others, the authors could find no sources applying standard control methods nor application of the most advanced 3D imagers prototyped today to intelligent wheelchairs. Therefore, NIST began developing the HLPR Chair [15] to investigate these specific areas of mobility, lift and rehabilitation, as well as advanced autonomous control.

This paper includes mechanical and electrical designs for the HLPR Chair in its prototype stage with designs dating back to December 2005. An initial prototype HLPR Chair concept, called RoboChair, was completed in July 2004.

\section{Introduction References}

[1] Pollack, Martha, "Intelligent Technology for Adaptive Aging” Presentation, AAAI-04 American Association for Artificial Intelligence Conference Keynote Address, 2004

[2] L.H.V. van der Woude , M.T.E. Hopman and C.H. van Kemenade, "Biomedical Aspects of Manual Wheelchair Propulsion: The State of the Art II,” Volume 5, Assistive Technology Research Series, 1999, 392 pp., hardcover

[3] Thrun, Sebastian, Visit to Stanford University to discuss healthcare mobility devices, August 2006.

[4] Marras, William, "Lifting Patients Poses High Risk for Back Injuries,” Ohio State University, http://researchnews.osu.edu/archive/resthome.htm. 1999.

[5] Blevins, Healthcare Statistics: Blevins Medical, Inc., http://www.patientlift.net/282164.html. 2006

[6]U.S. Bureau of Labor Statistics, from Blevins website: http://www.patientlift.net/282164.html, 1994. 
[7] John Henshaw, http://www.osha.gov/SLTC/ nursinghome/solutions.html, Occupational Safety and Health Administration, 2005

[8] Wasatch Digital iQ, "InTouch Health's Remote Presence Robot Used by Healthcare Experts," http://www.wasatchdigitaliq.com/parser.php?nav=article\&article_id=43, Santa Barbara, CA \& Salt Lake City --(Business Wire)--June 16, 2003.

[9] Bostelman, Roger; Albus, James, "Survey of Patient Mobility and Lift Technologies Toward Advancements and Standards” NISTIR \#7384, 2006.

[10] NIST Intelligent Control of Mobility Systems Program website: http://www.isd.mel.nist.gov/ research_areas/mobility/index.htm

[11] Kuno, Y., Murashima, T., Shimada, N., Shirai, Y., "Intelligent Wheelchair Remotely Controlled by Interactive Gestures," International Conference on Pattern Recognition, vol. 04, no. 4, p. 4672, 2000.

[12] Patel, S., Jung, S-H., Ostrowski, J., Rao, R., Taylor, C., "Sensor based door navigation for a nonholonomic vehicle,” GRASP Laboratory, University of Pennsylvania, Proceedings of the 2002 IEEE International Conference on Robotics and Automation, Washington, DC, May 2002.

[13] Song W.-K.; Lee H.; Bien Z., "KAIST - KARES: Intelligent wheelchair-mounted robotic arm system using vision and force sensor," Robotics and Autonomous Systems, vol. 28, no. 1, pp. 83-94(12), 31, Publisher: Elsevier Science, July 1999.

[14] Yanco, H., Hazel, A., Peacock, A., Smith, S. and Wintermute, H. "Initial Report on Wheelesley: A Robotic Wheelchair System,” Department of Computer Science, Wellesley College, 1995

[15] Bostelman, R., Albus, J., "HLPR Chair - A Service Robot for the Healthcare Industry," 3rd International Workshop on Advances in Service Robotics, Vienna, Austria, July 7, 2006 


\section{Concept}

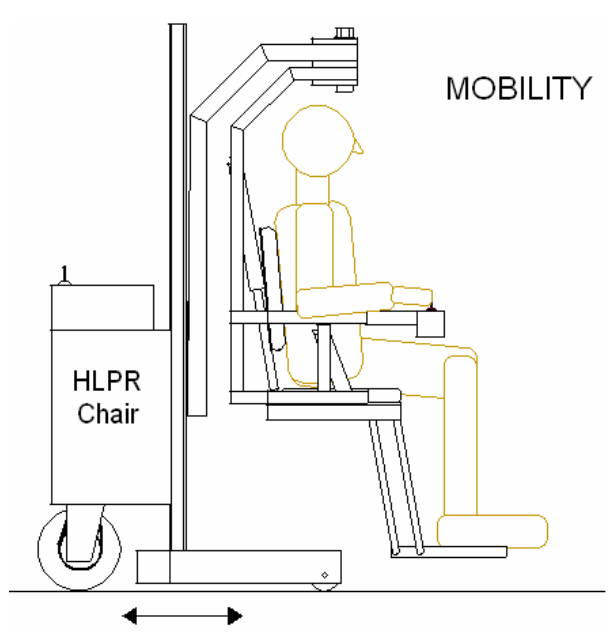

HLPR Chair is shown in the powered chair configuration with controls that the patient can use to drive the chair or a nurse/caregiver can use the controls from behind the chair to mobilize the patient.

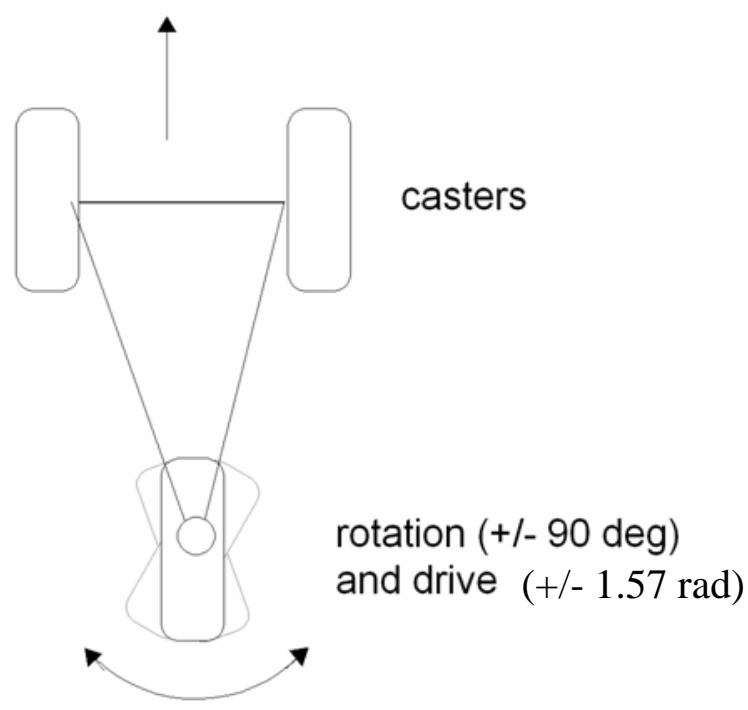

Top view of the HLPR Chair rear steering and drive wheel and fixed front casters configuration.

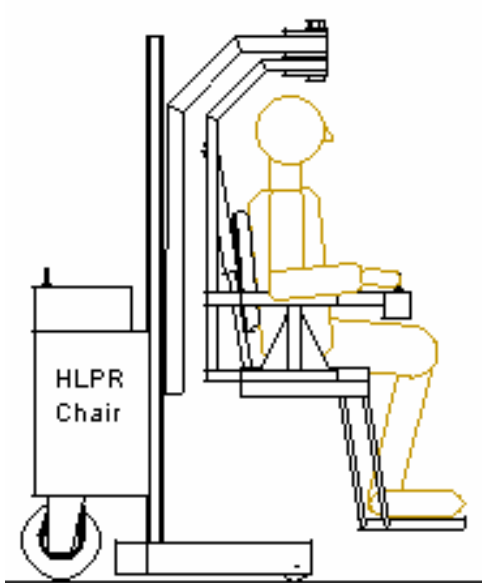

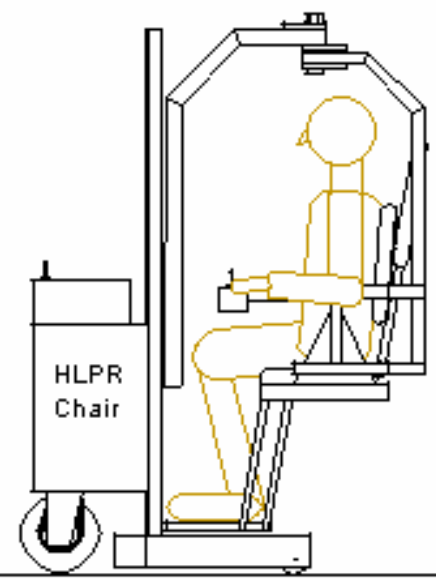

(a)

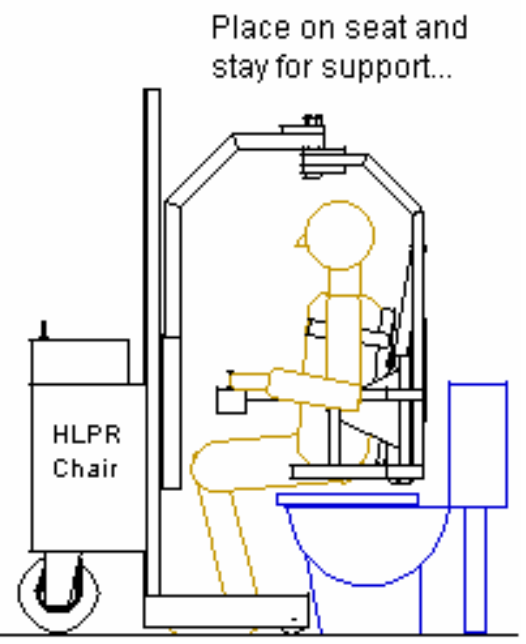

Place on seat and stay for support... 


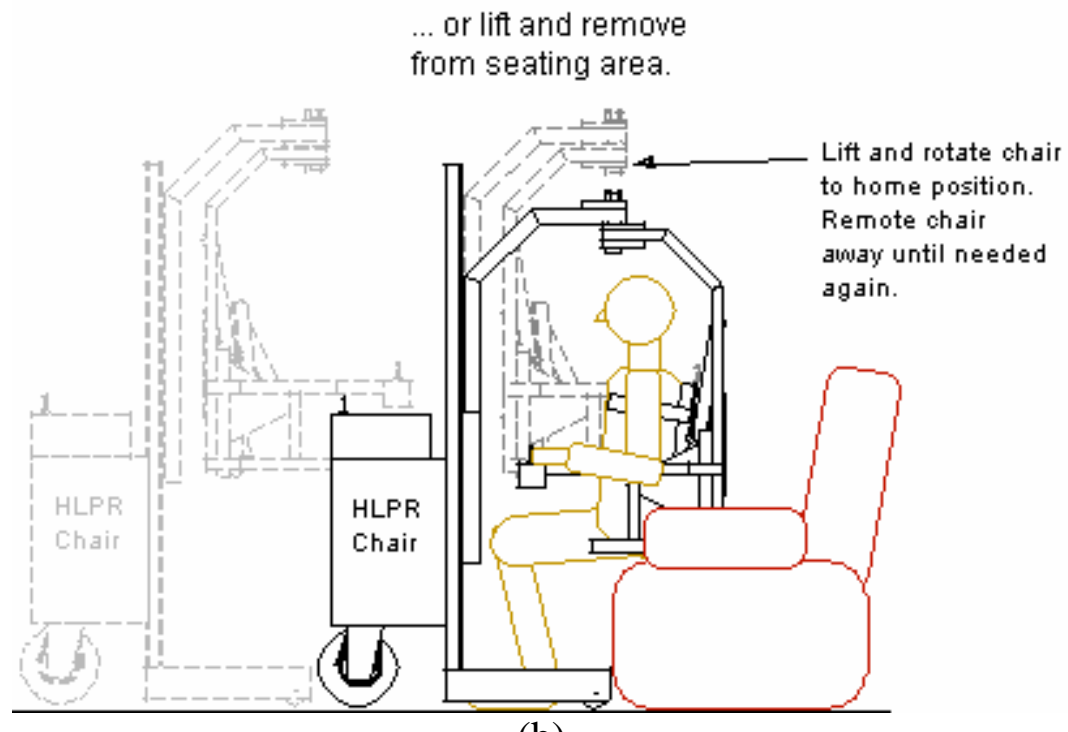

(b)

(a) HLPR Chair can be used to carry a patient to a chair or toilet, rotate the patient ready to place them on the seat, remove the footrest, raise the torso lifts and patient above the HLPR Chair seat, remove the HLPR Chair seat from beneath the patient, and place the patient on the target chair or toilet. (b) HLPR Chair can be used for patient placement on a comfortable chair. Additionally, controls can be designed to allow the patient to command using voice or remote interface to control the HLPR Chair go away until or come when needed.

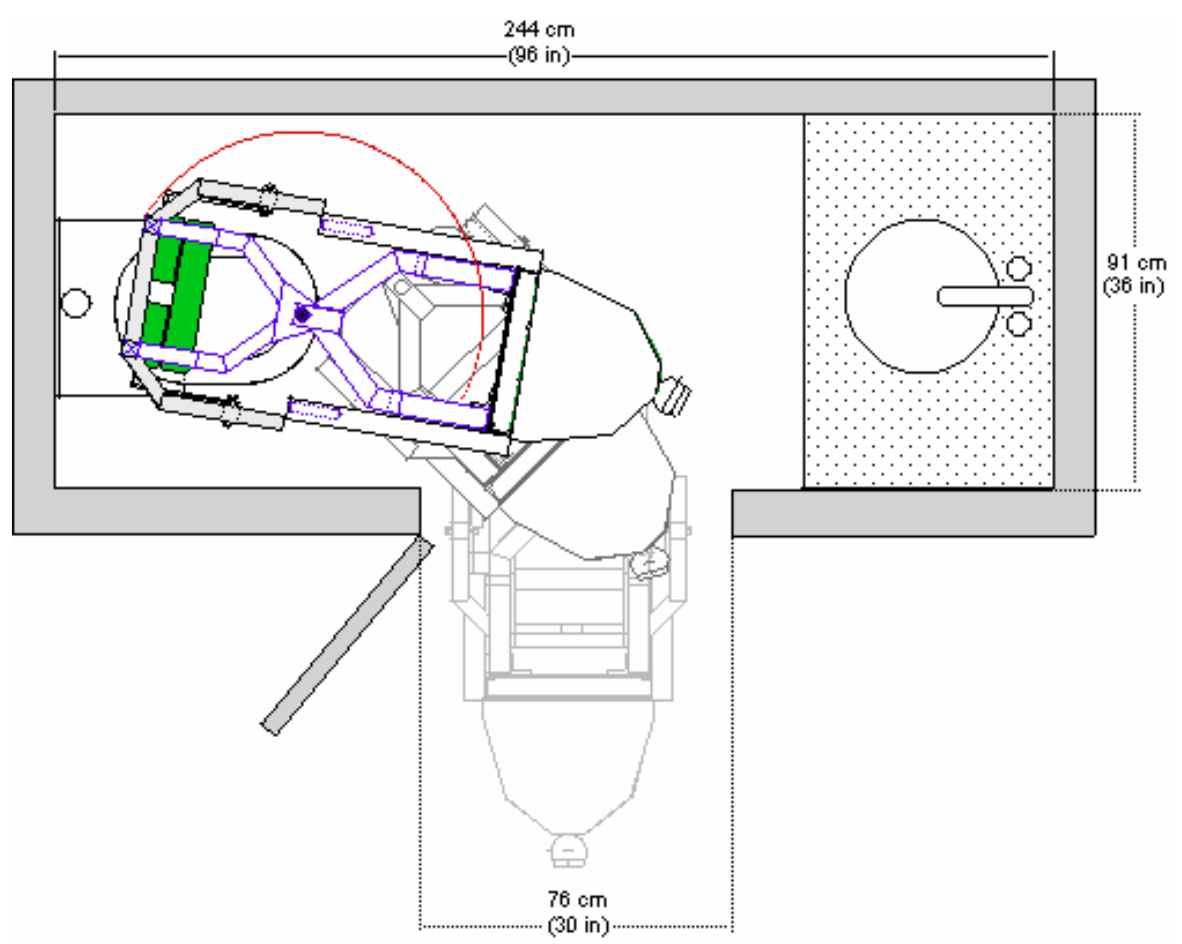

Top view showing HLPR Chair accessing a toilet in a bathroom. The red arc shows the maximum radius of seat frame rotation needed. 


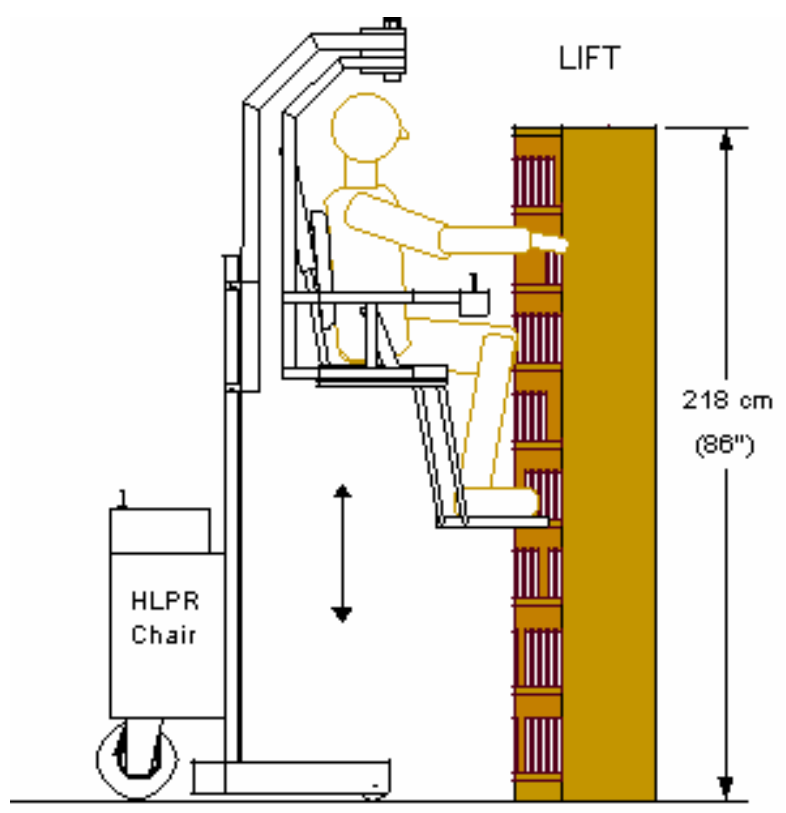

HLPR Chair allows lift, currently up to 0.9 m (36 in) above mobility configuration height.

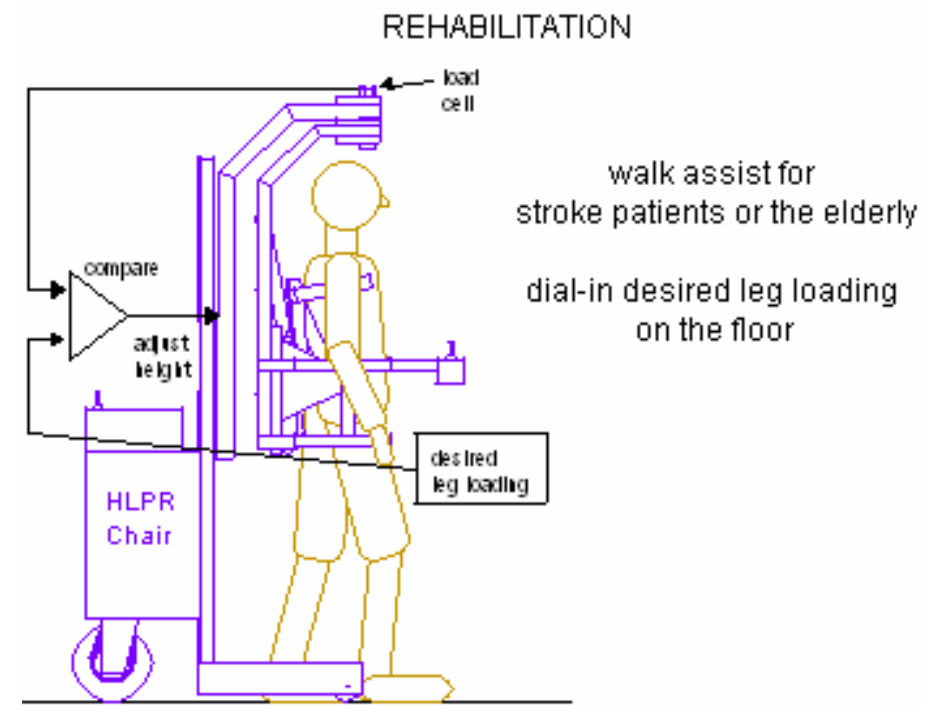

HLPR Chair can be used for patient rehabilitation and incorporate future legs load control. 


\section{Prototype}

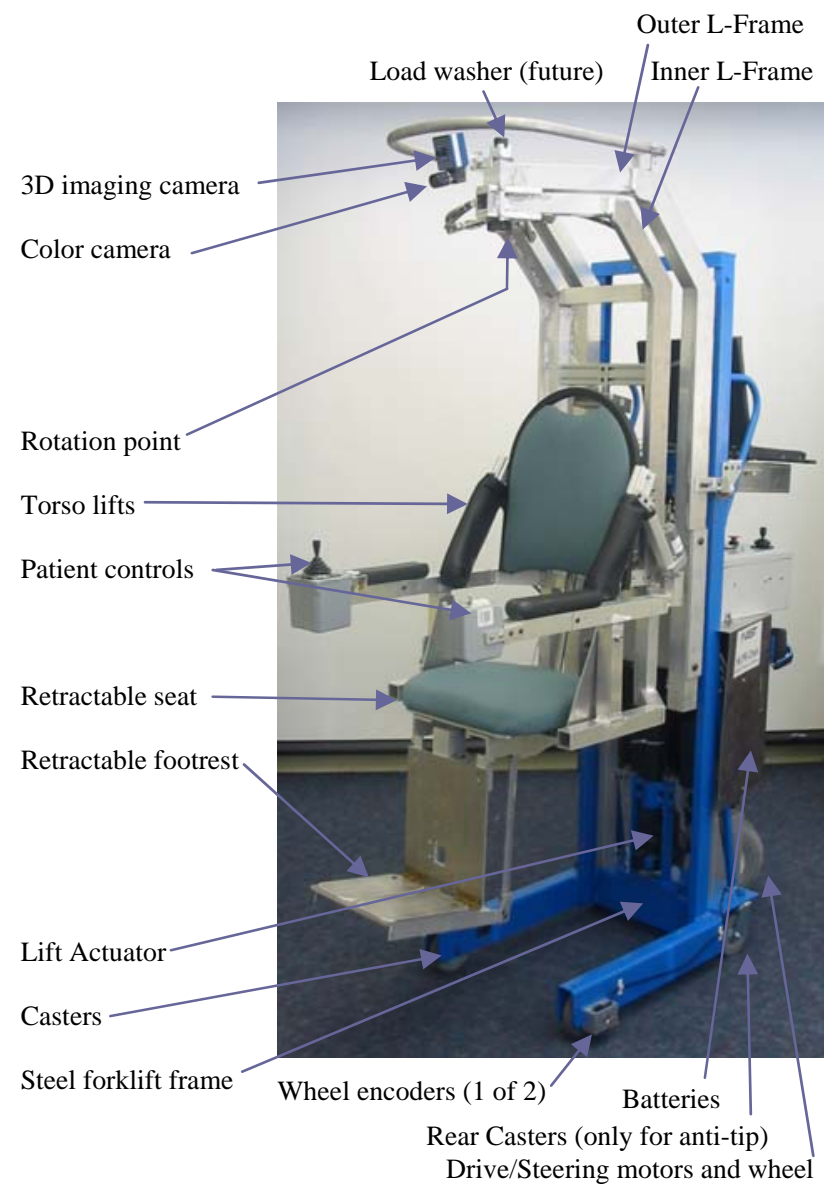

Photograph 1 of the HLPR Chair prototype.
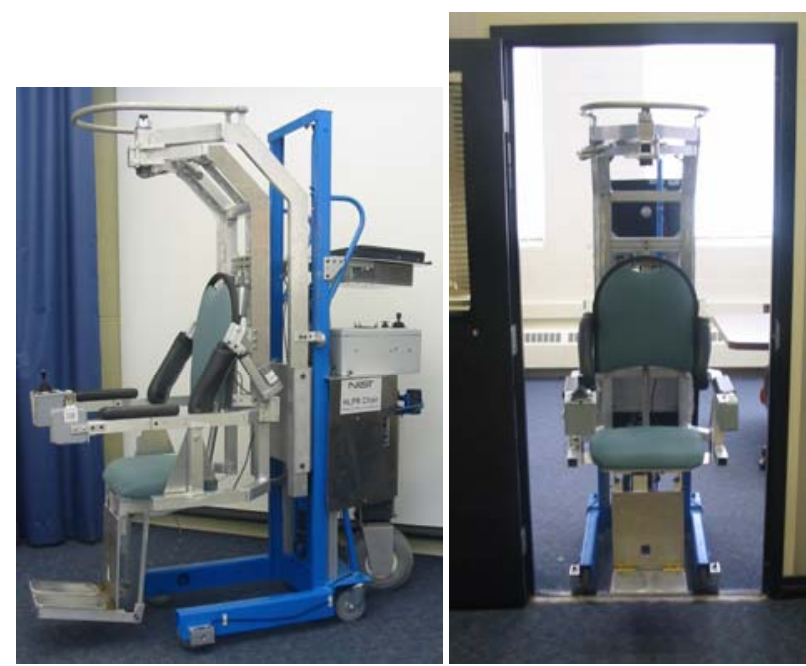

Photograph 2 (left) of the HLPR Chair in the mobility configuration showing the side view and Photograph 3 (right) front view relative to a typical doorway. 

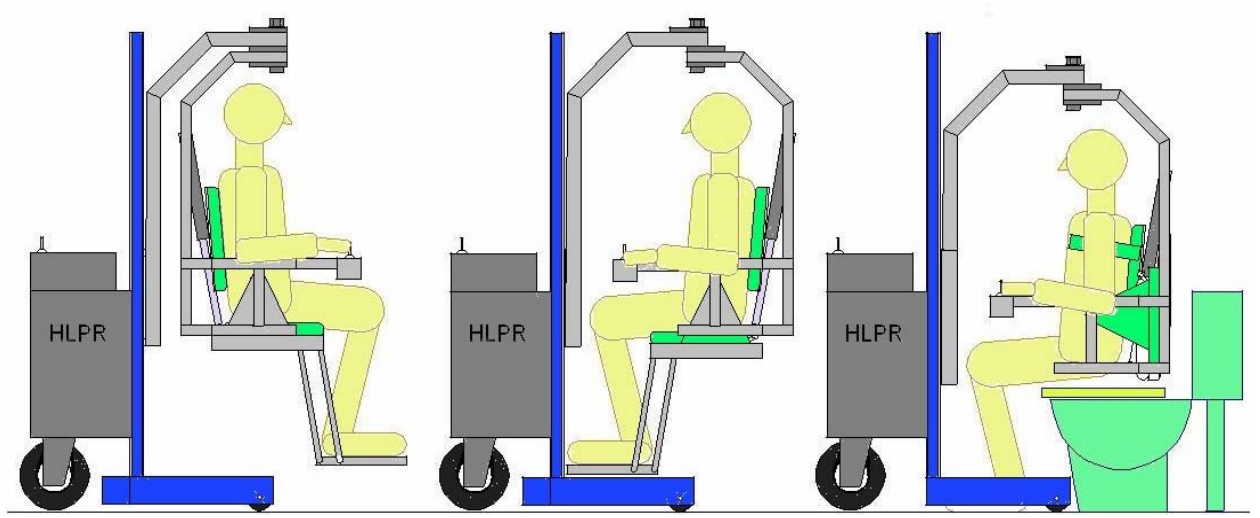

Graphic showing the concept of placing a patient onto a toilet or chair with the HLPR Chair. The patient drives to the target seat (left), manually rotates near or over the seat (middle) while the torso lifts support the patient and the seat retracts, and then is lowered onto the seat - toilet, chair or bed (right)
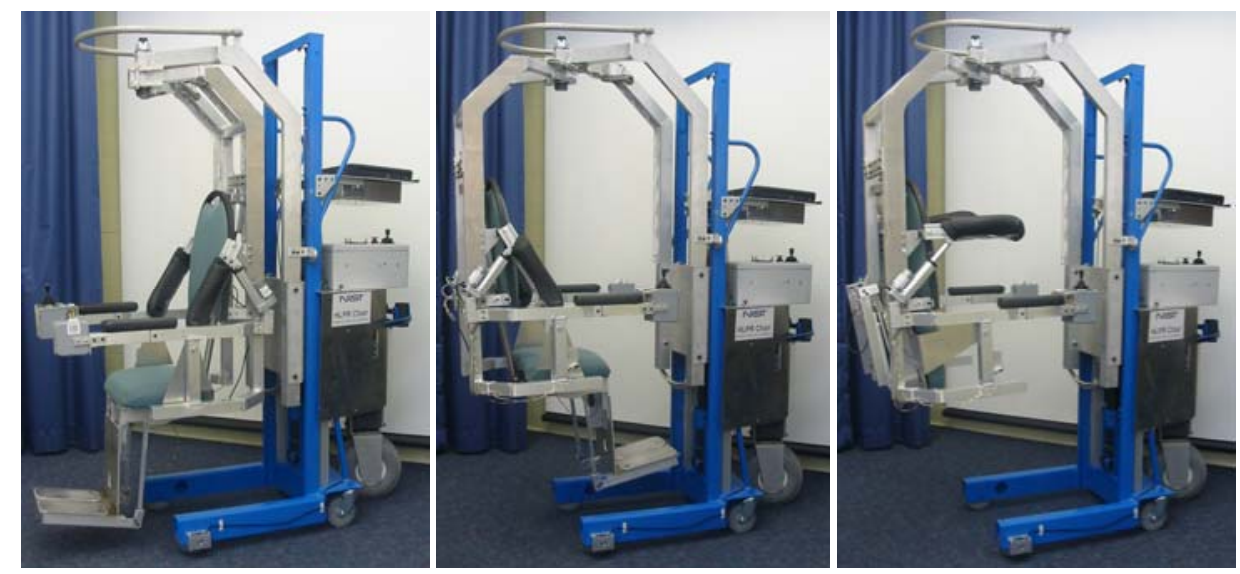

Photographs 4, 5, and 6 (lt. to rt.) of the HLPR Chair prototype in the same configurations as in the graphic above placing a patient on a toilet.

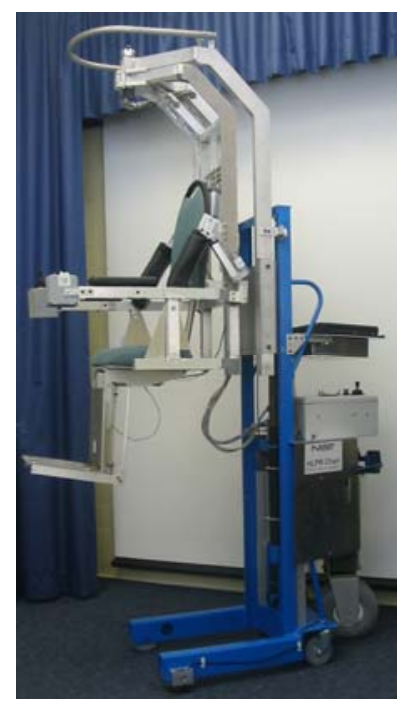

Photograph 7 of the HLPR Chair prototype shown in the patient lift position. 


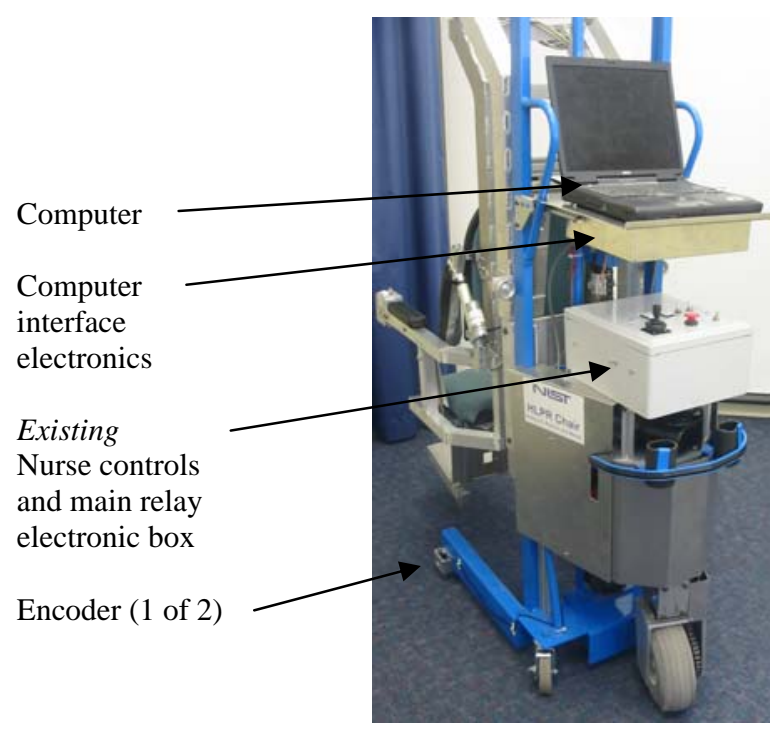

Photograph 8 of the HLPR Chair with recently added front wheel encoders, development computer and interface electronics.

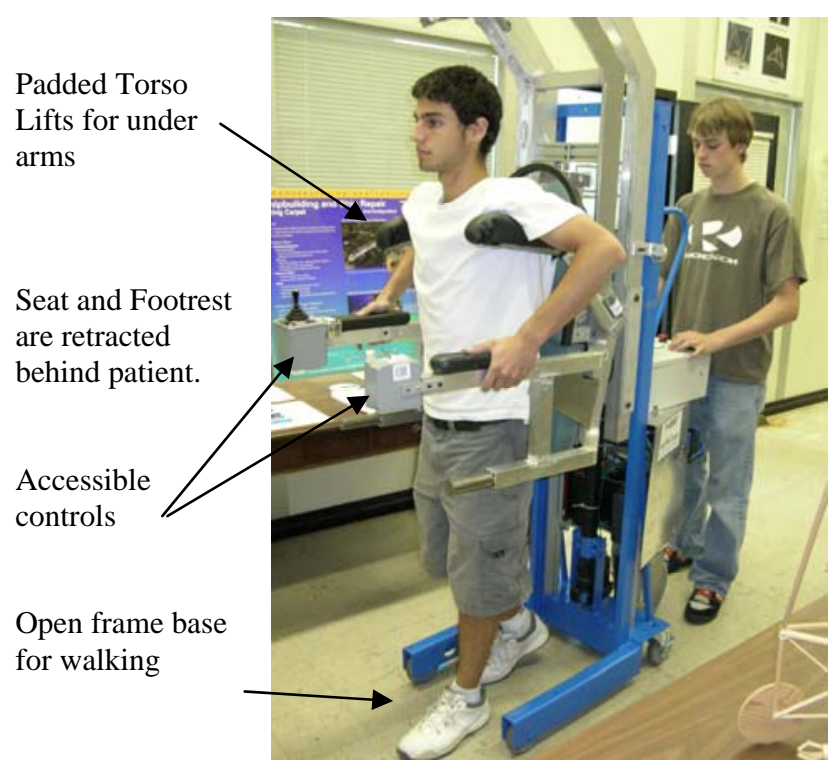

Photograph 9 of the HLPR Chair prototype in the rehabilitation/walking configuration. Summer Interns (Alex Page and Robert Vlacich) demonstrate the patient and nurse configuration as part of their official duties. 


\section{Specifications}

\begin{tabular}{|c|c|}
\hline Size: & \\
\hline \multirow{3}{*}{ Mobility Configuration } & $145 \mathrm{~cm}$ long x $58 \mathrm{~cm}$ wide x $178 \mathrm{~cm}$ high \\
\hline & (57” long x 23” wide x 70” high) \\
\hline & with $57 \mathrm{~cm}(22$ 1/2”) seat ht. above floor \\
\hline \multirow[t]{4}{*}{ Full Lifted Configuration } & $145 \mathrm{~cm}$ long x $58 \mathrm{~cm}$ wide x $241 \mathrm{~cm}$ high \\
\hline & (57” long x 23” wide x 95” high) \\
\hline & with $125 \mathrm{~cm}$ (49”) seat ht. above floor - currently \\
\hline & can be adjusted to lift $91 \mathrm{~cm}(36 ”)$ \\
\hline Weight (unloaded) & 136 kg (300 Lbs.) \\
\hline \multirow[t]{2}{*}{ Payload: } & 136 kg (300 Lbs.) (designed) \\
\hline & 91 kg (200 Lbs.) (tested to date) \\
\hline Tilt & $0.06 \mathrm{rad}(10 \mathrm{deg})$ \\
\hline Max. Speed & 0.7 mps (28 ips) \\
\hline Turning Radius & $86 \mathrm{~cm}$ (34”) centered about the rider \\
\hline Chair Rotate Angle & $0.5 \mathrm{rad}(90 \mathrm{deg}) \mathrm{CCW}$ to $1 \mathrm{rad}(180 \mathrm{deg}) \mathrm{CW}$ \\
\hline \multicolumn{2}{|l|}{ Wheels: } \\
\hline Rear Drive/Steer & 10” diameter pneumatic \\
\hline Front Caster & 5” diameter solid \\
\hline Ground Clearance & $4.4 \mathrm{~cm}(13 / 4 ”)$ \\
\hline Battery & 2-12Vdc dry cells (series 24V) \\
\hline Per-Charge Range & unknown to date \\
\hline Battery weight & 11.6 kg (26 Lbs) each \\
\hline Drive Train & 1 motor chain drive, 1 gearmotor direct steer \\
\hline Battery Chargers & two (one per battery), off-board \\
\hline
\end{tabular}




\title{
Mechanical Design
}

\author{
Manual Fork Lift Base Frame ${ }^{1}$
}

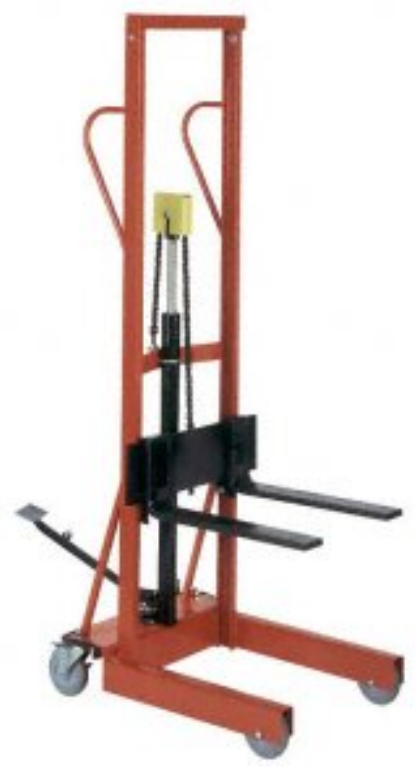

Hydraulic Lift

Foot operated hydraulic pump makes raising the load a simple task.

Foot pedal release results in controlled lowering to reduce the risk of accidents. Wheels are on swivel casters and lock into position for load lifting and lowering.

Two forks lower to $10.8 \mathrm{~cm}$ (4.3 in) above the floor and raise loads up to $137 \mathrm{~cm}$ (54 in) to get your machinery or heavy objects at an accessible level.

227 kg (500 Lbs) capacity.

For the HLPR Chair Design, the hydraulic piston was replaced with an electric ball screw actuator with $454 \mathrm{~kg}$ (1000 Lbs) lift capacity and $0.45 \mathrm{~m}$ (18 in) stroke. The fork lift chain design allows a 2:1 lift height for $0.9 \mathrm{~m}$ (36 in) fork (chair) lift with half the payload or $227 \mathrm{~kg}$ (500 Lbs).

\footnotetext{
${ }^{1}$ NIST does not endorse products or organizations.
} 


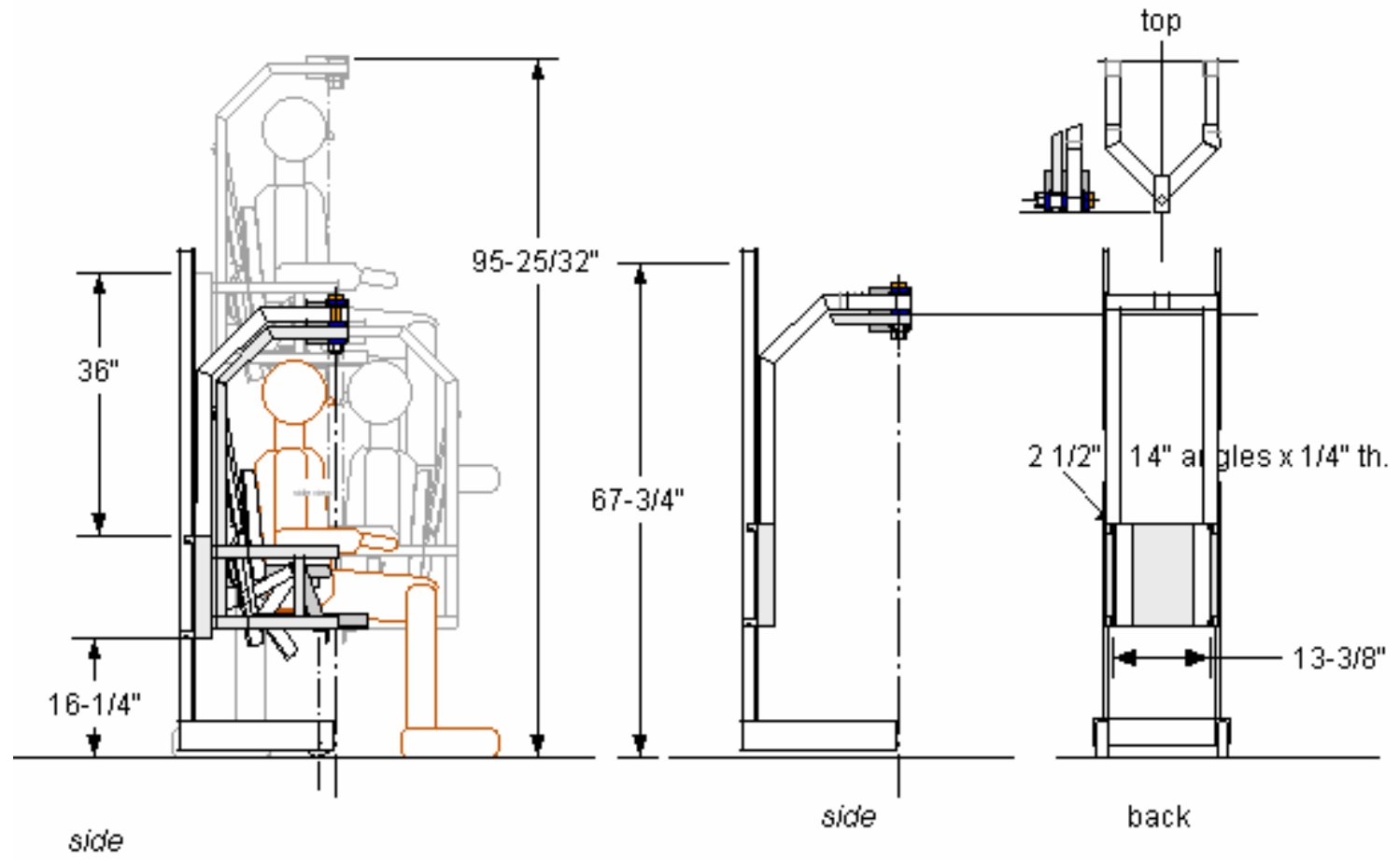

Left (side) view shows $0.9 \mathrm{~m}$ (36 in) base and seat frame travel and maximum system height. Center side view shows $37.4 \mathrm{~cm}$ (95 25/32 in). Center (side) and right (back) views show only the base frame with the forklift frame components with the seat frame removed and the rotation (top) joint view.

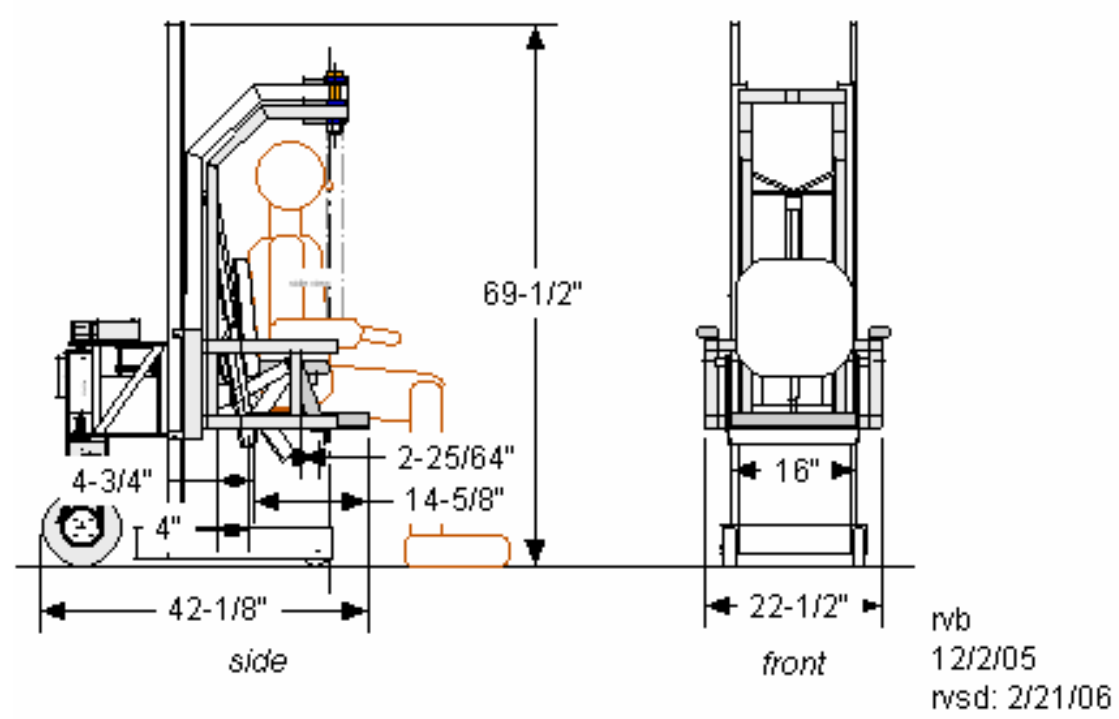

Side and front views of the HLPR Chair with minimal dimensions for length, height, and width while in the mobility configuration. 


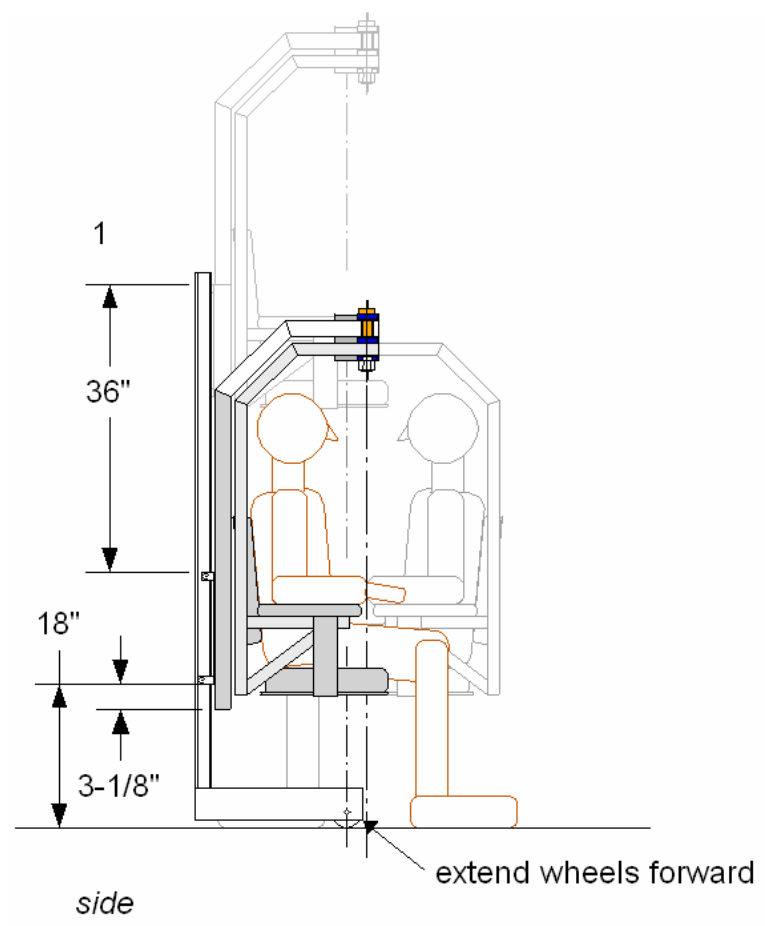

HLPR Chair side view without the rear drive system and suggested front wheel extension to allow the seat rotation point to be within the wheelbase. This modification was not added to the prototype and is not necessary with appropriate counterweight (e.g., drive and battery system) added to the rear.

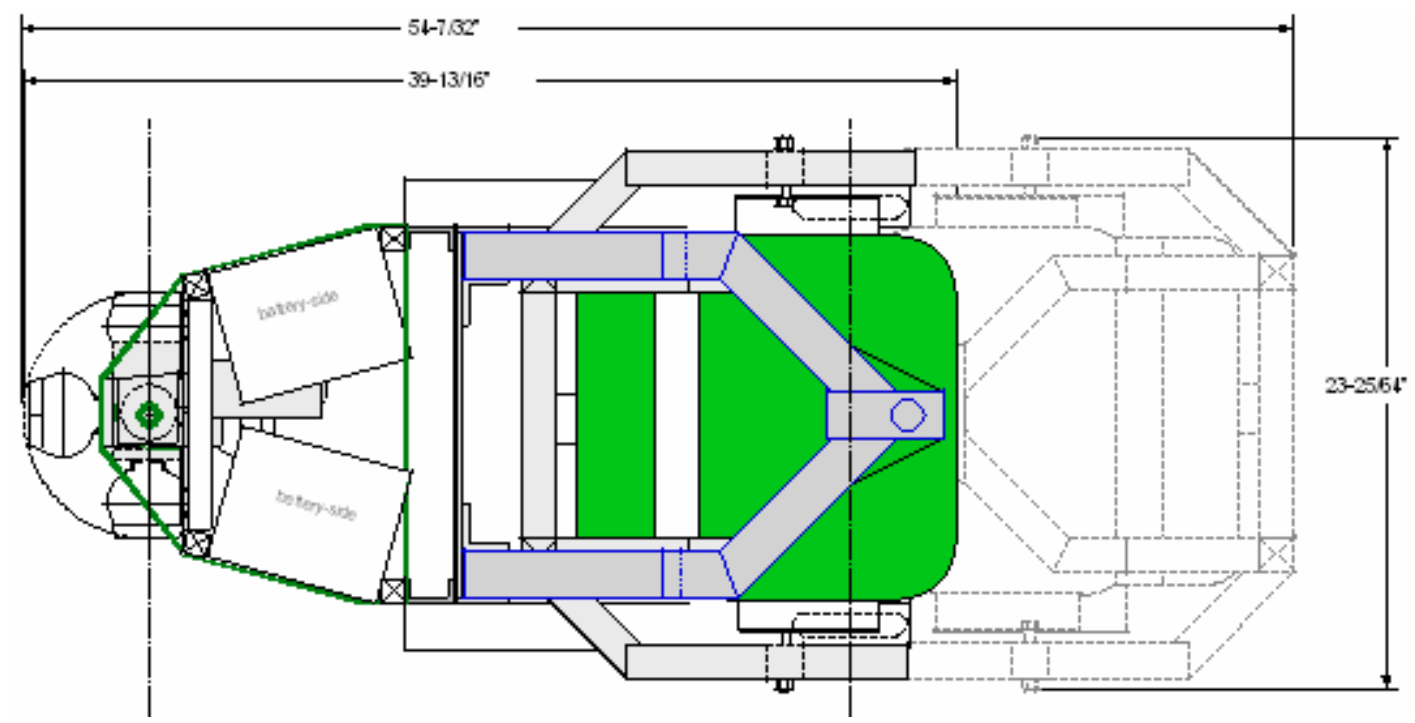

(a) 


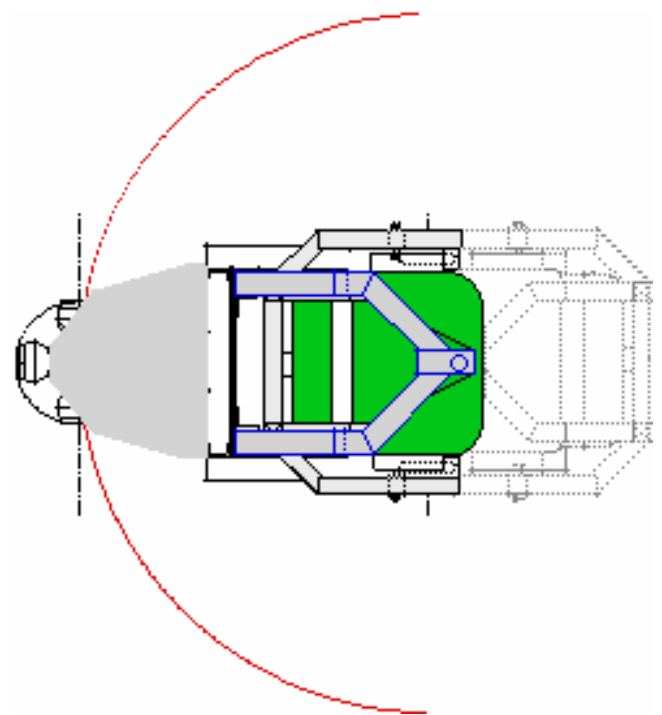

(b)

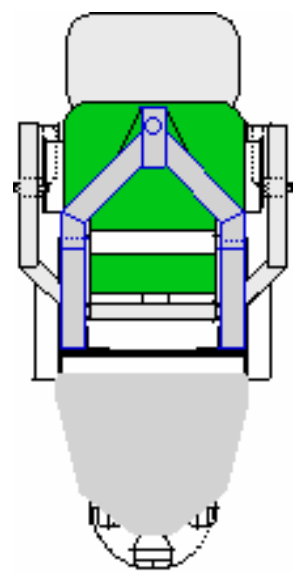

(c)

Top views of the HLPR Chair showing (a) Maximum length and width, (b) minimum HLPR Chair rotation about the front casters axle center $76 \mathrm{~cm}$ (30 in) and (c) top view of the HLPR Chair. 


\section{HLPR Chair Component Labels}

These labels refer to drawings that follow.

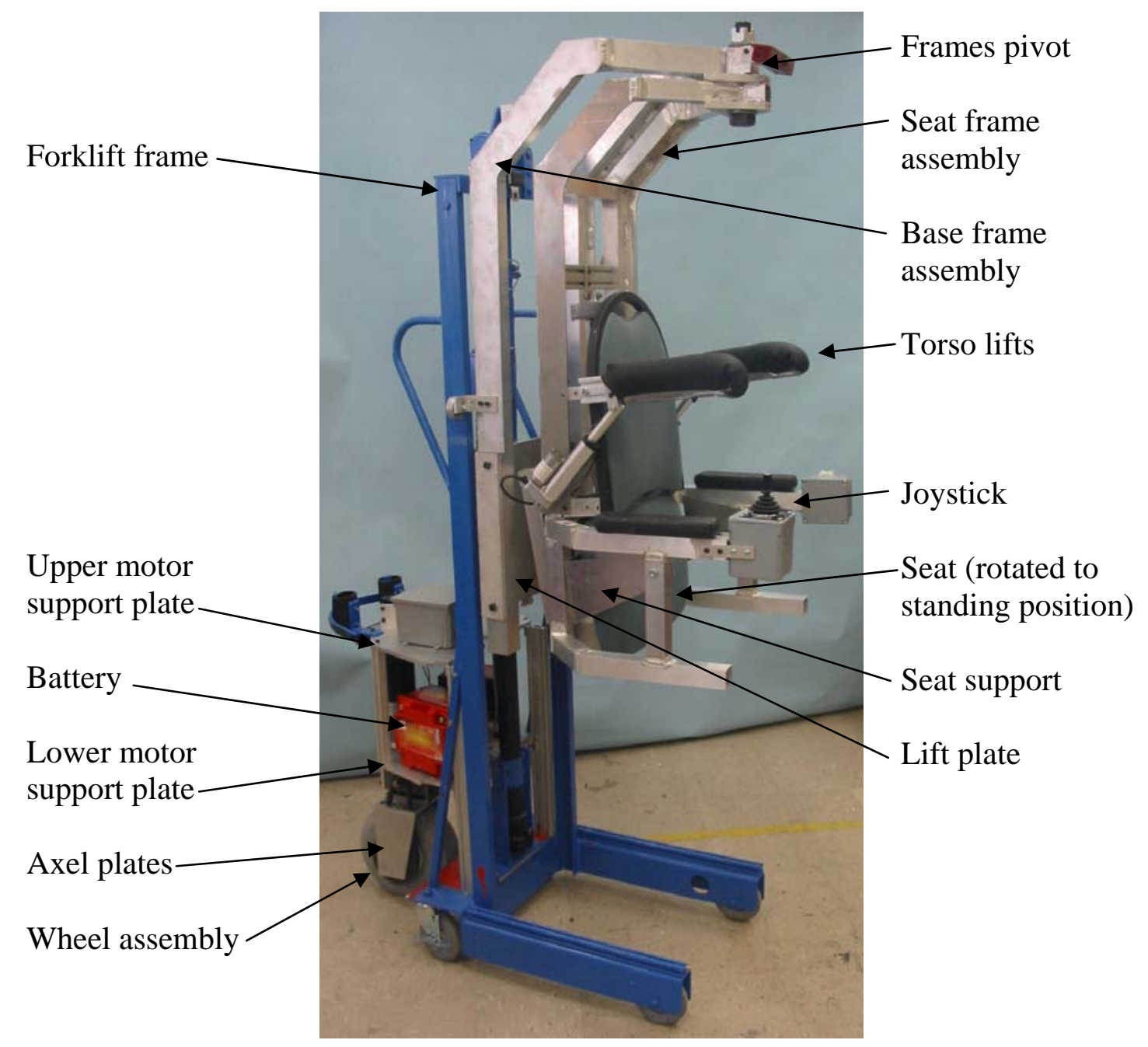




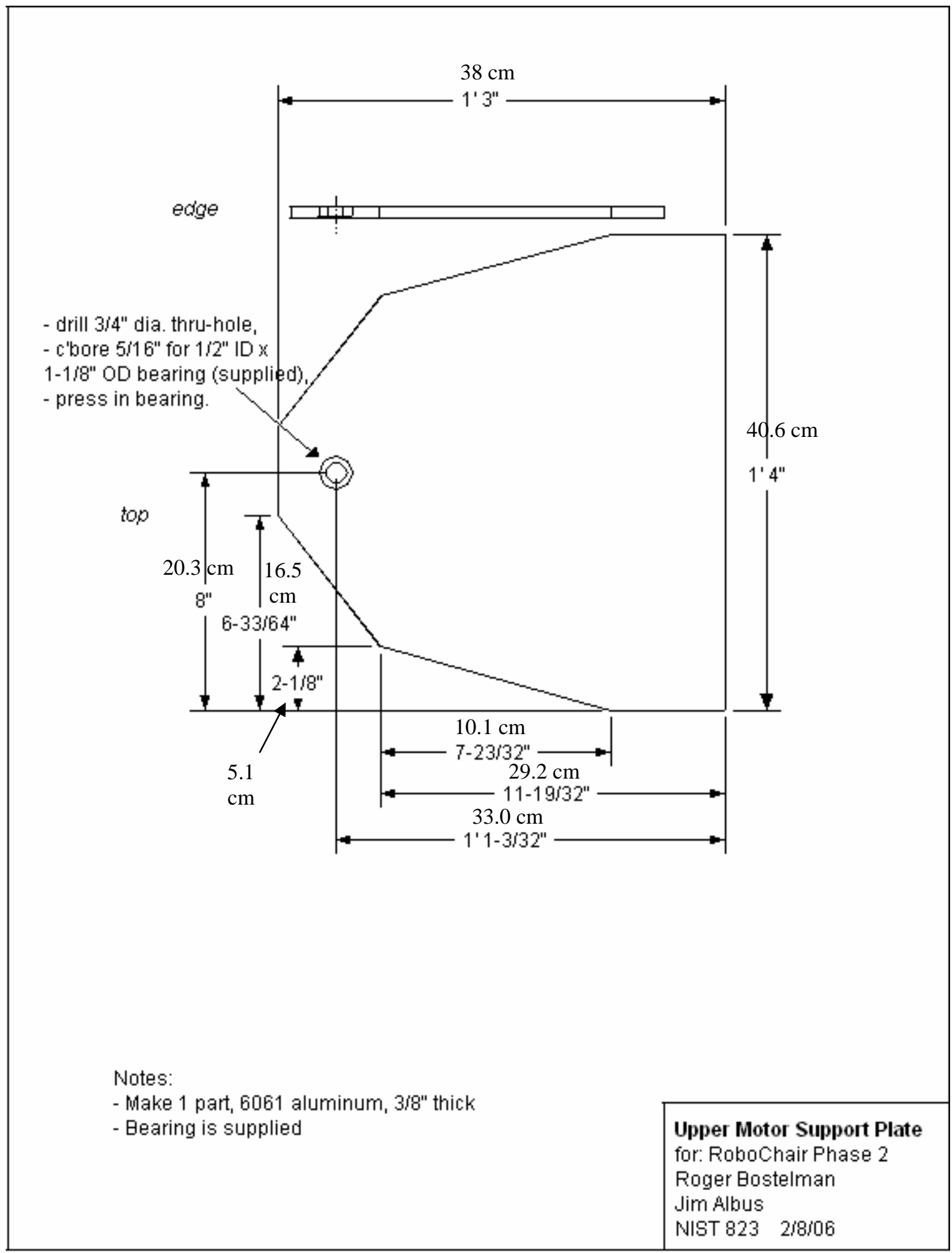




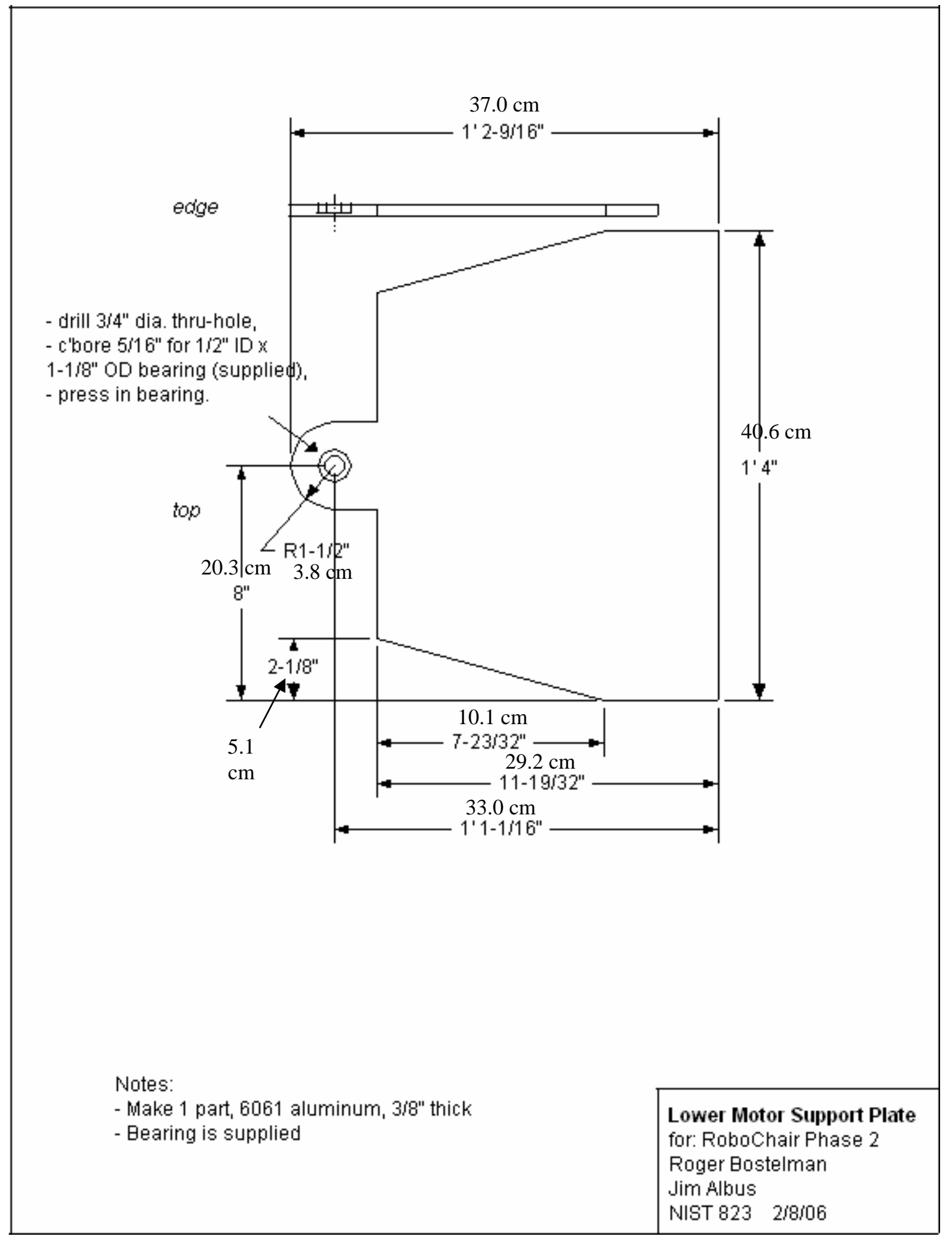




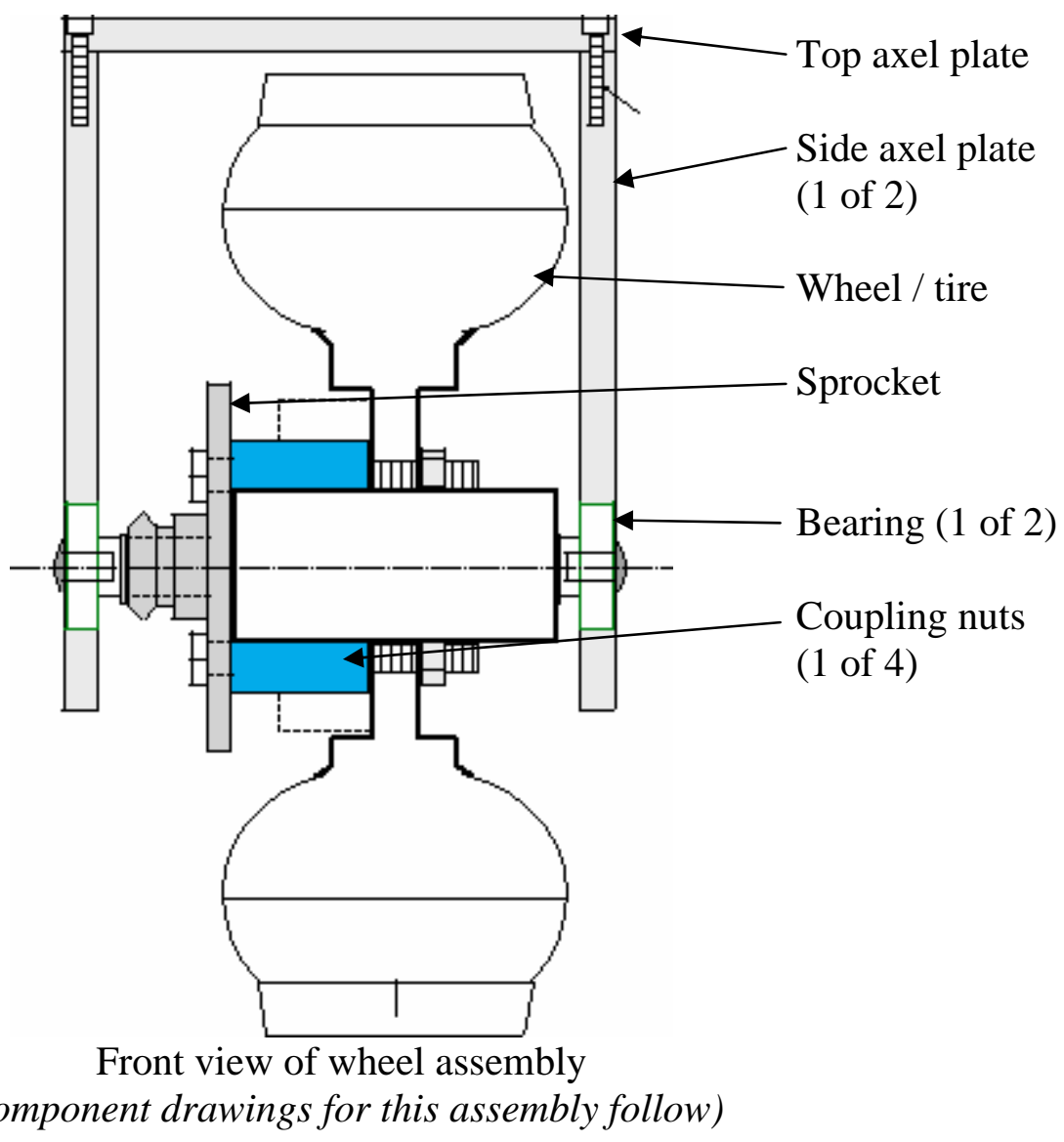


Design of the HLPR Chair

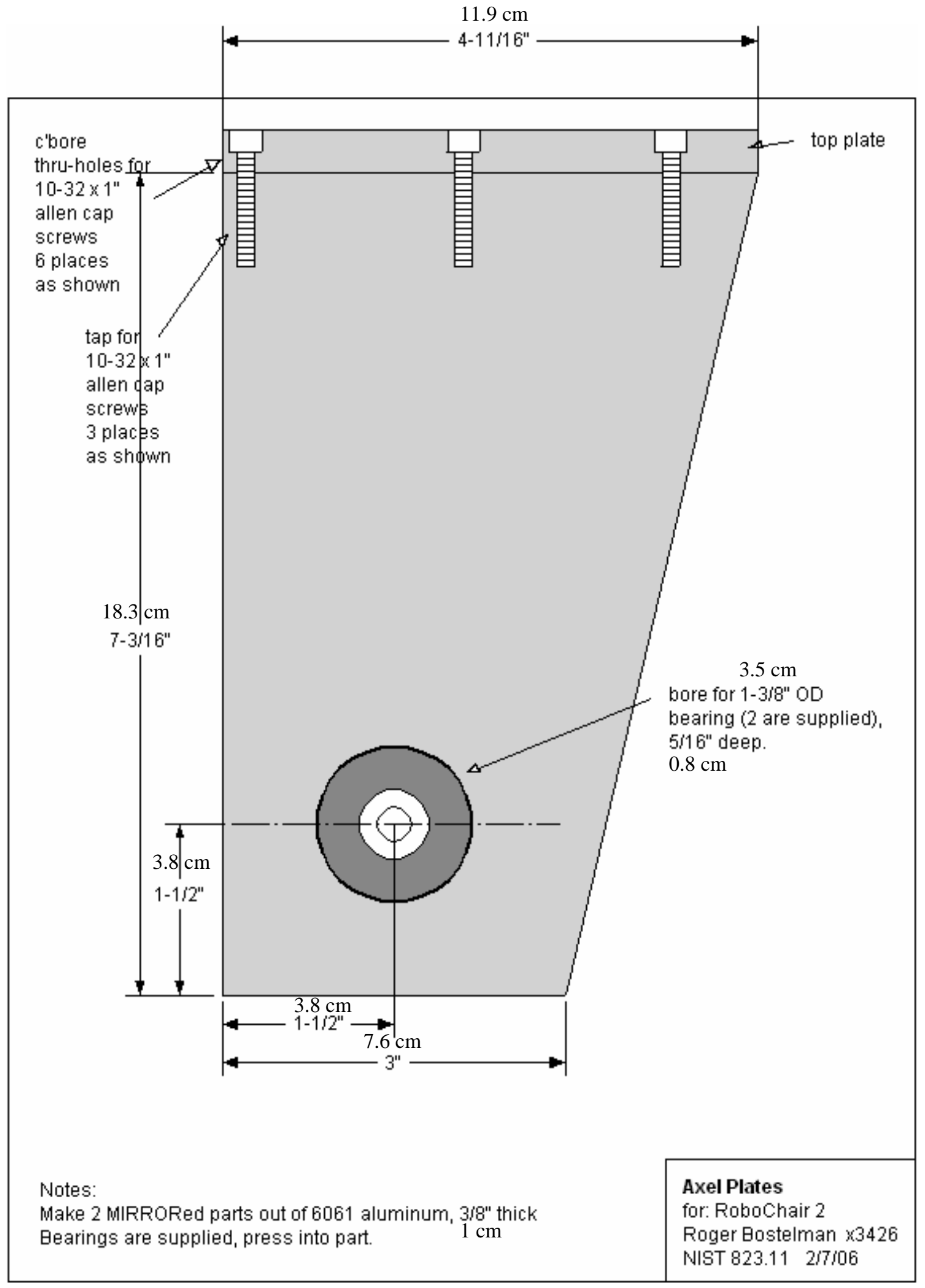


Design of the HLPR Chair

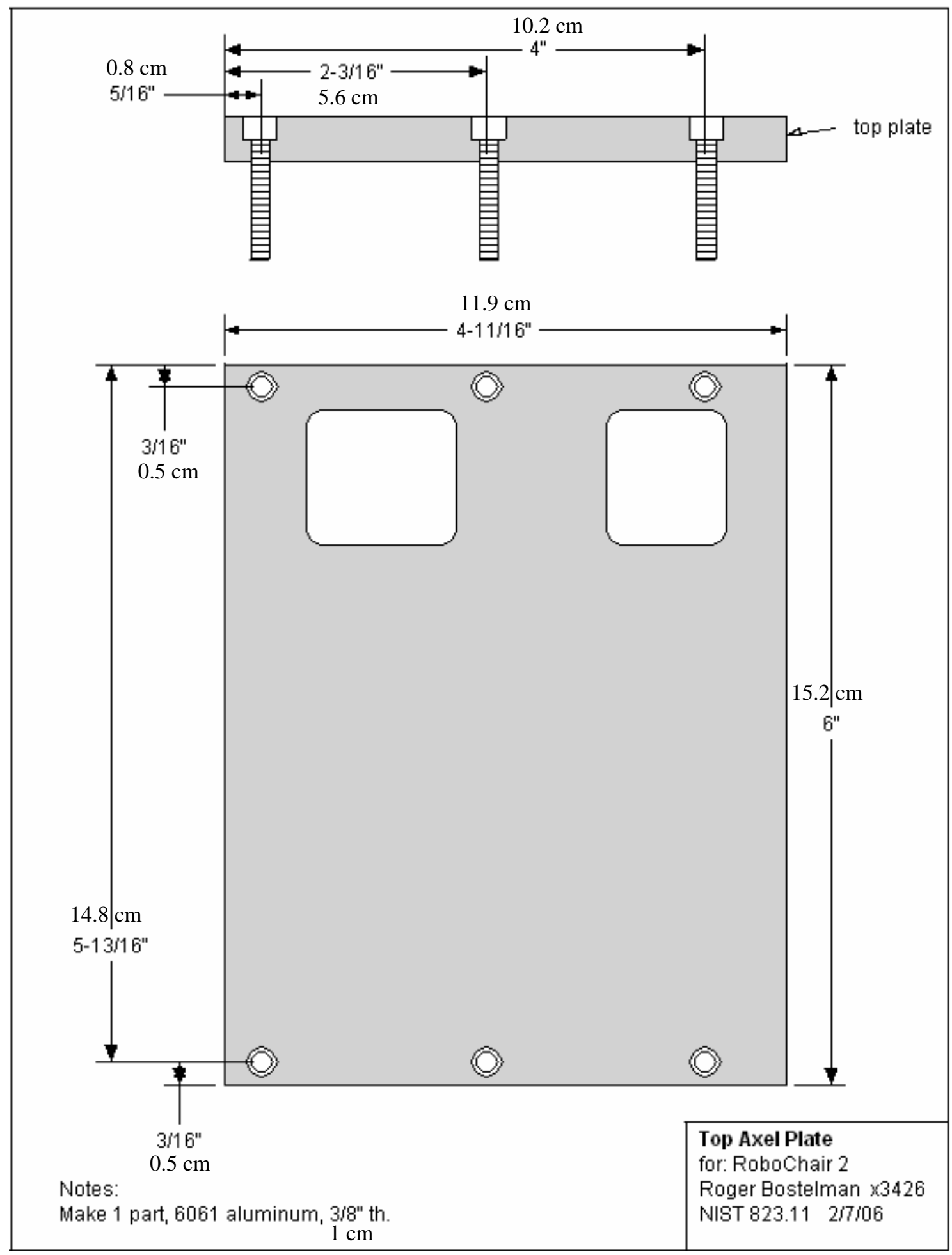




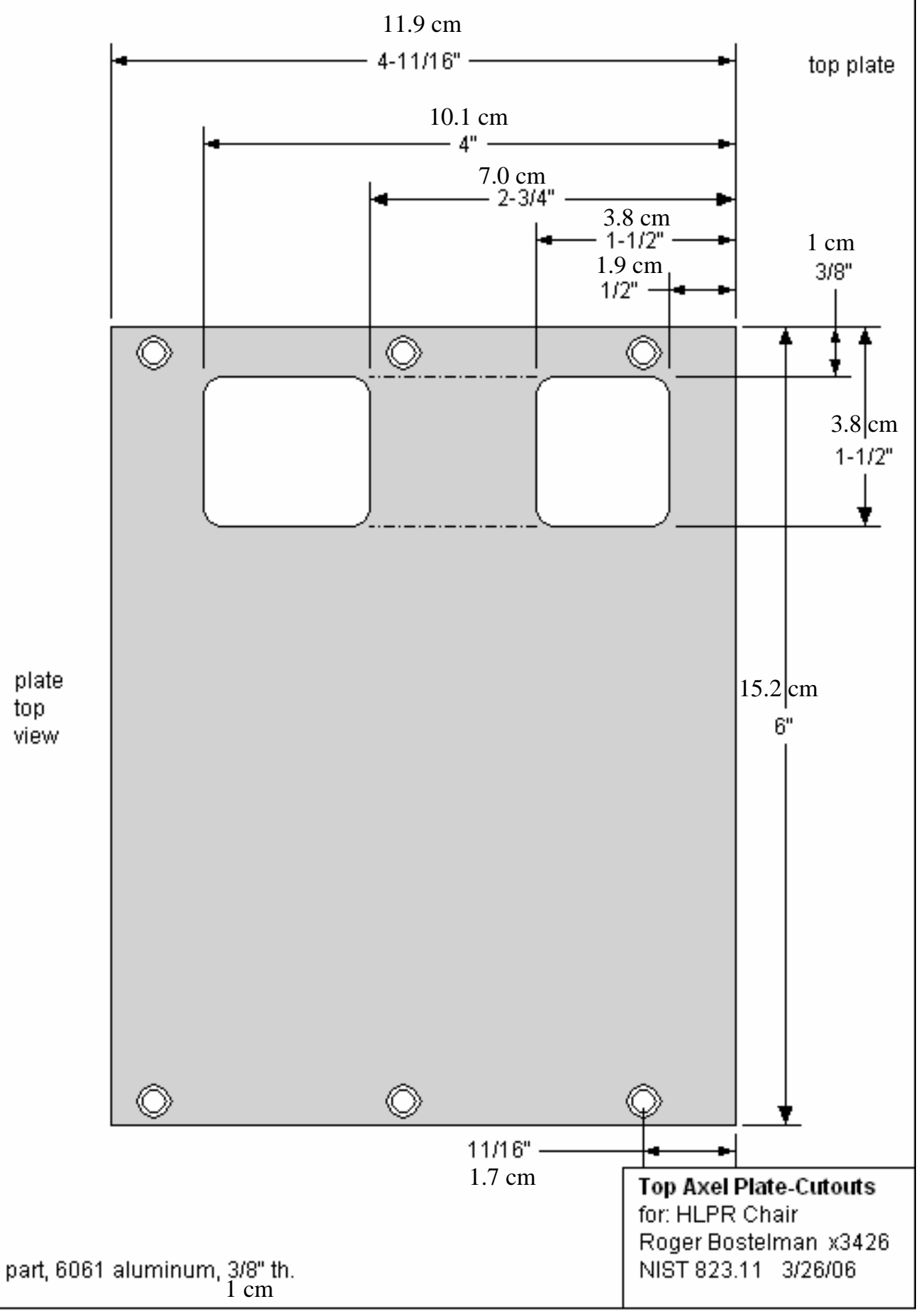


Design of the HLPR Chair

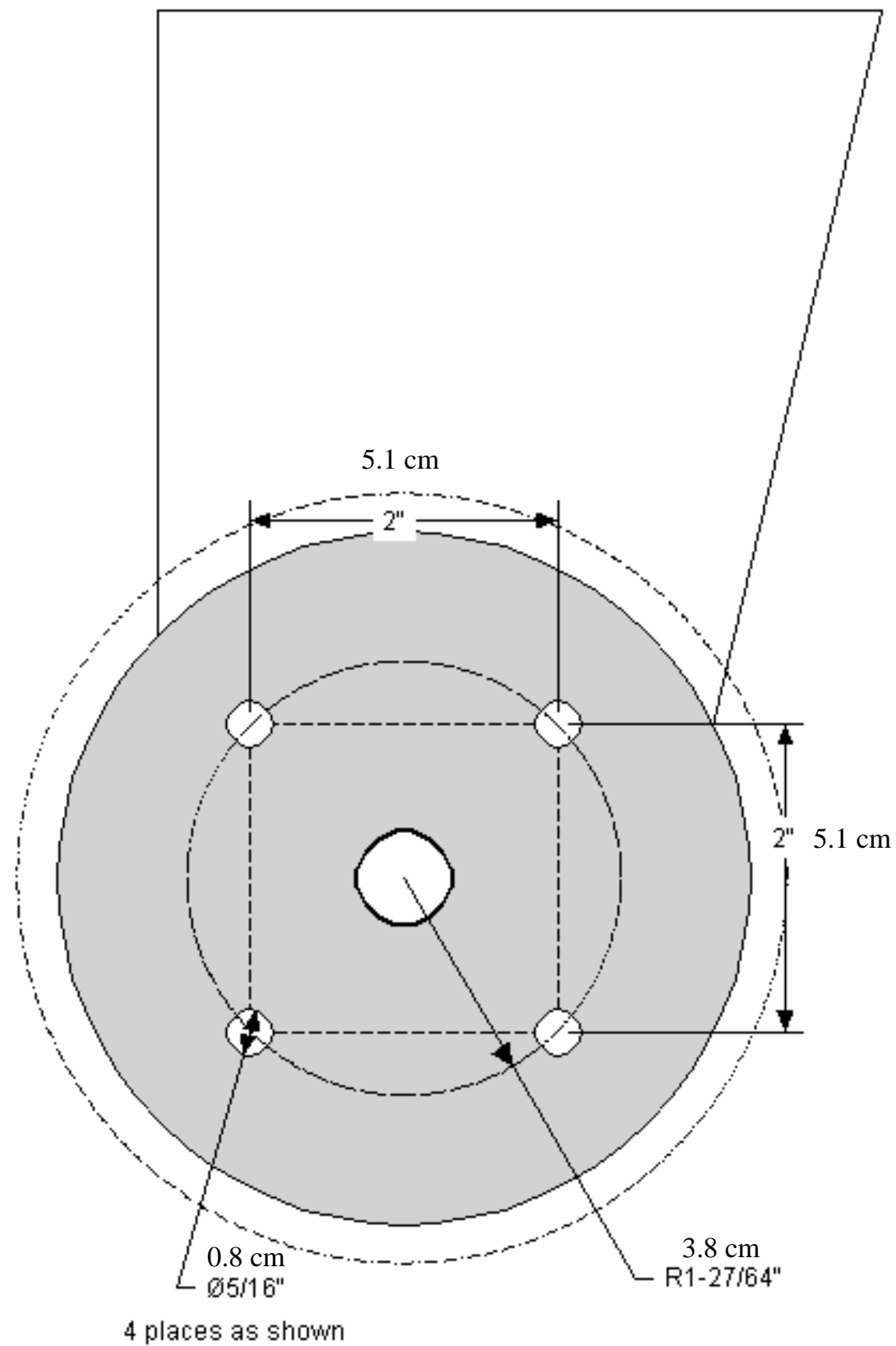

Notes:

drill 4 holes as shown on drawing

Wheel Drive Sprocket

for: Robochair 2

Roger Bostelman $\times 3426$

NIST 823.11 2/7/06, 2/22/06 
1)

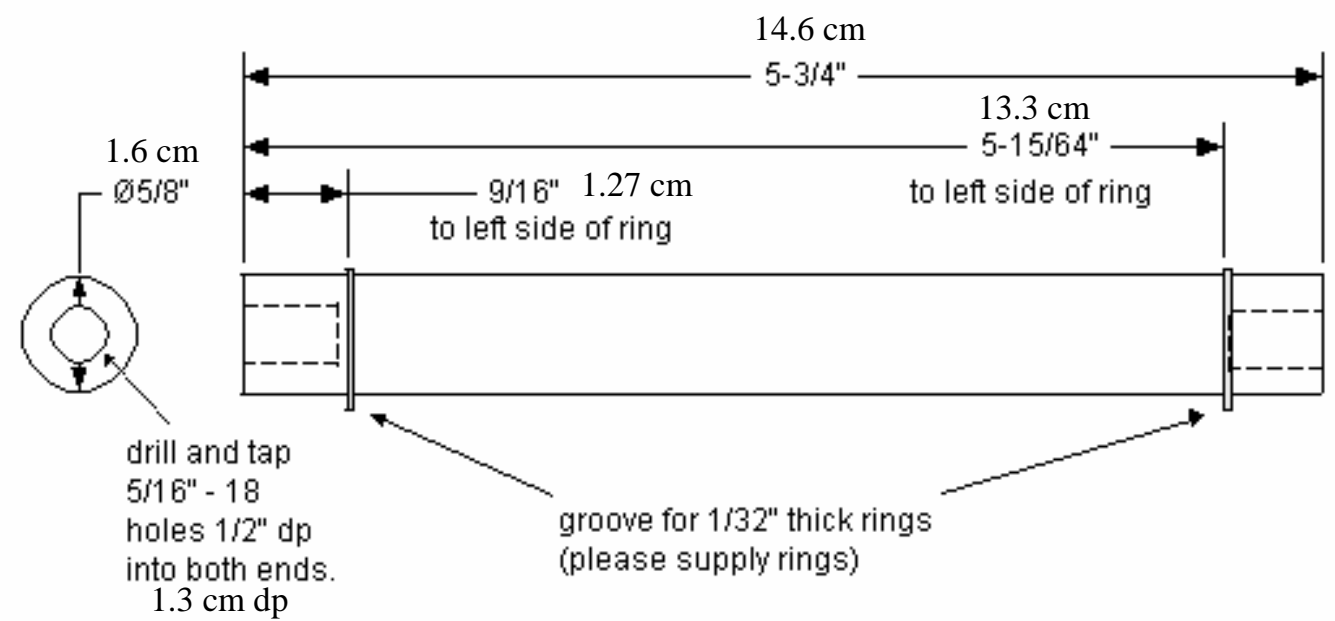

NOTES:

Steel rod, 5/8" dia. $1.6 \mathrm{~cm}$ dia.

make 1

2)

Also, Cut down to 1-1/2" long, the 4 steel nuts supplied.

$3.8 \mathrm{~cm}$

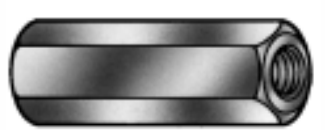

Coupling nut

Wheel Axle, nuts

for: HLPR Chair

Roger Bostelman $\times 3426$

NIST $823.115 / 15 / 07$ 


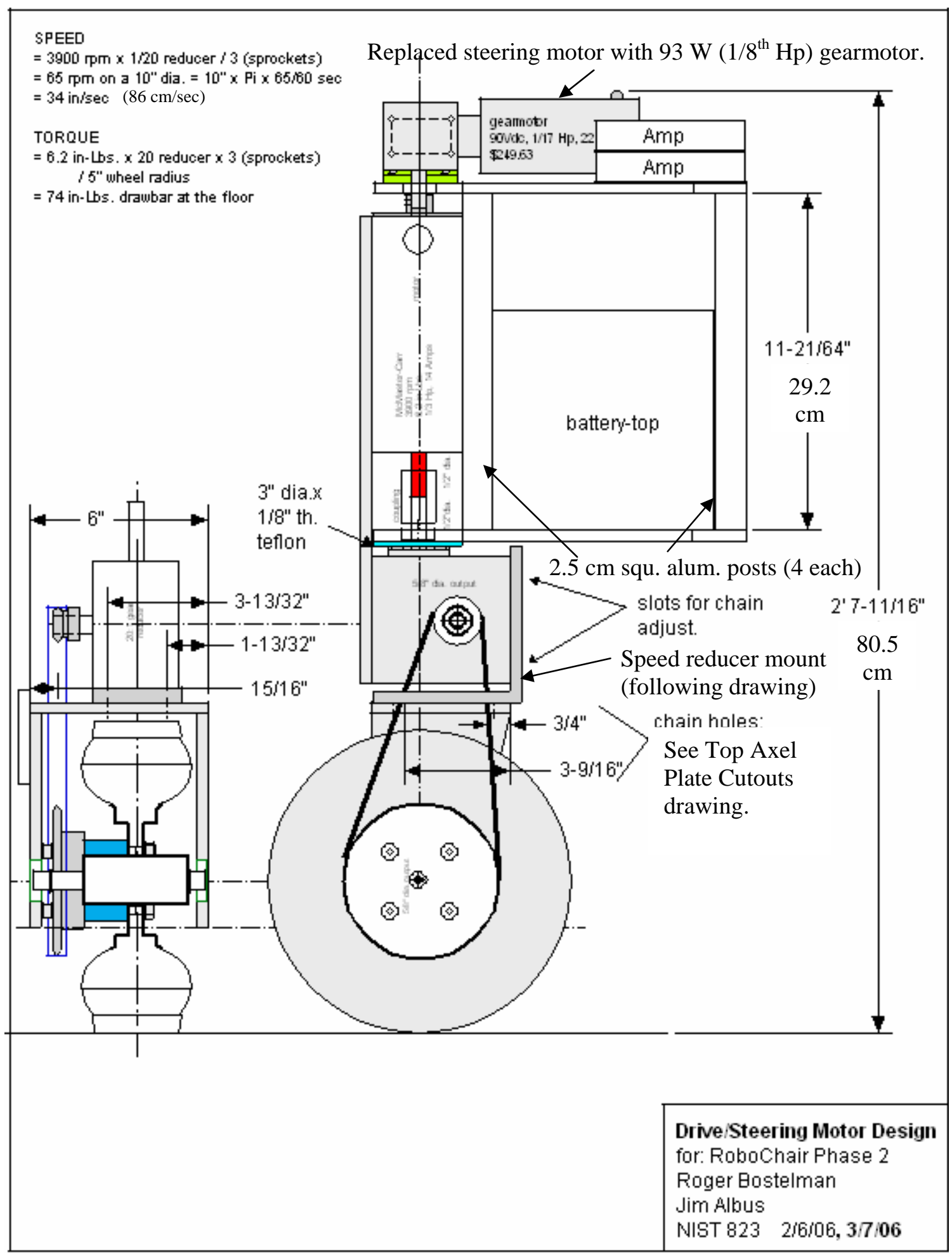




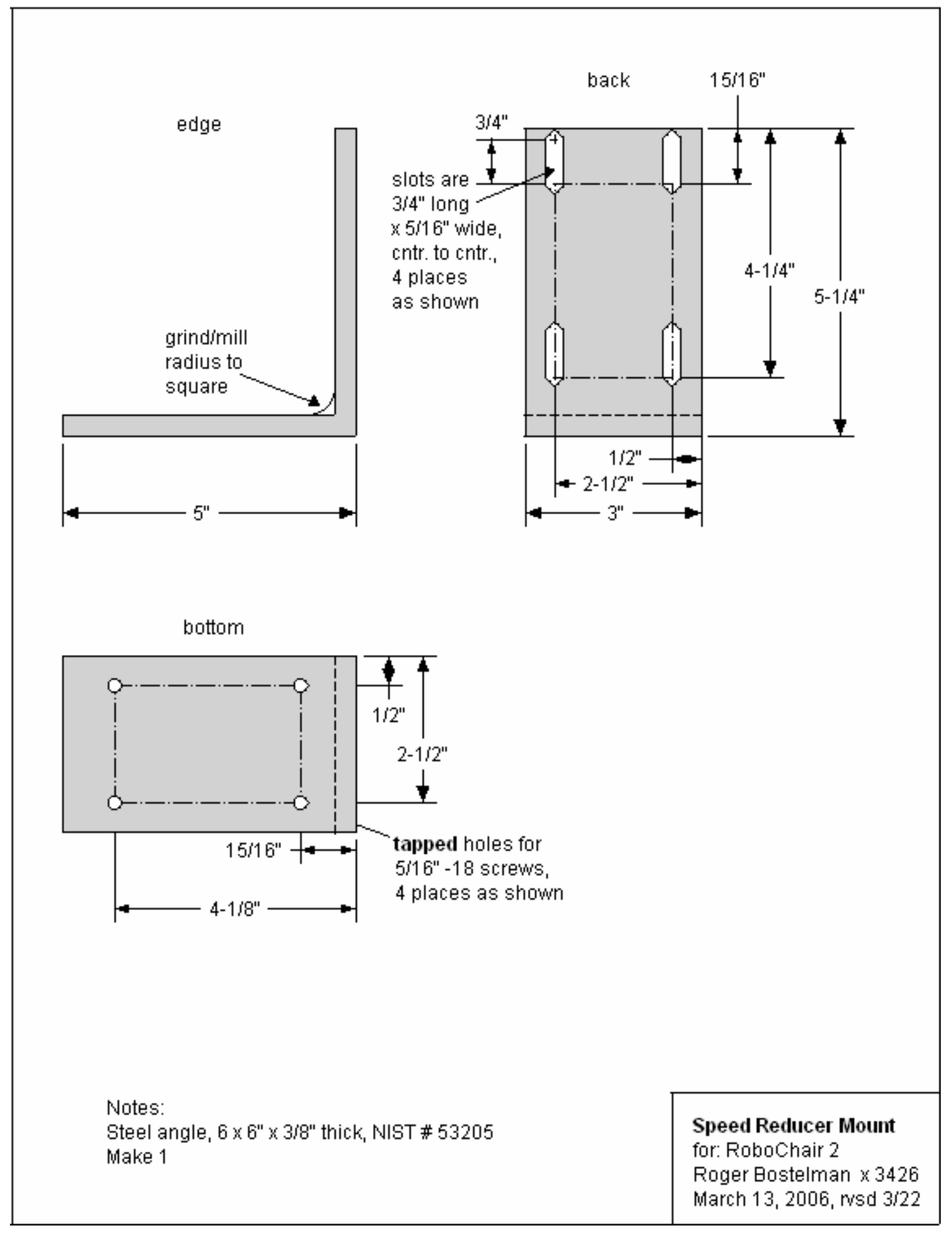




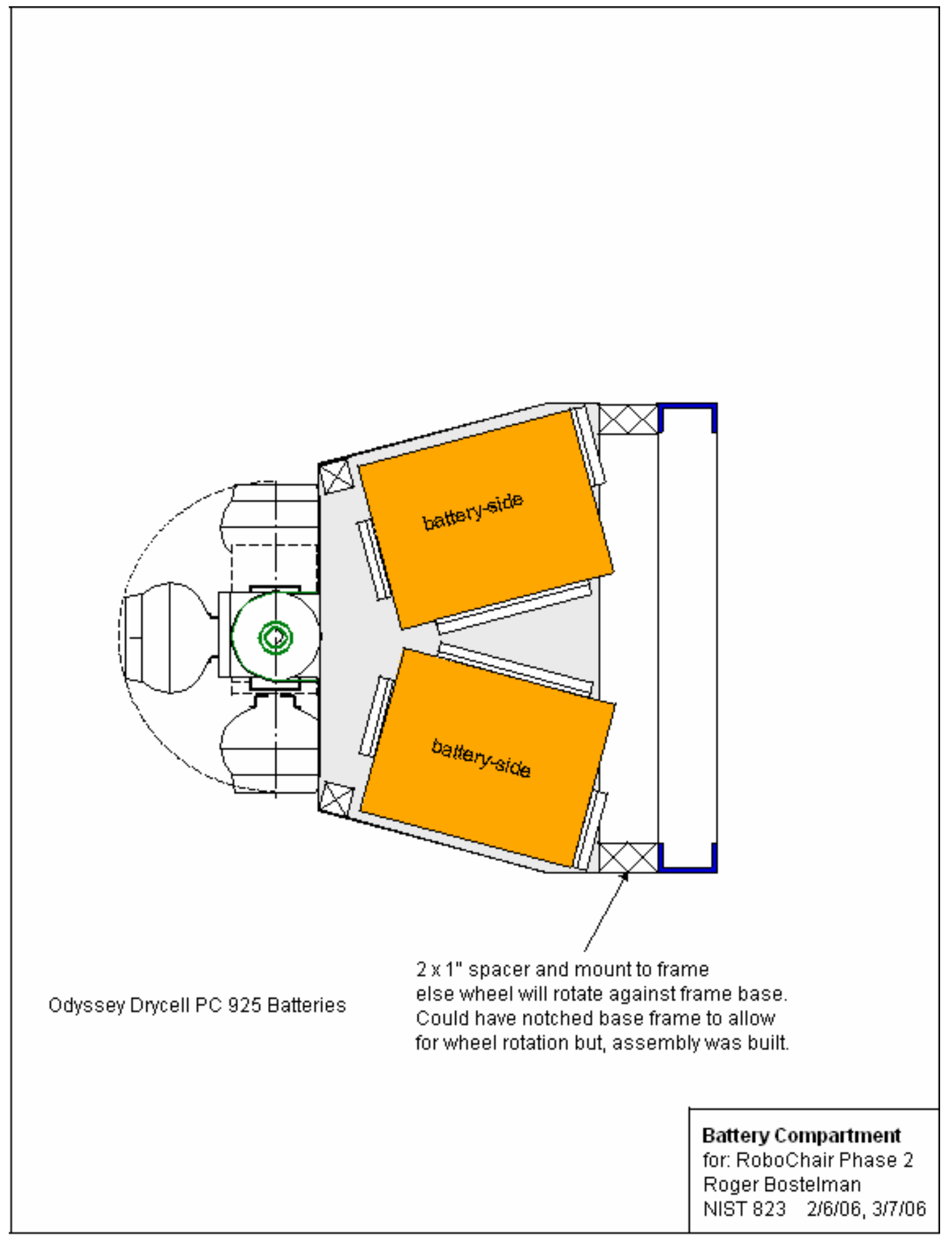


Design of the HLPR Chair

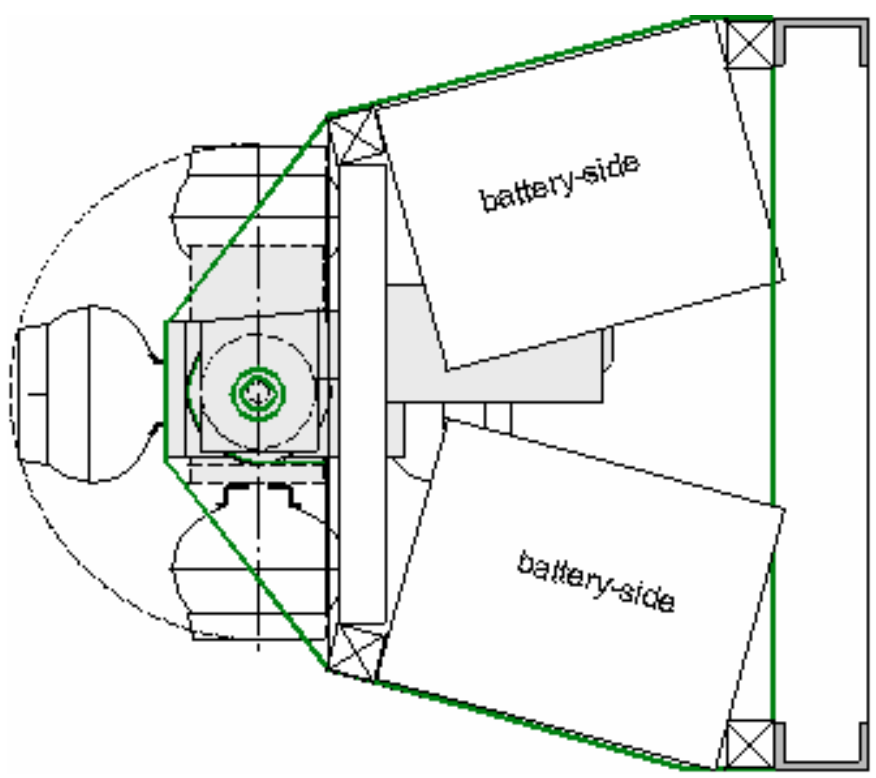

Top view of battery compartment. 


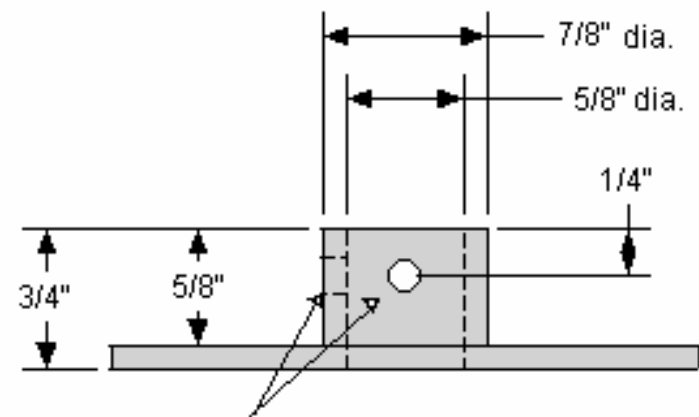

side view

10-32 tapped holes,

90 degrees apart,

for set screws, 2 each

(please supply them!)

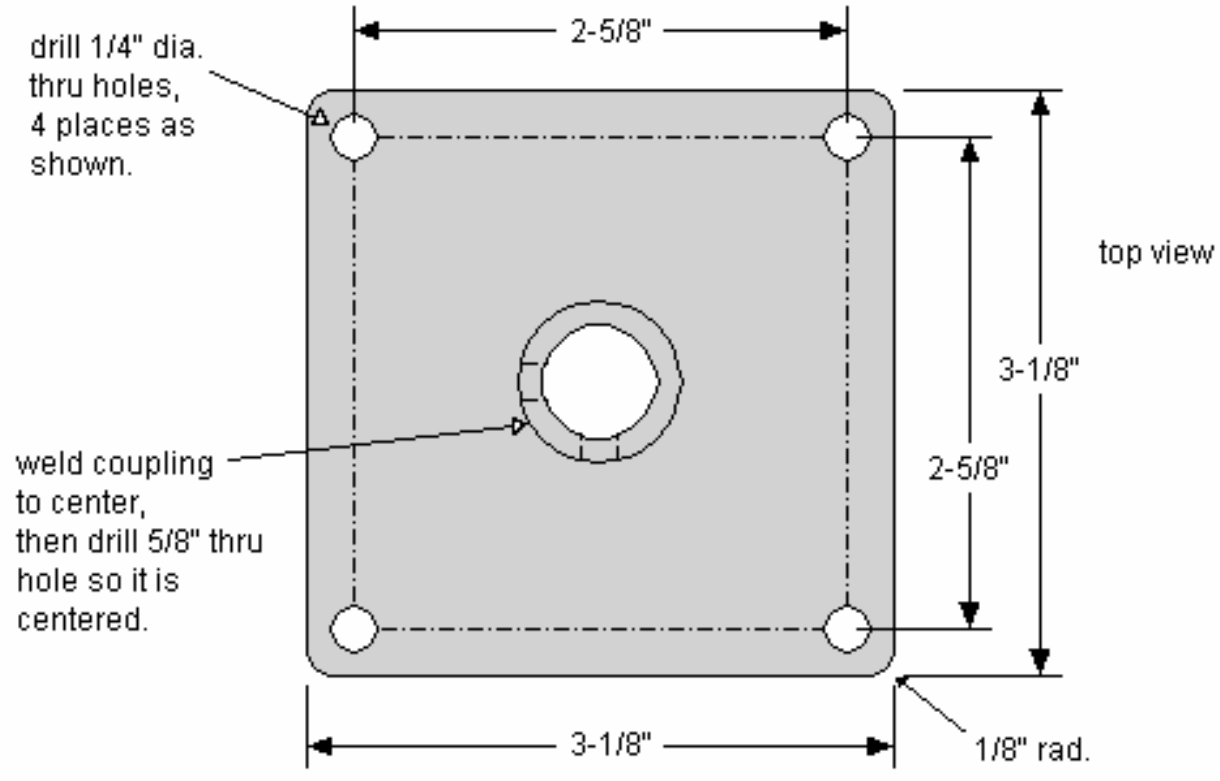

Note:

- Steel plate and rod

- Make one.

- Weld center coupling, then drill so hole is ensured part center.

Motor-End, Adapter Plate for: HLPR

Roger Bostelman $\times 3426$

NST $823.11 \quad 5 / 17 / 07$ 


\section{Design of the HLPR Chair}

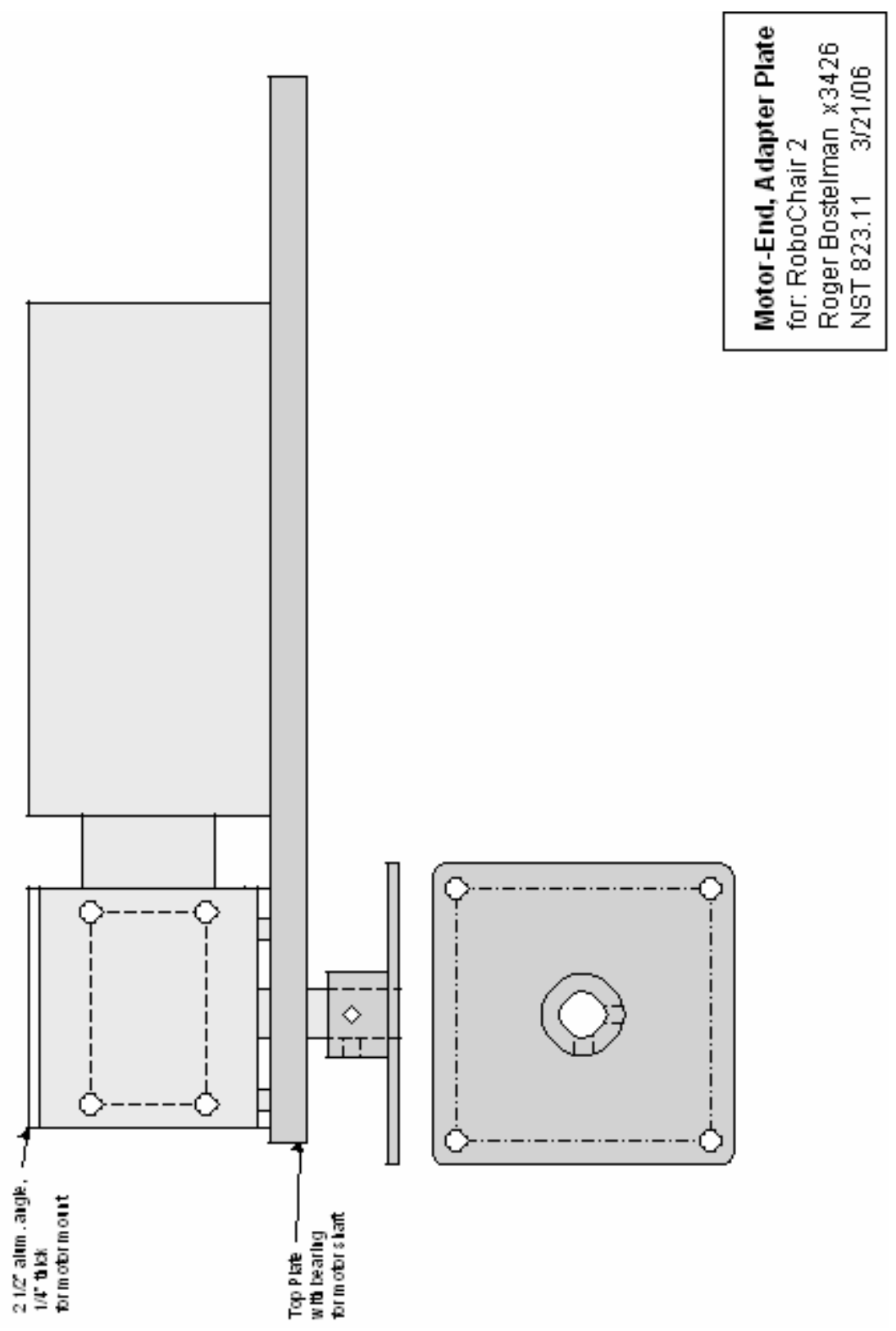


Design of the HLPR Chair

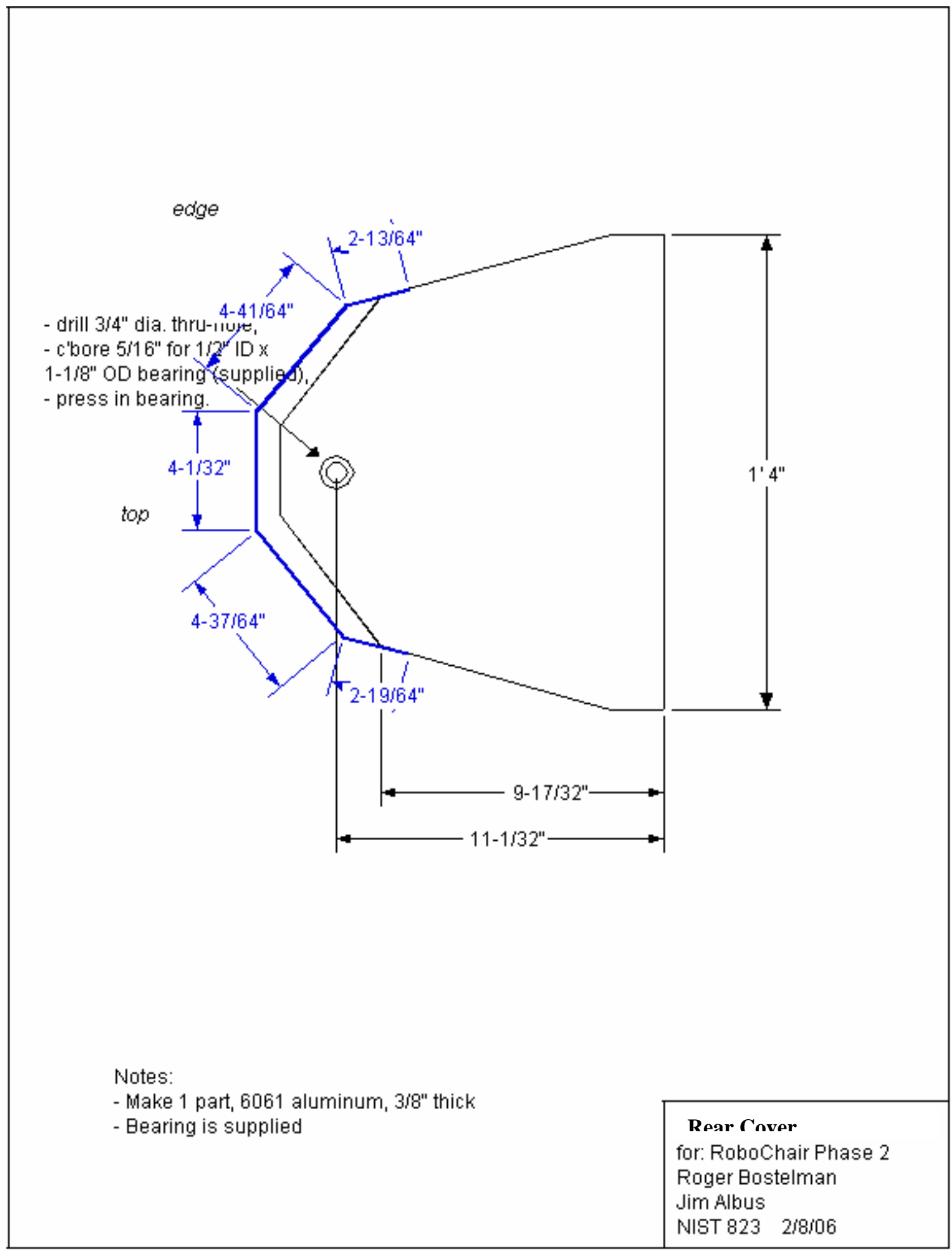


Design of the HLPR Chair

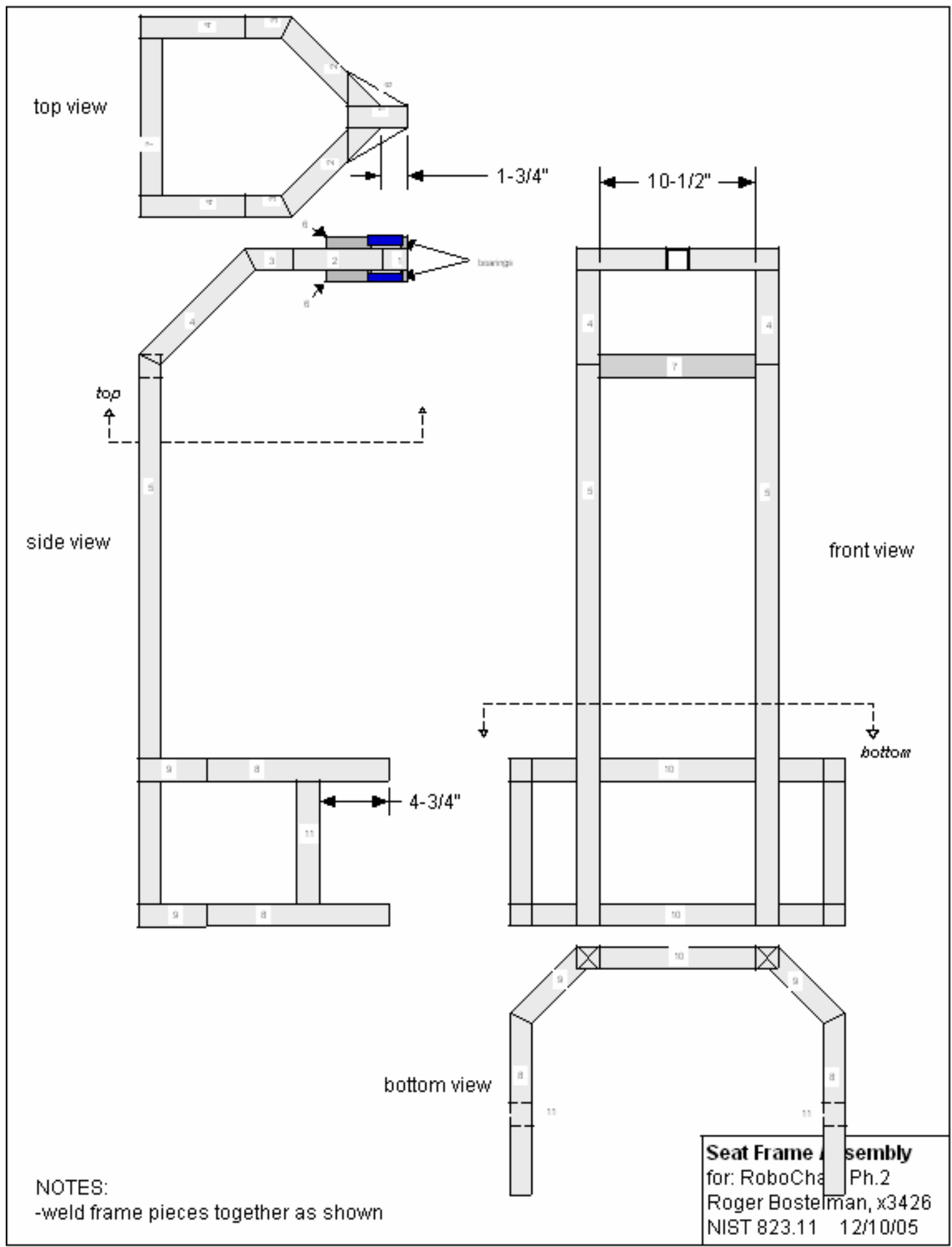

See Modifications to Existing Design section for new version of the seat frame assembly. 


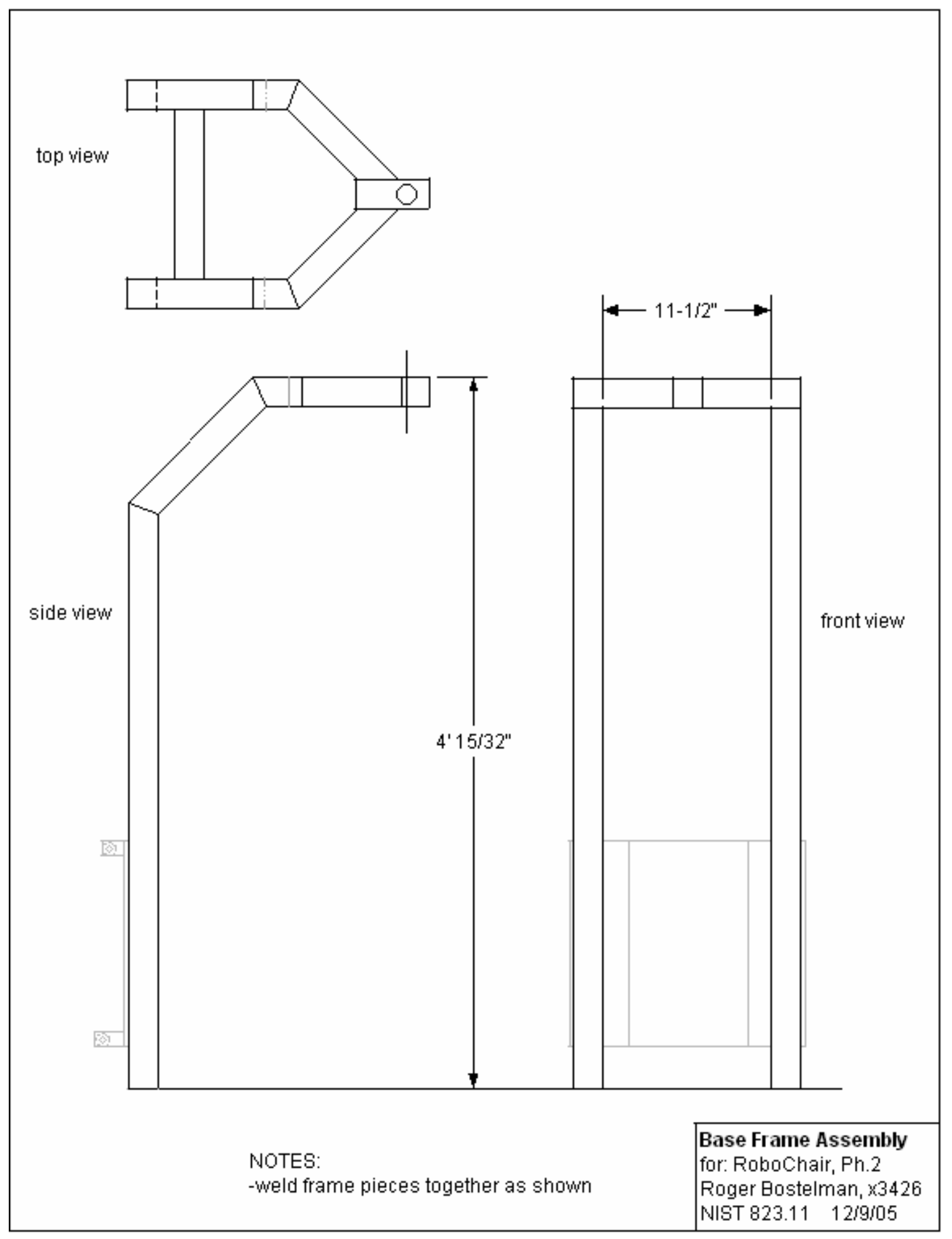

See Modifications to Existing Design section for new version of the base frame assembly. 


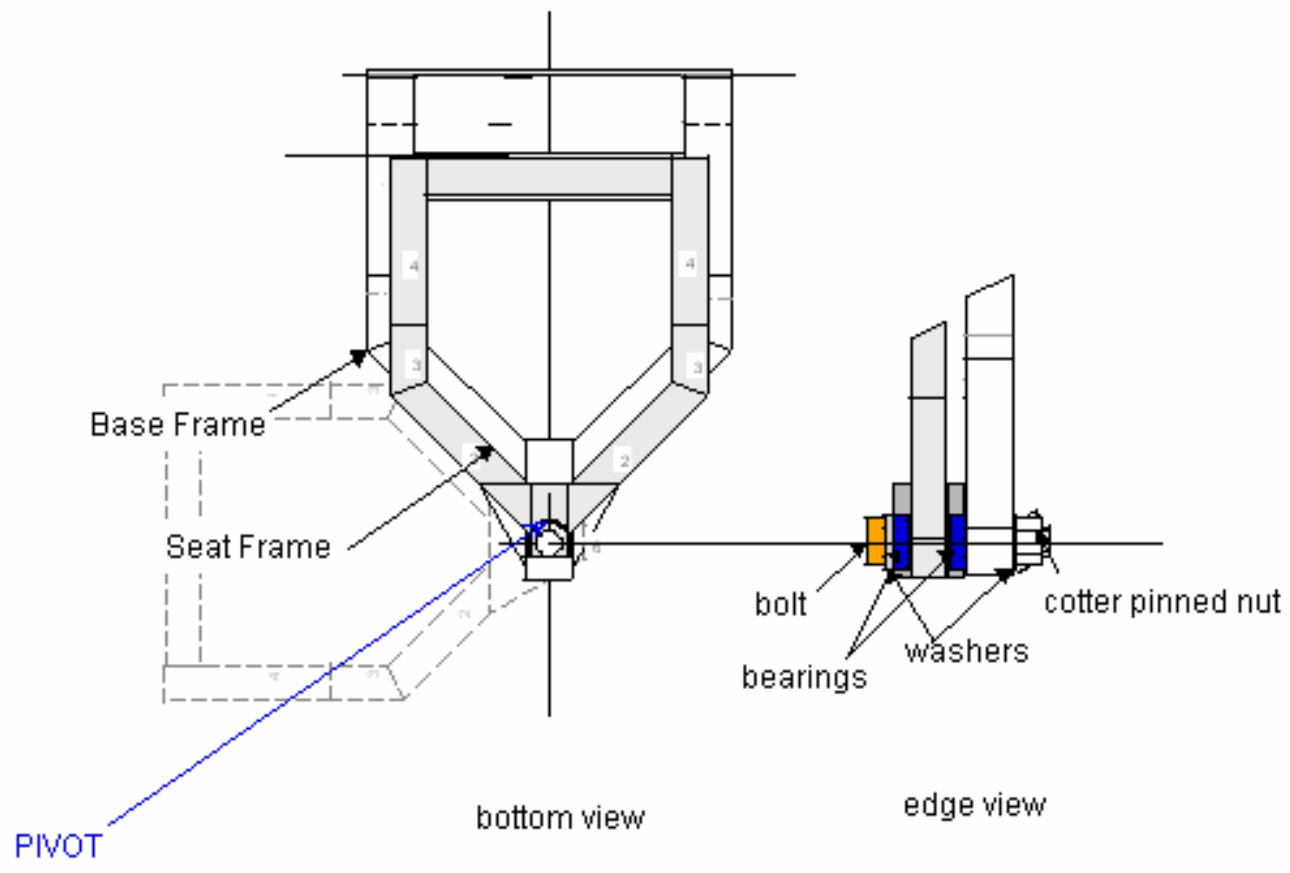

Frames Pivot

for: Robochair, Ph.2

Roger Bostelman, $\times 3426$

NIST $823.11 \quad 12 / 8 / 05$

See Modifications to Existing Design section for new version of the frames pivot. 
Design of the HLPR Chair

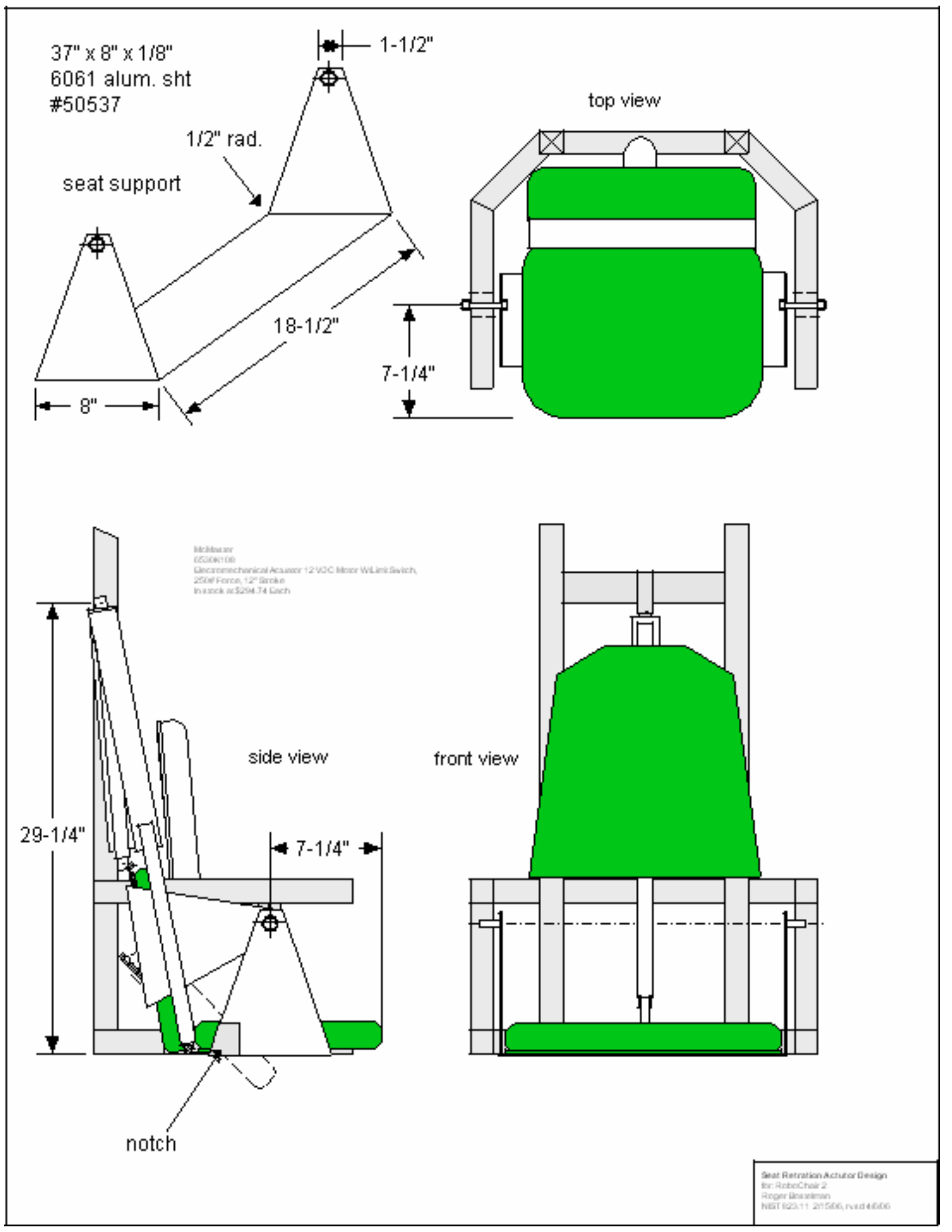


Design of the HLPR Chair

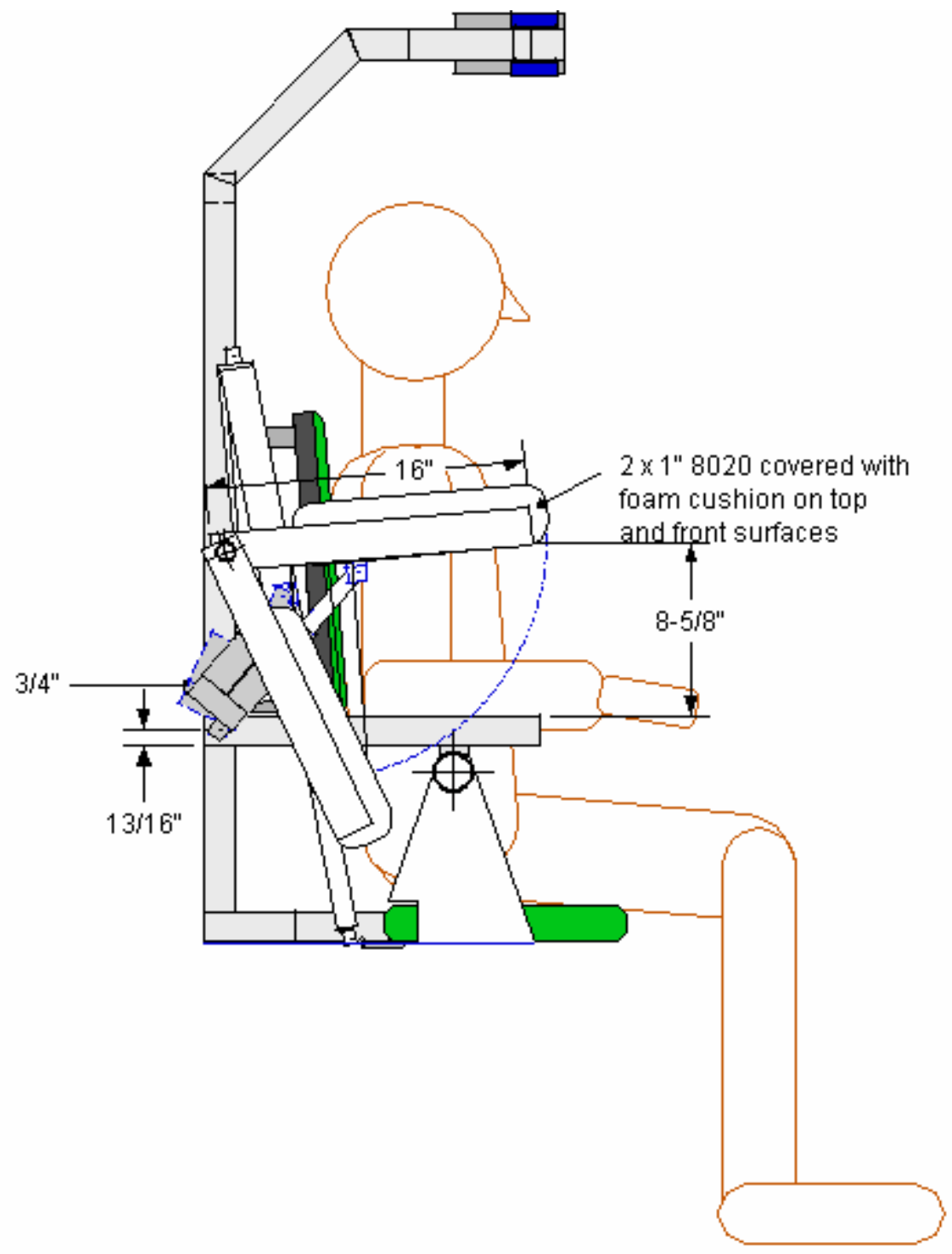

Torso Lift Design

for: Robochair 2

Roger Bostelman

NIST 823.11 4/24/06 


\section{Design of the HLPR Chair}

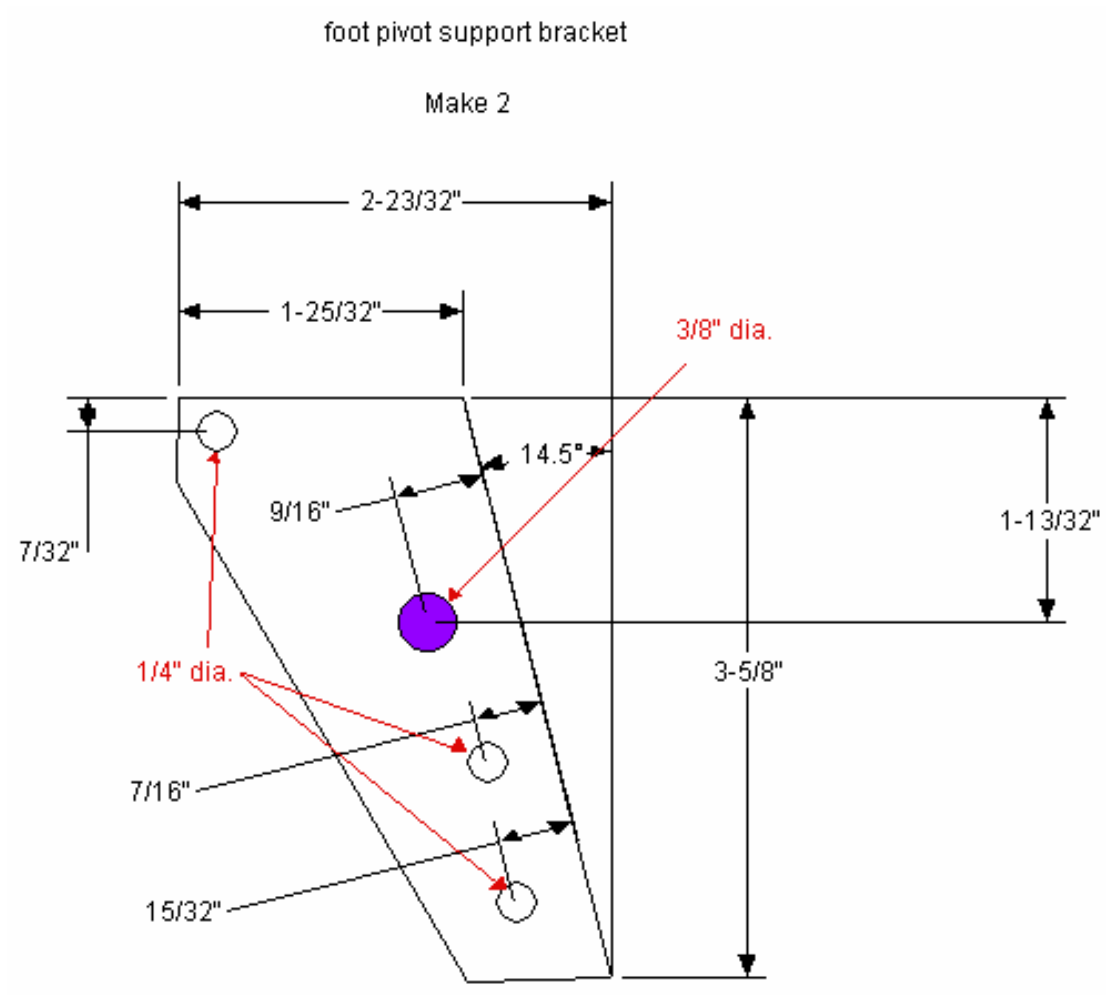


Design of the HLPR Chair

actuator support bracket

Make 1
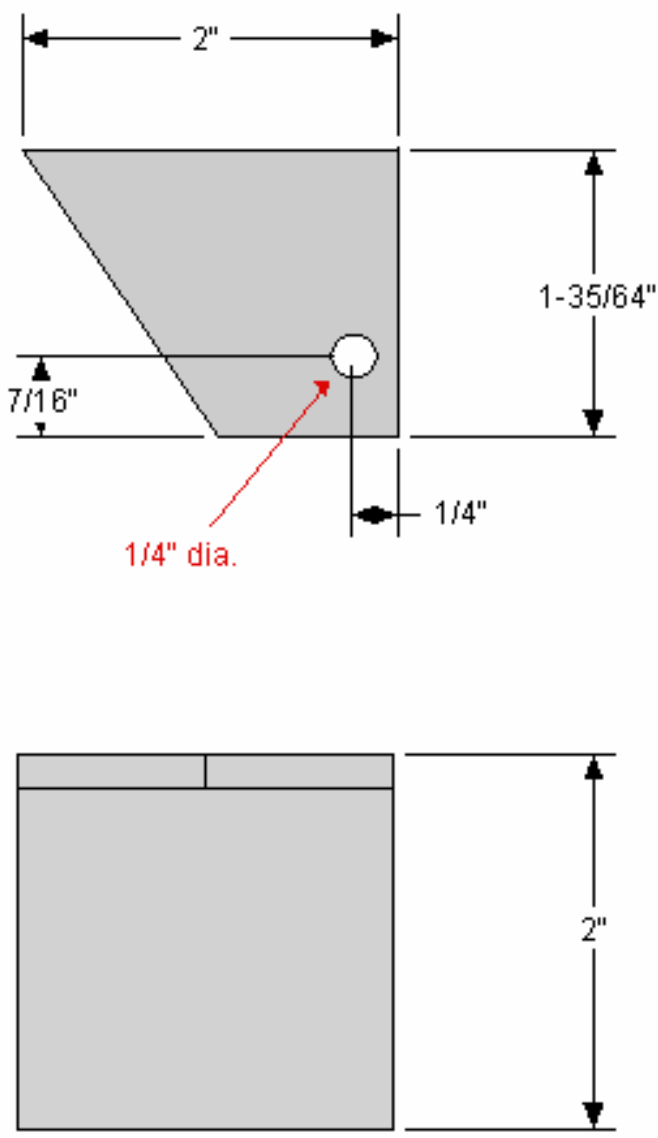

39 of 88 
Design of the HLPR Chair

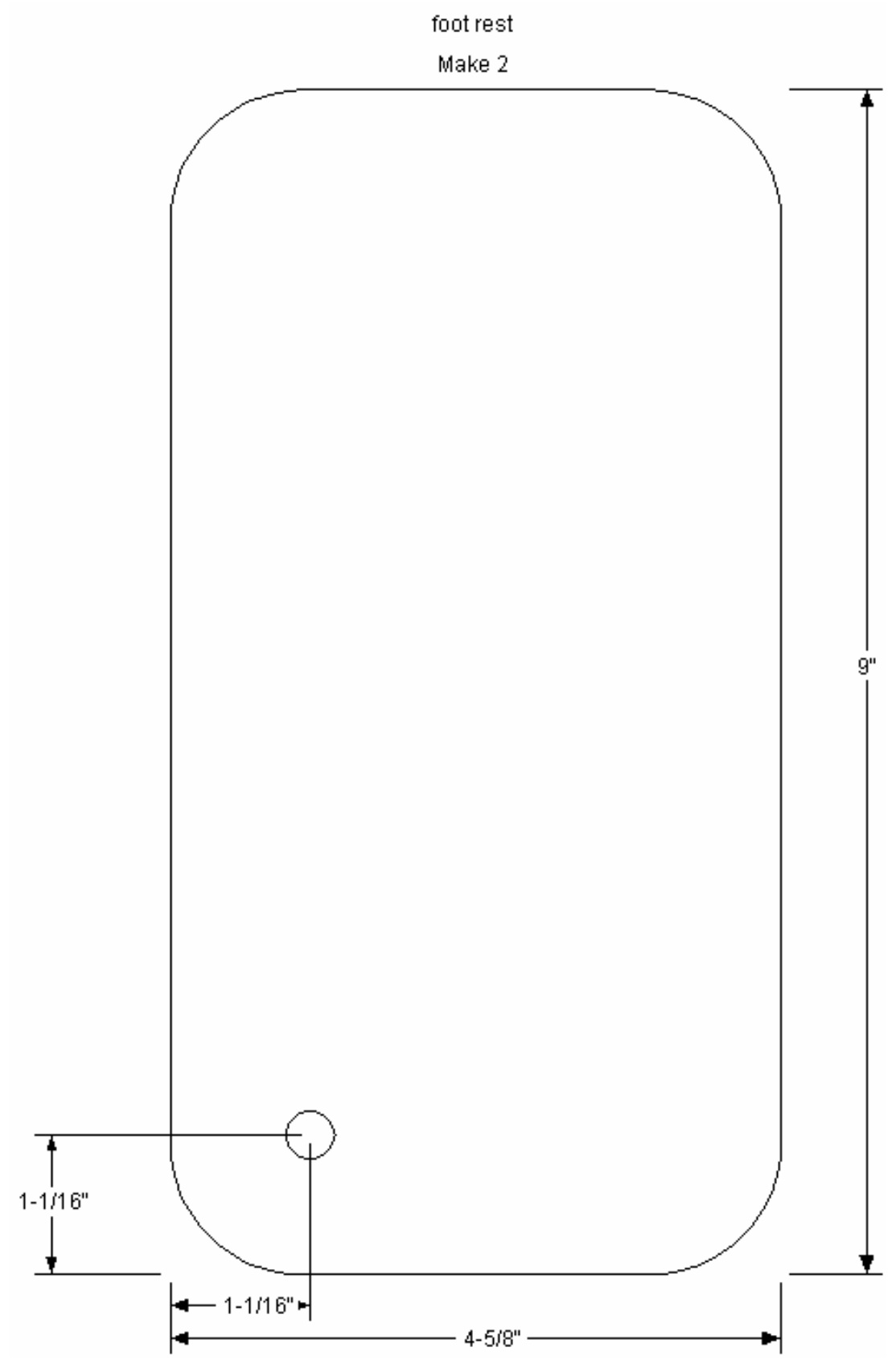




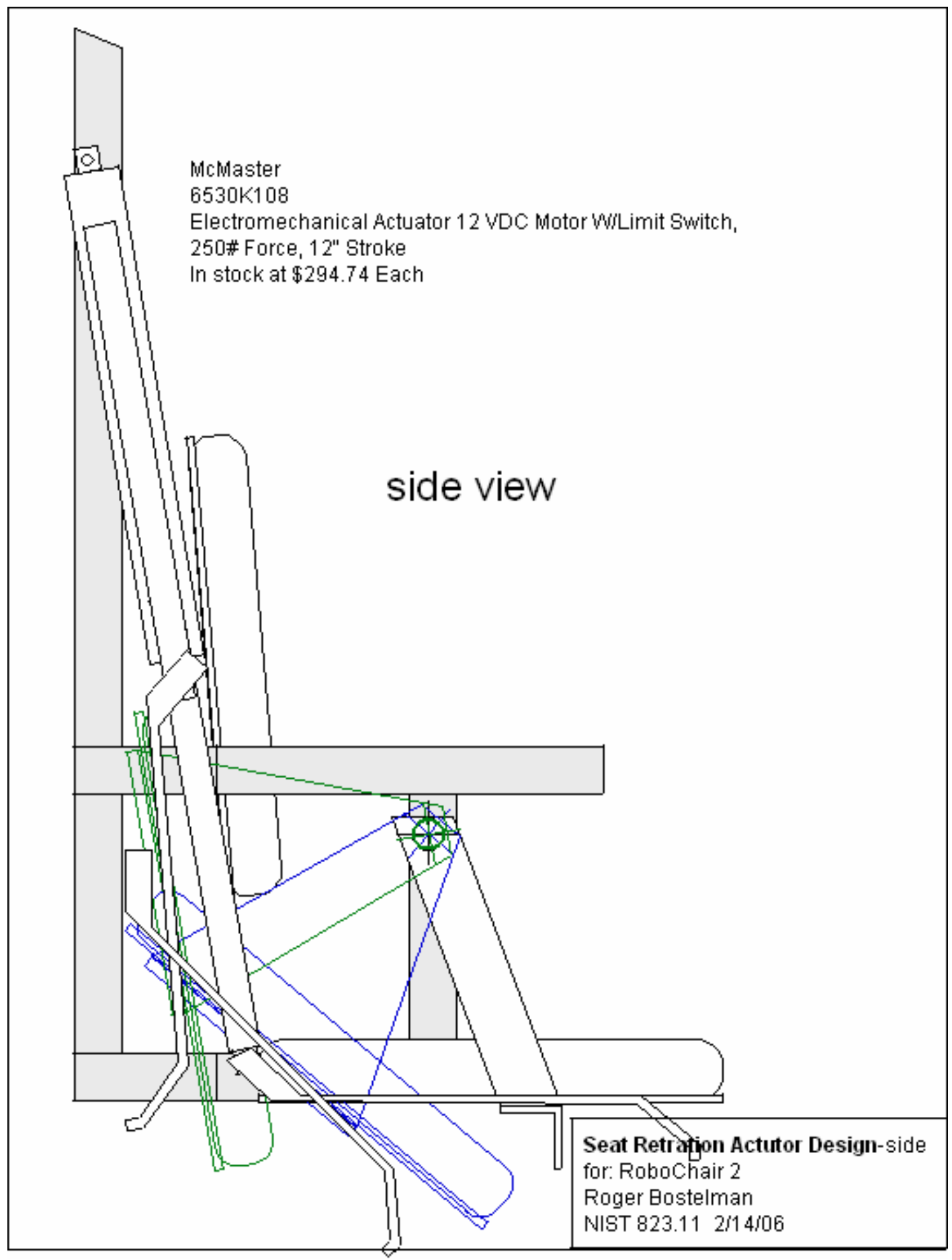


Design of the HLPR Chair

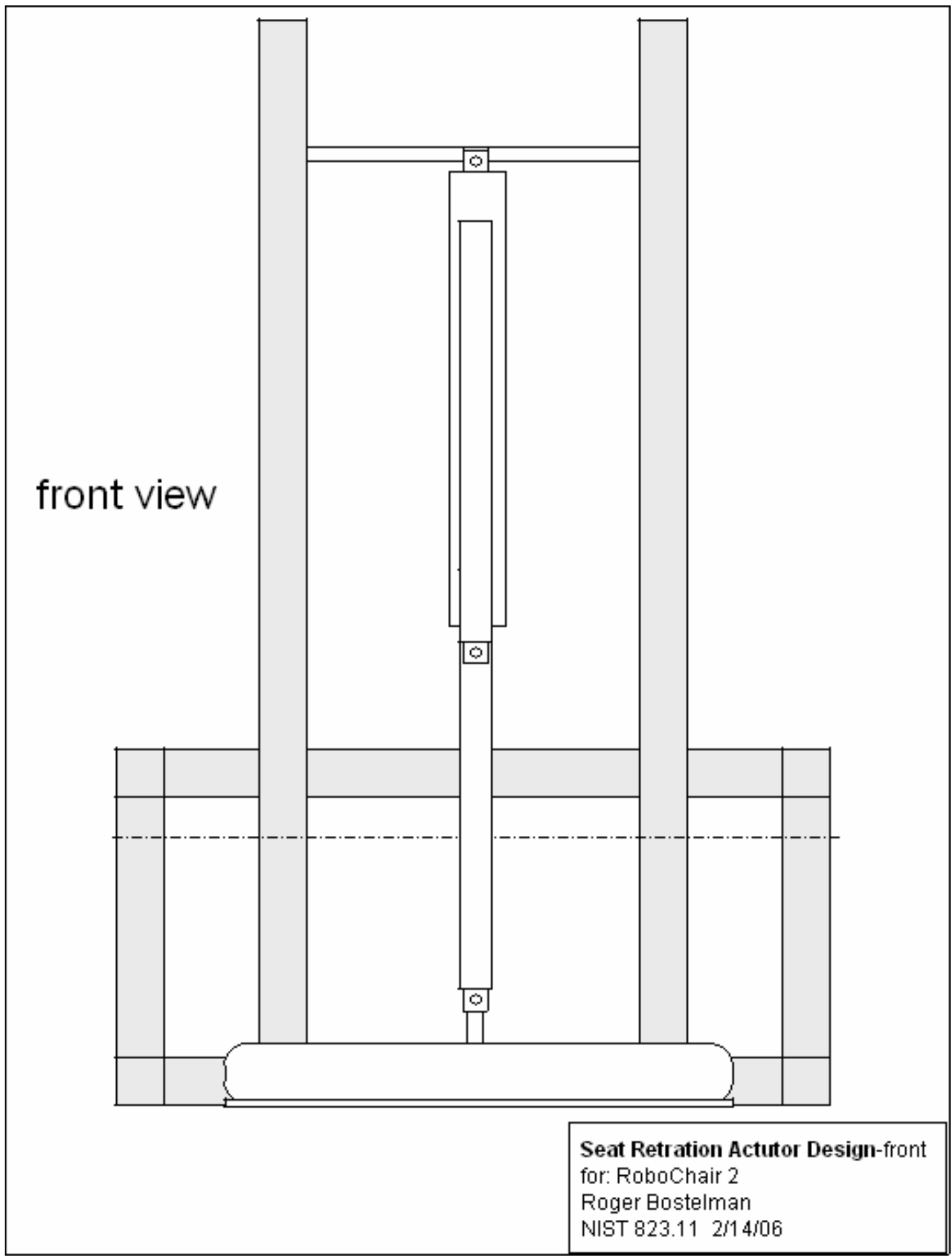

42 of 88 


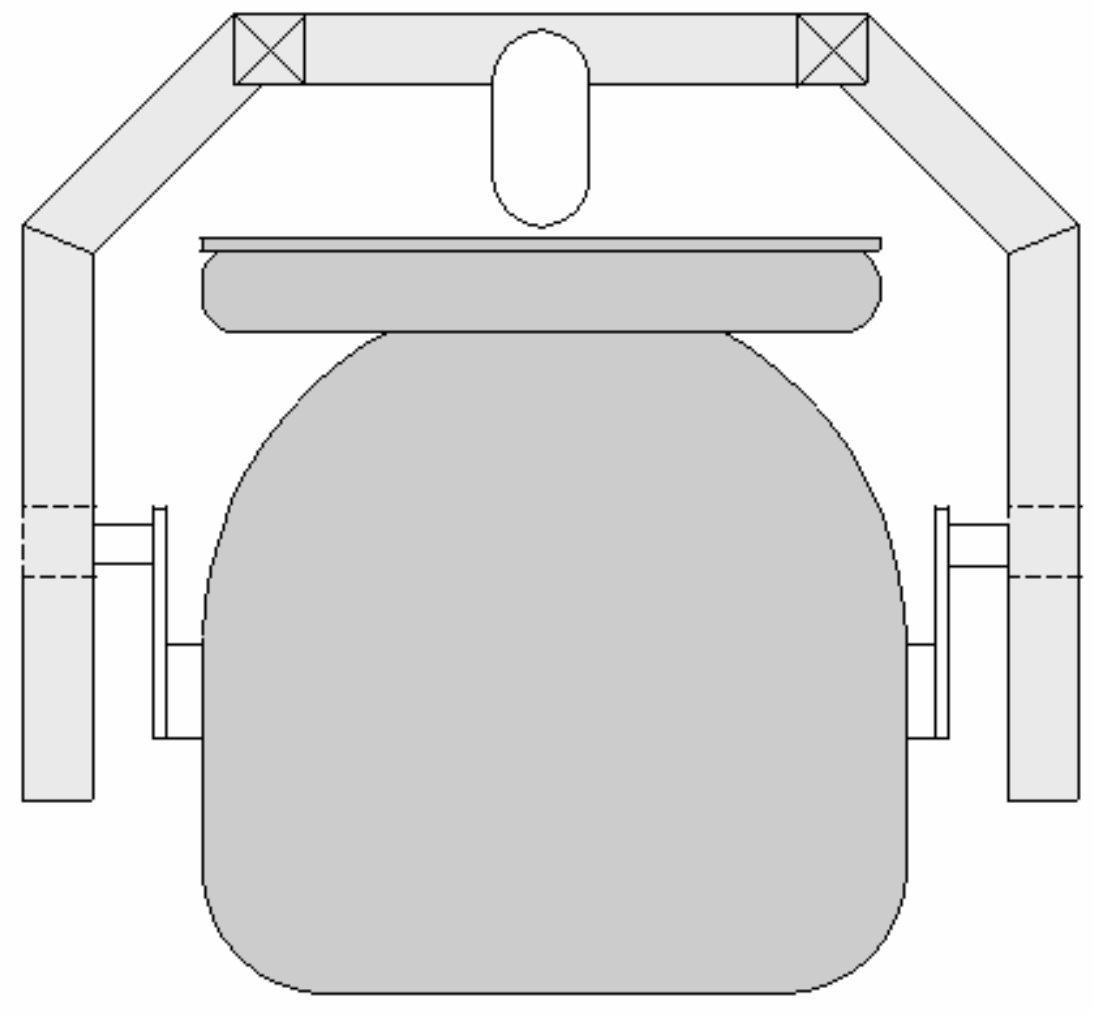

Seat Retration Actutor Design-top for: Robochair 2

Roger Bostelman

NIST $823.112 / 14 / 06$ 
Design of the HLPR Chair

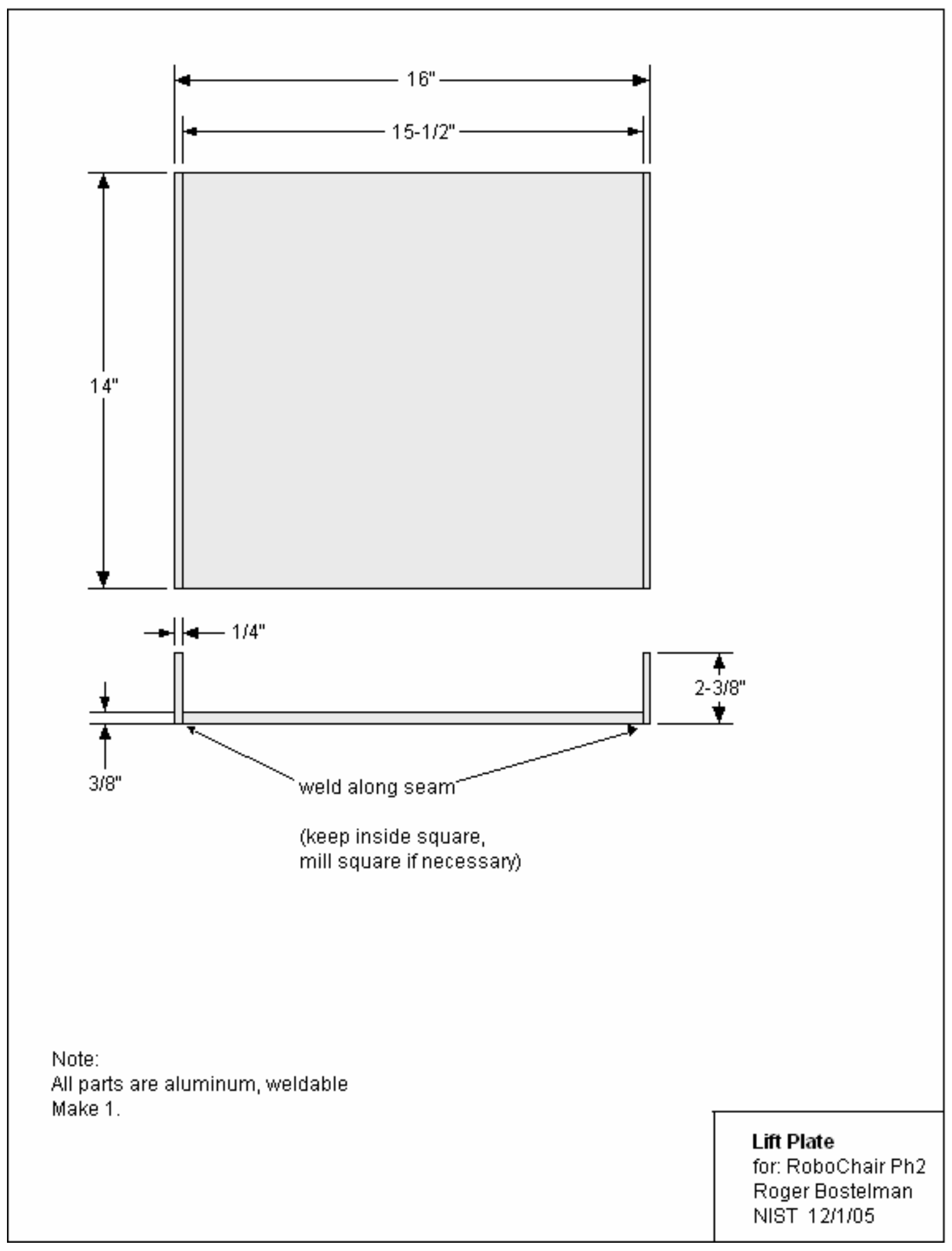




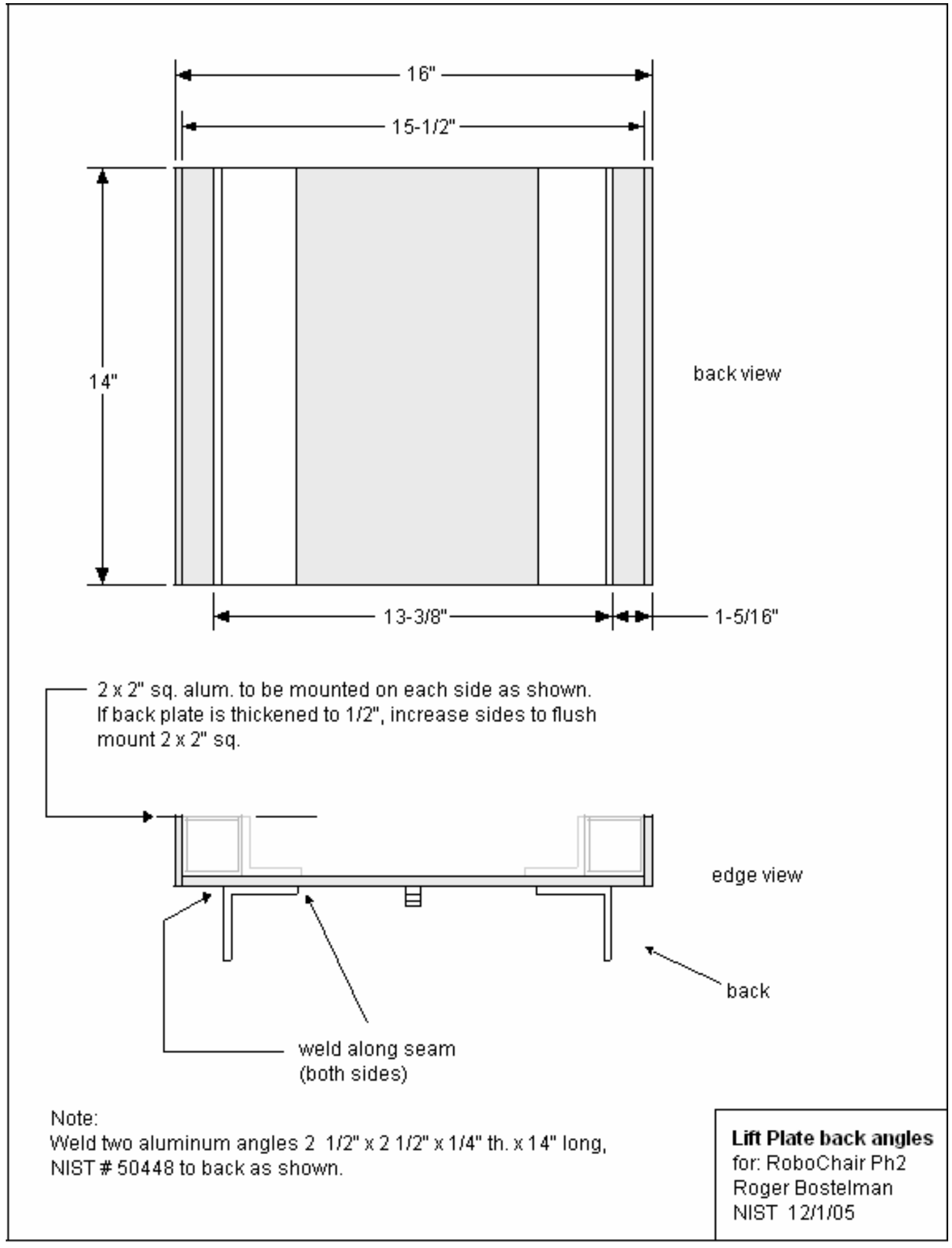




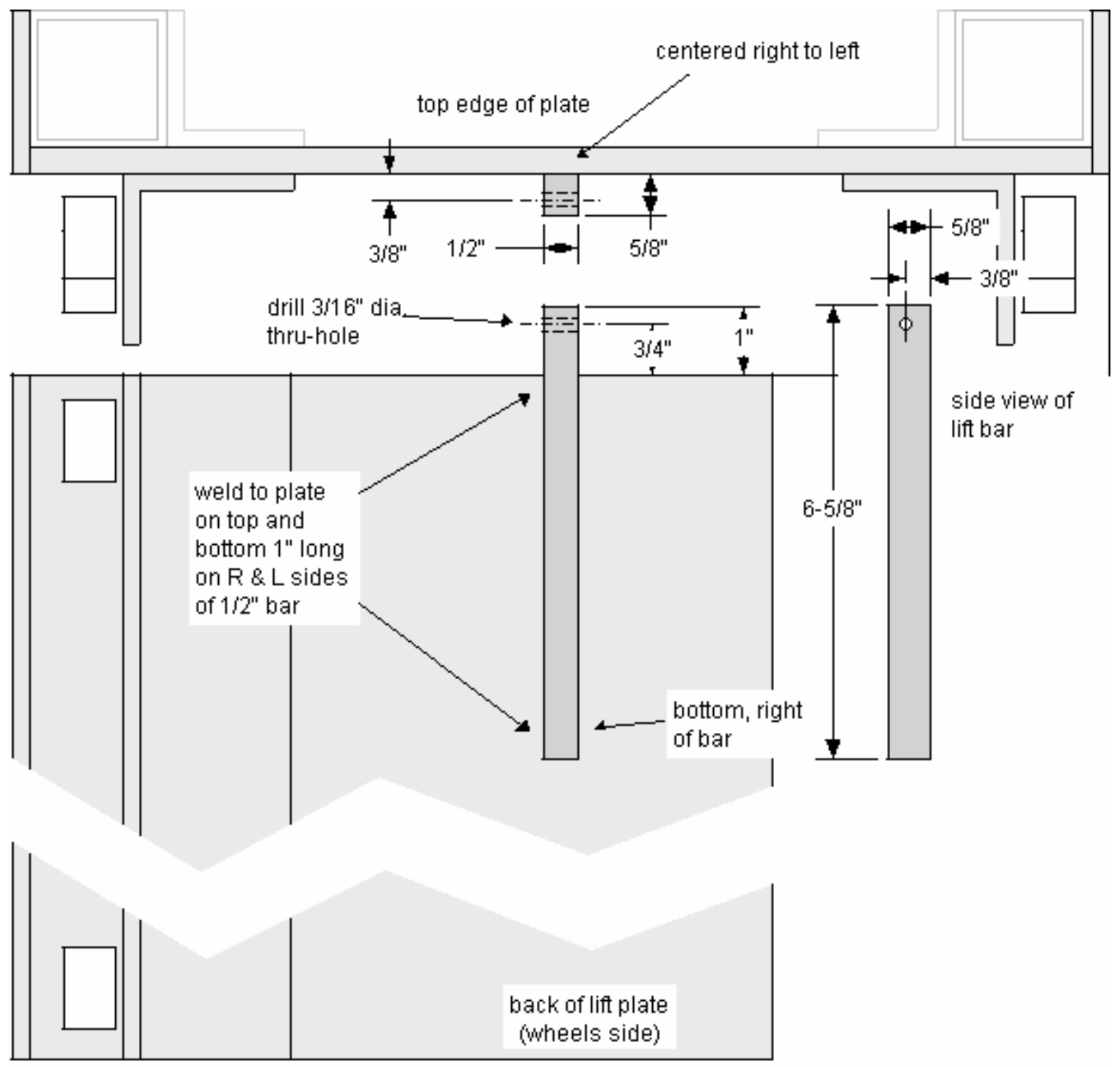

Notes:

Make one part, weld it to lift plate (supplied)

Aluminum, 6061 bar stock.
Lift Bar

for: Robochair 2

Roger Bostelman 2/10/06 NIST 823.11 


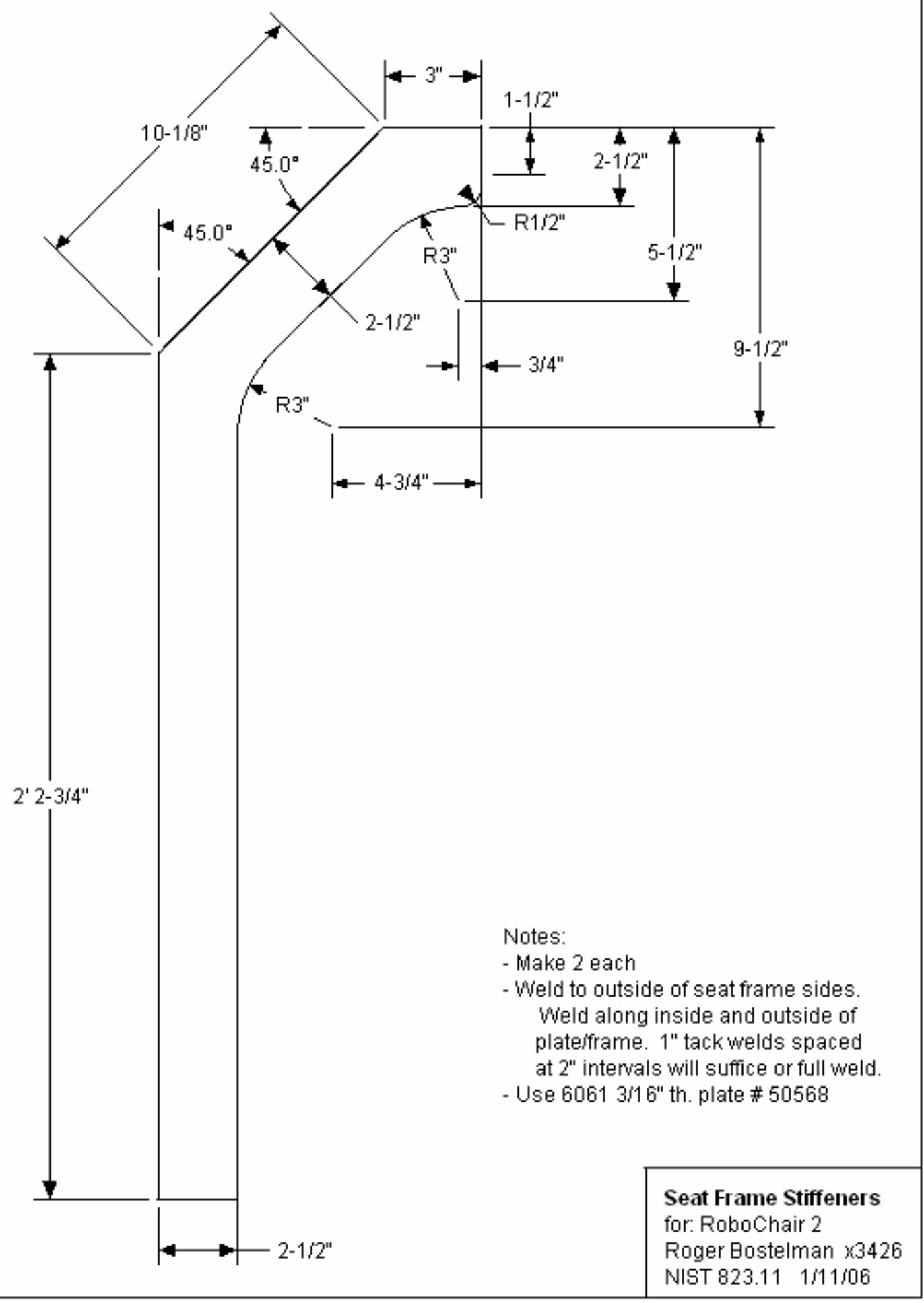




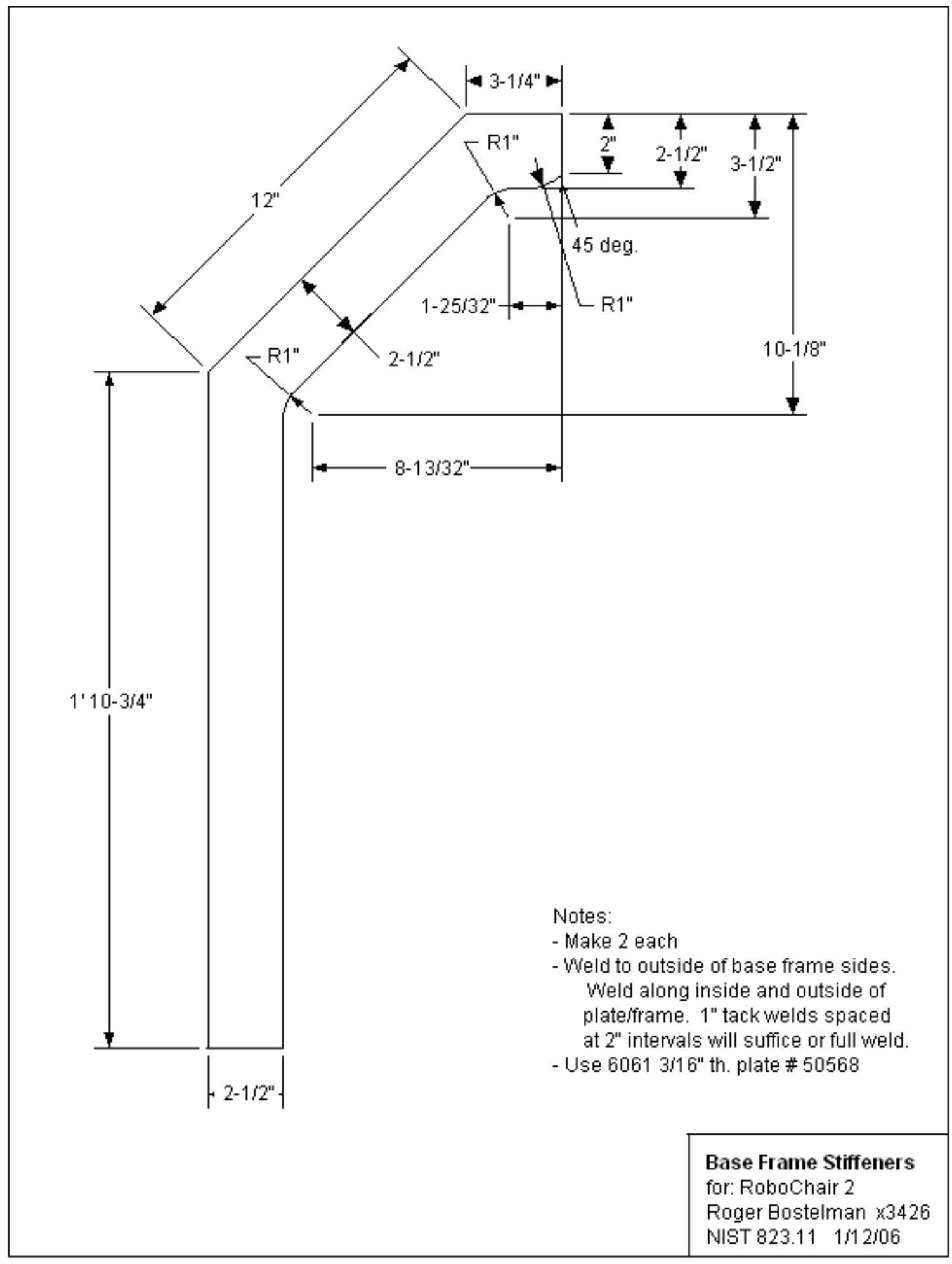




\section{Design of the HLPR Chair}

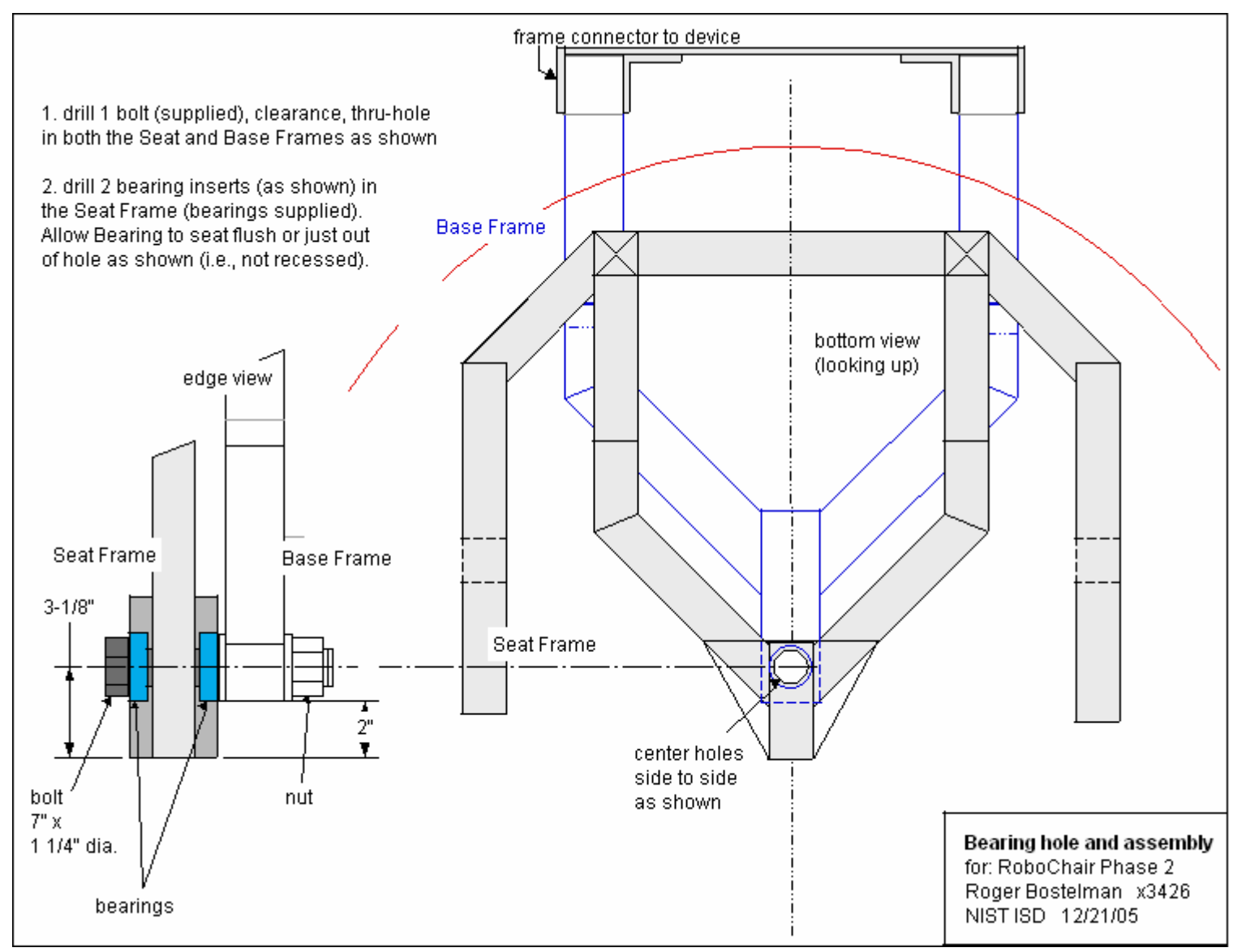


Design of the HLPR Chair

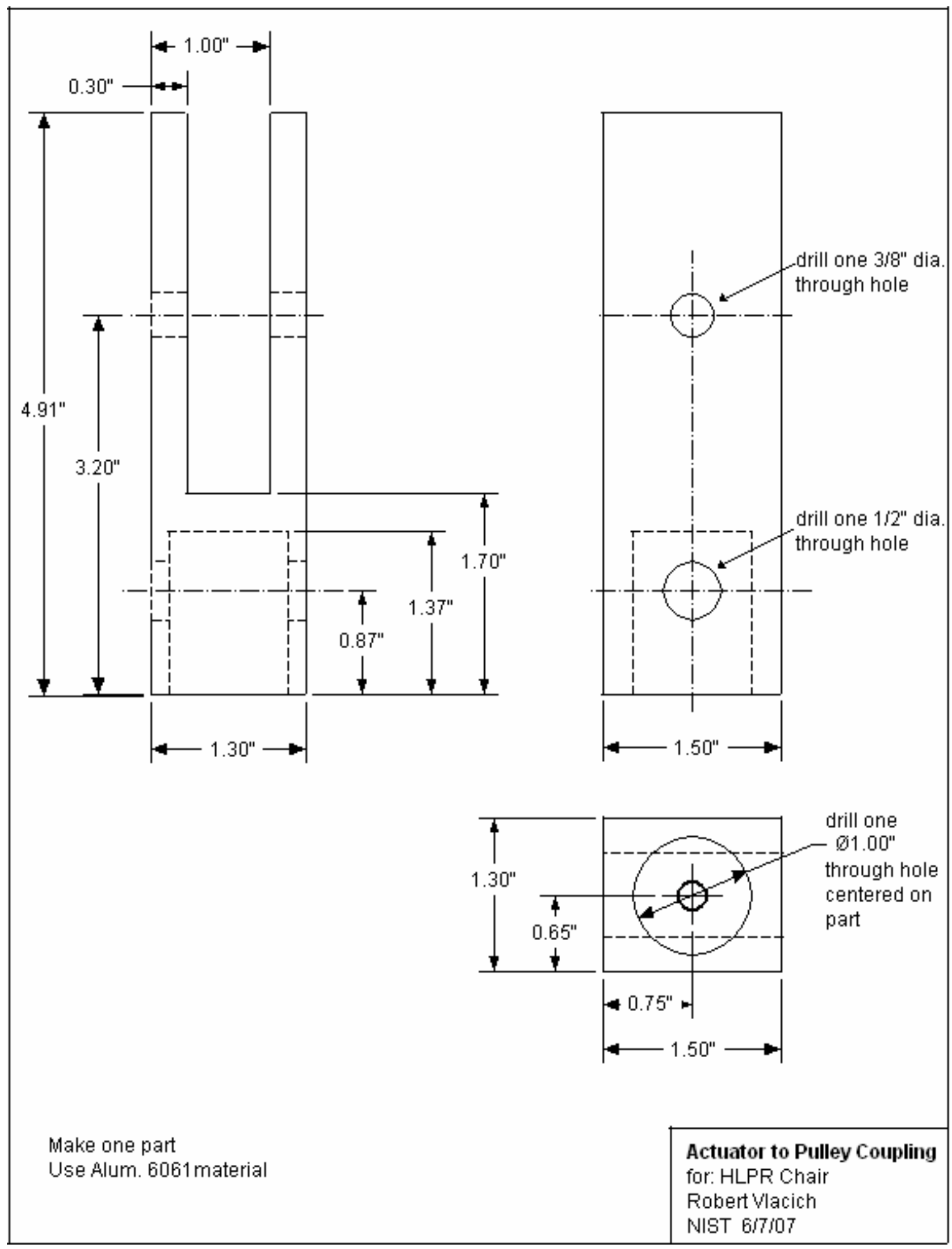




\section{Modifications to Original Designs}

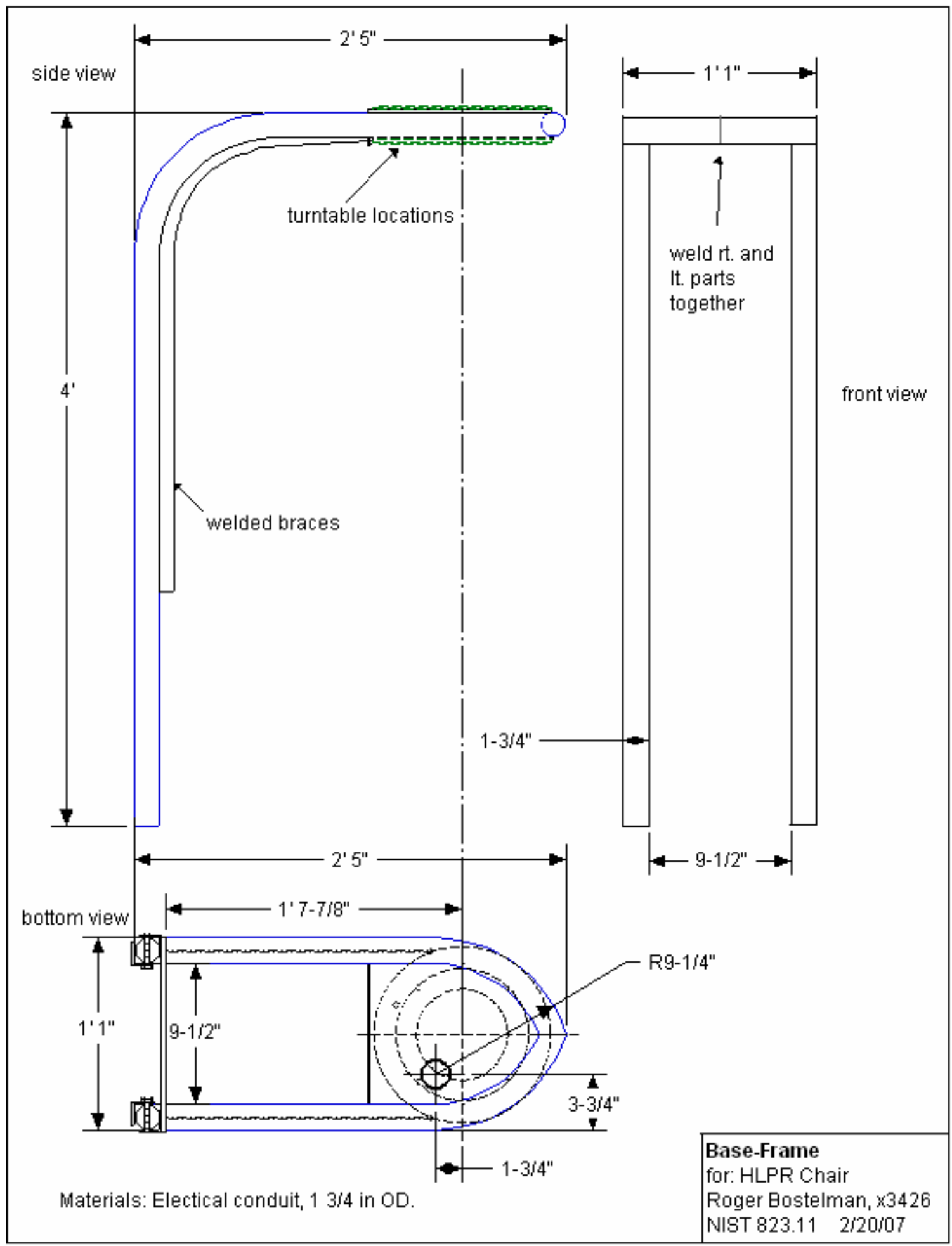


Design of the HLPR Chair

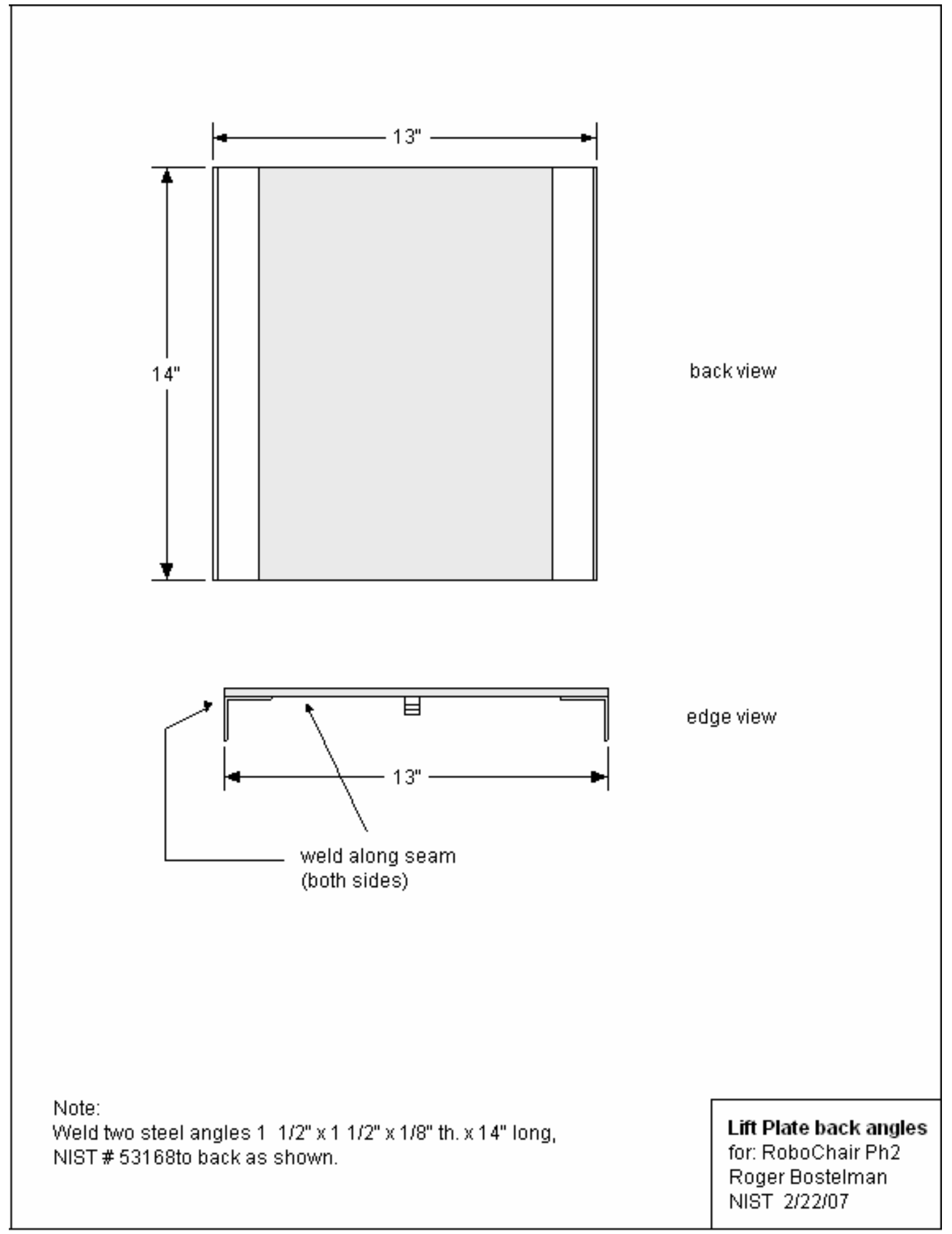




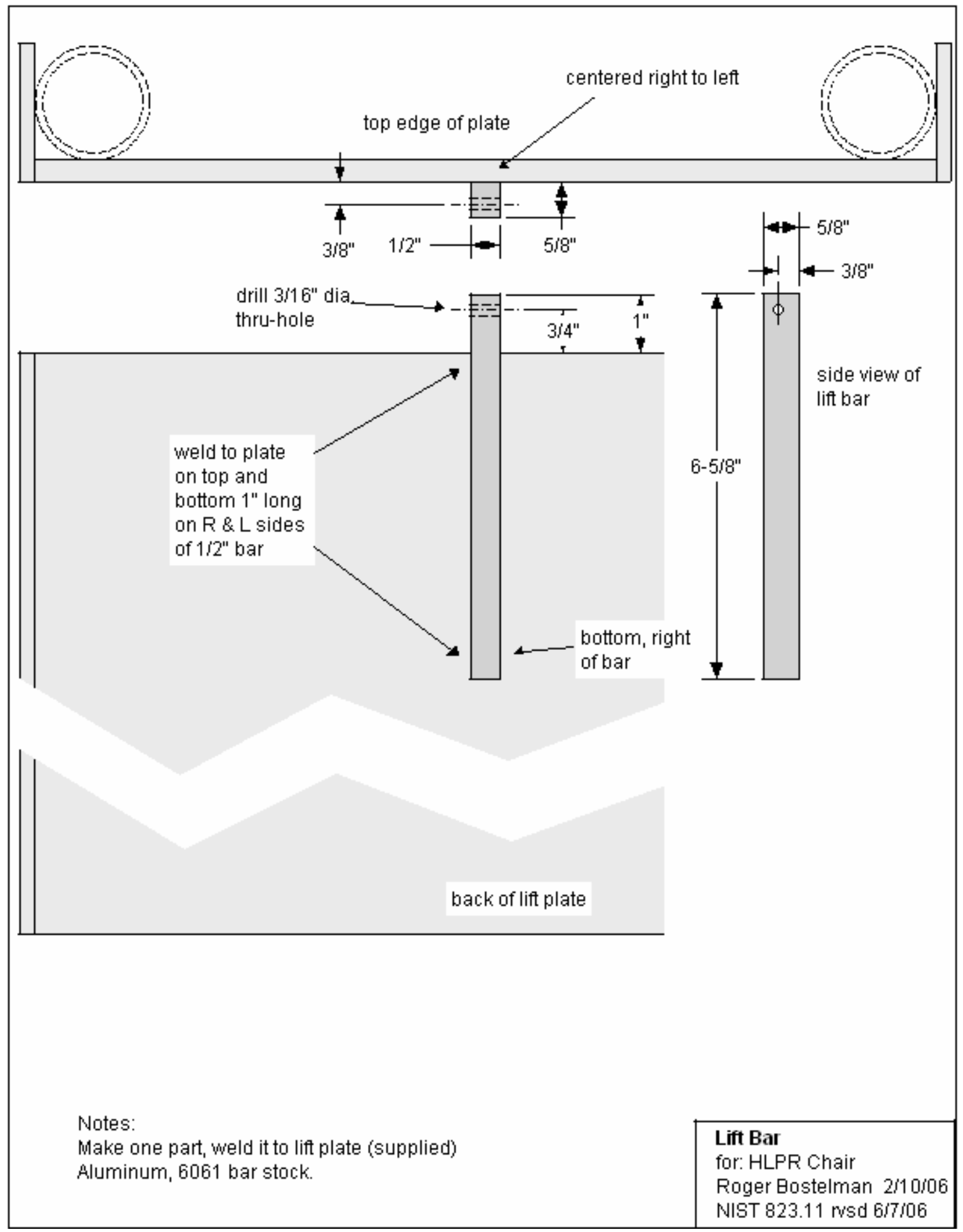


Design of the HLPR Chair

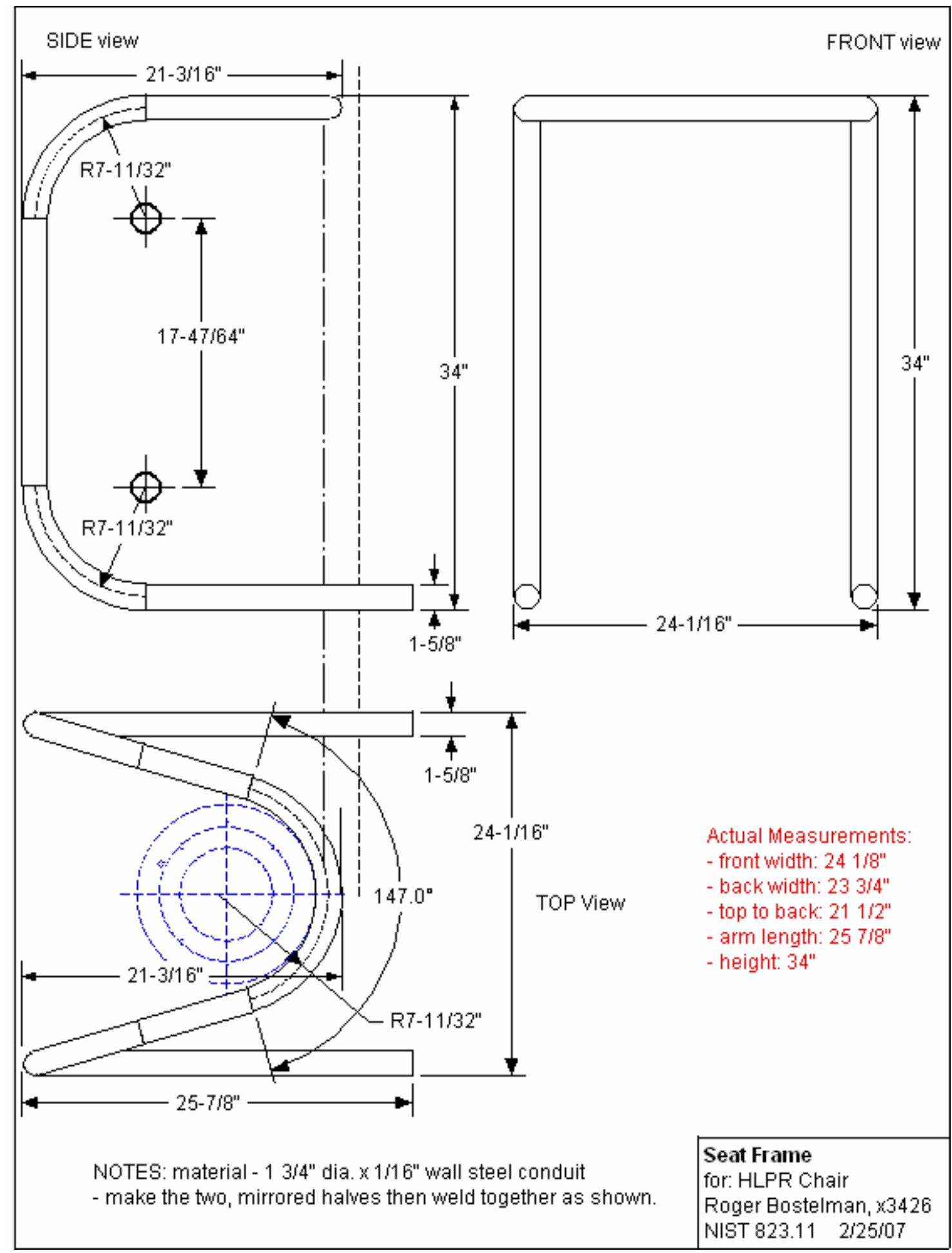




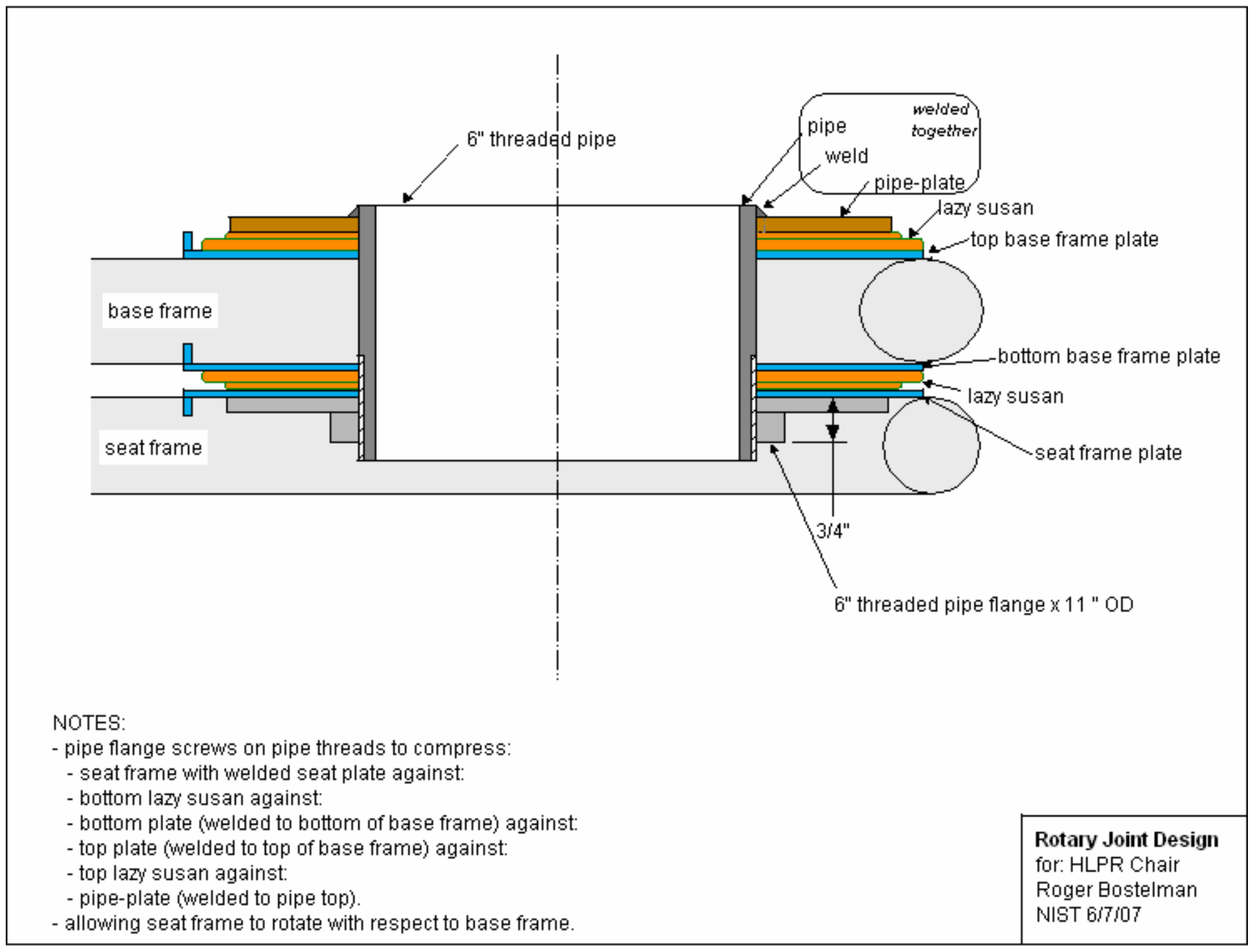




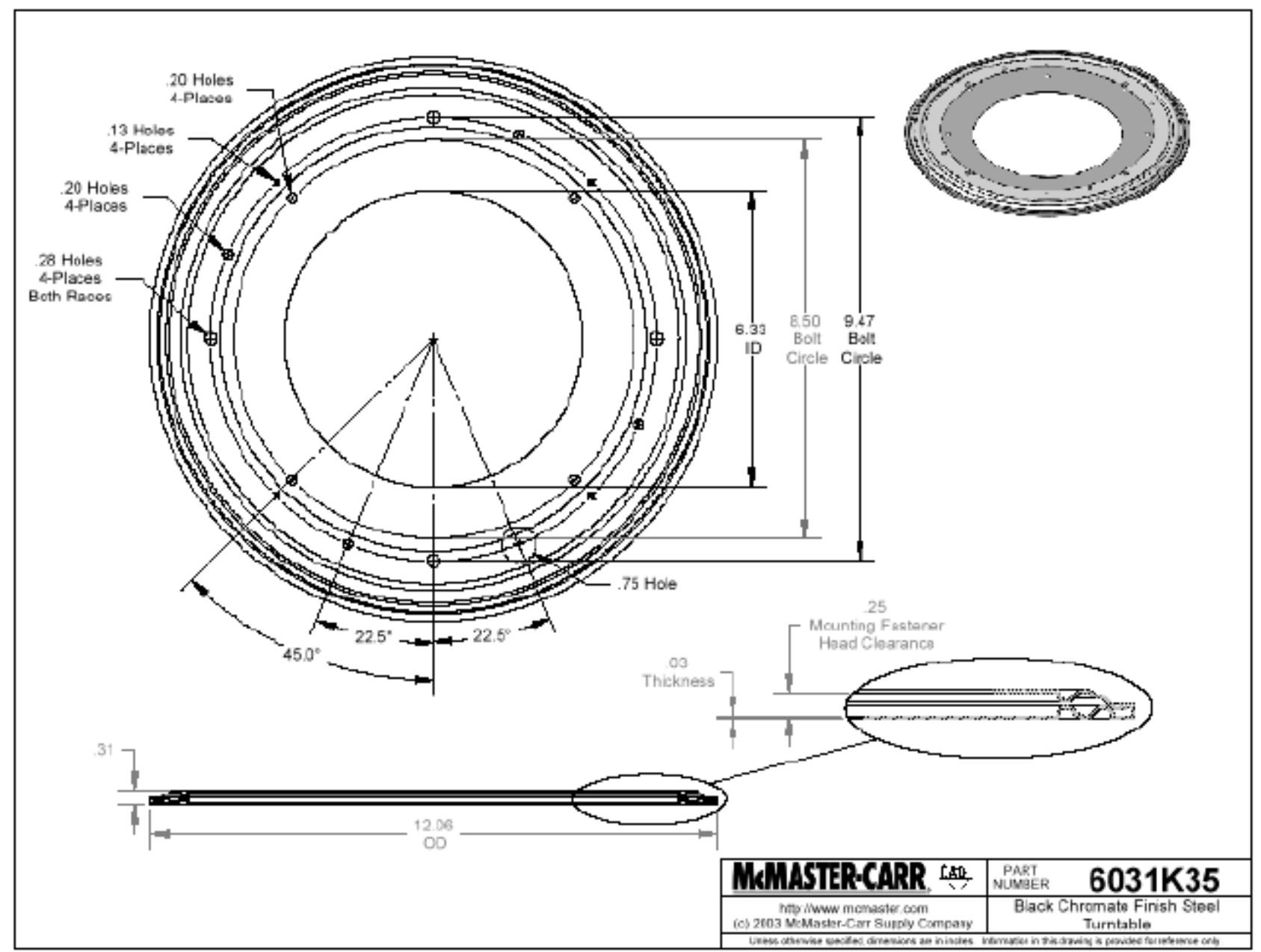

This drawing provided courtesy of McMaster-Carr. Other manufactured turntables could also be used. 
Design of the HLPR Chair

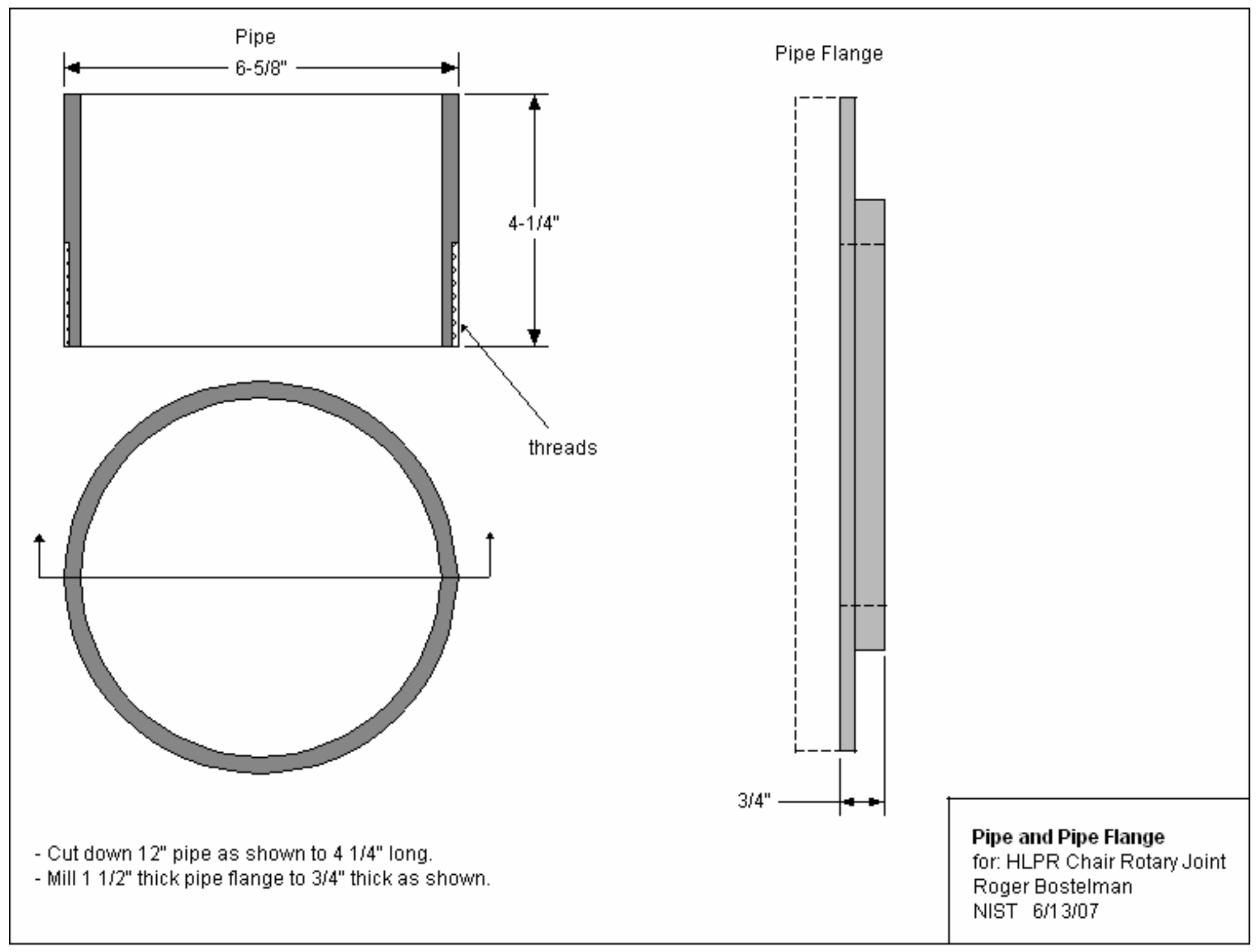


Design of the HLPR Chair

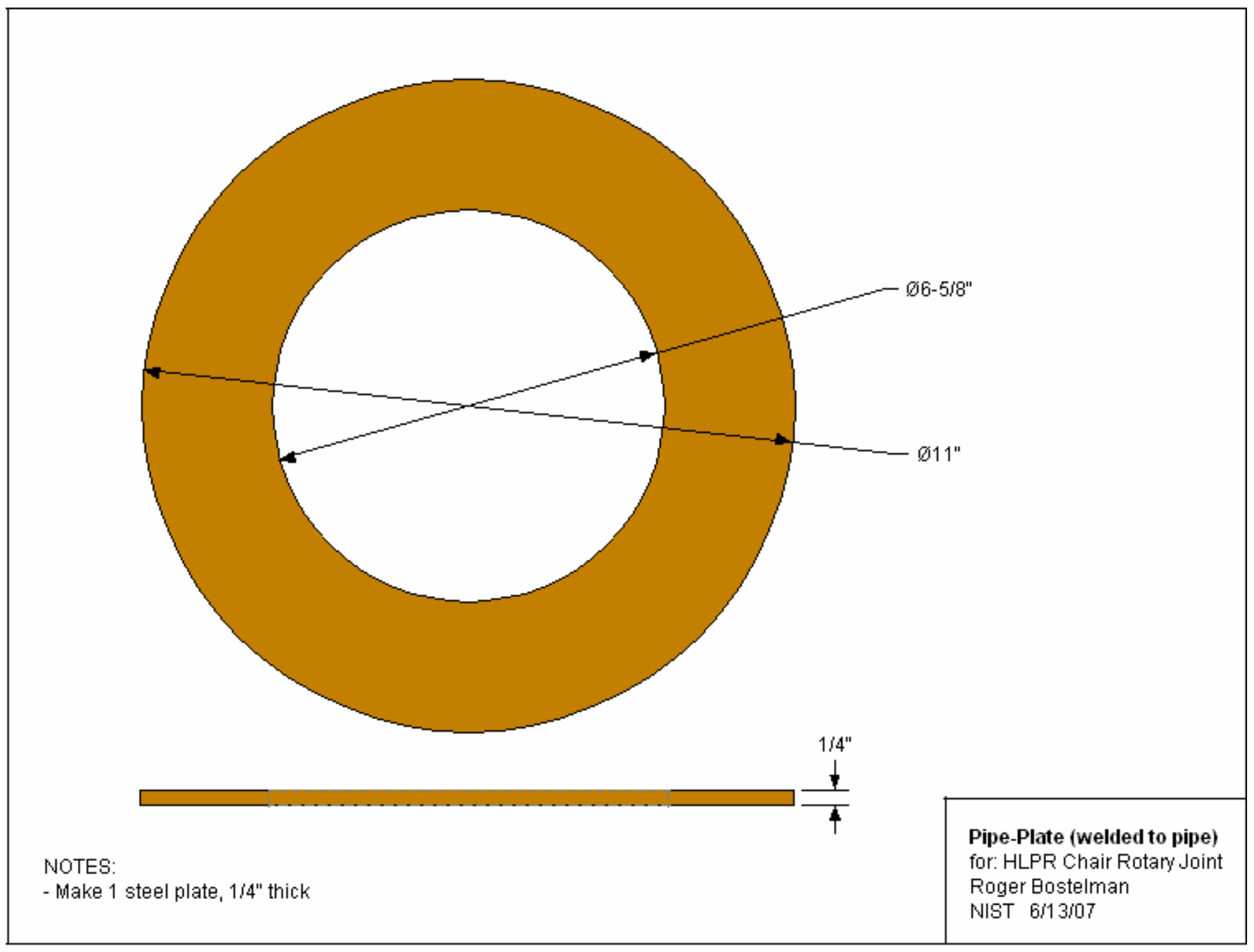


Design of the HLPR Chair

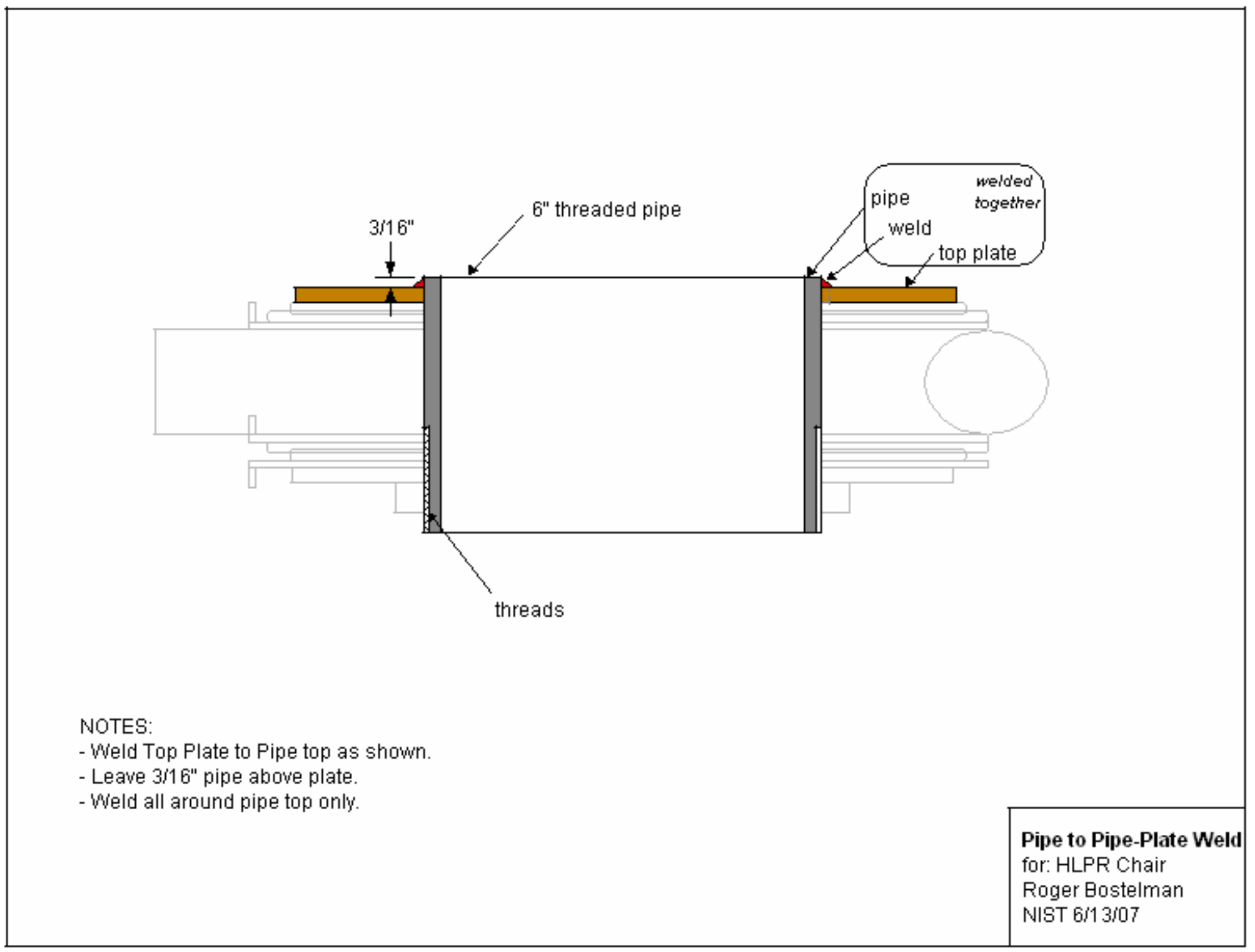


Design of the HLPR Chair

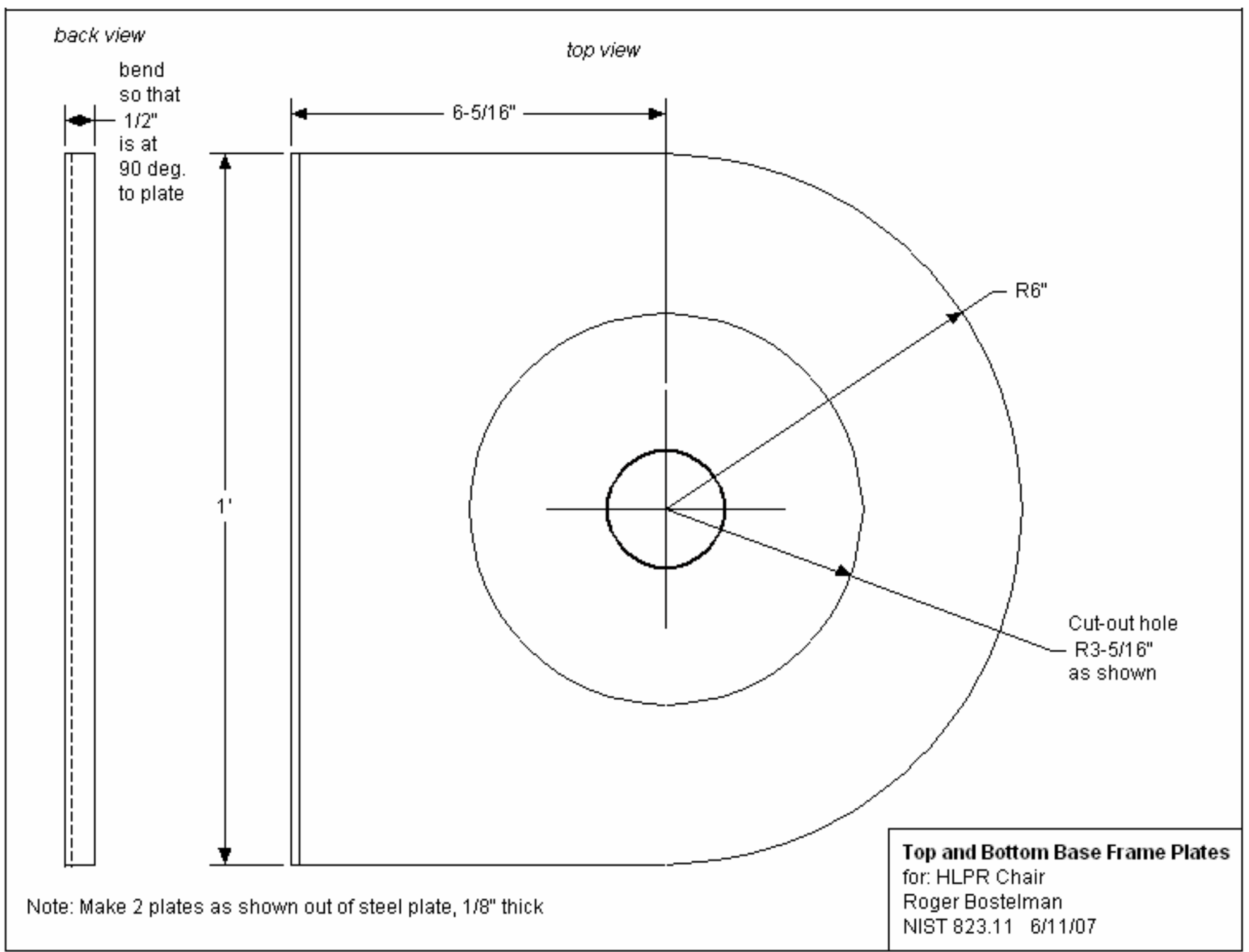




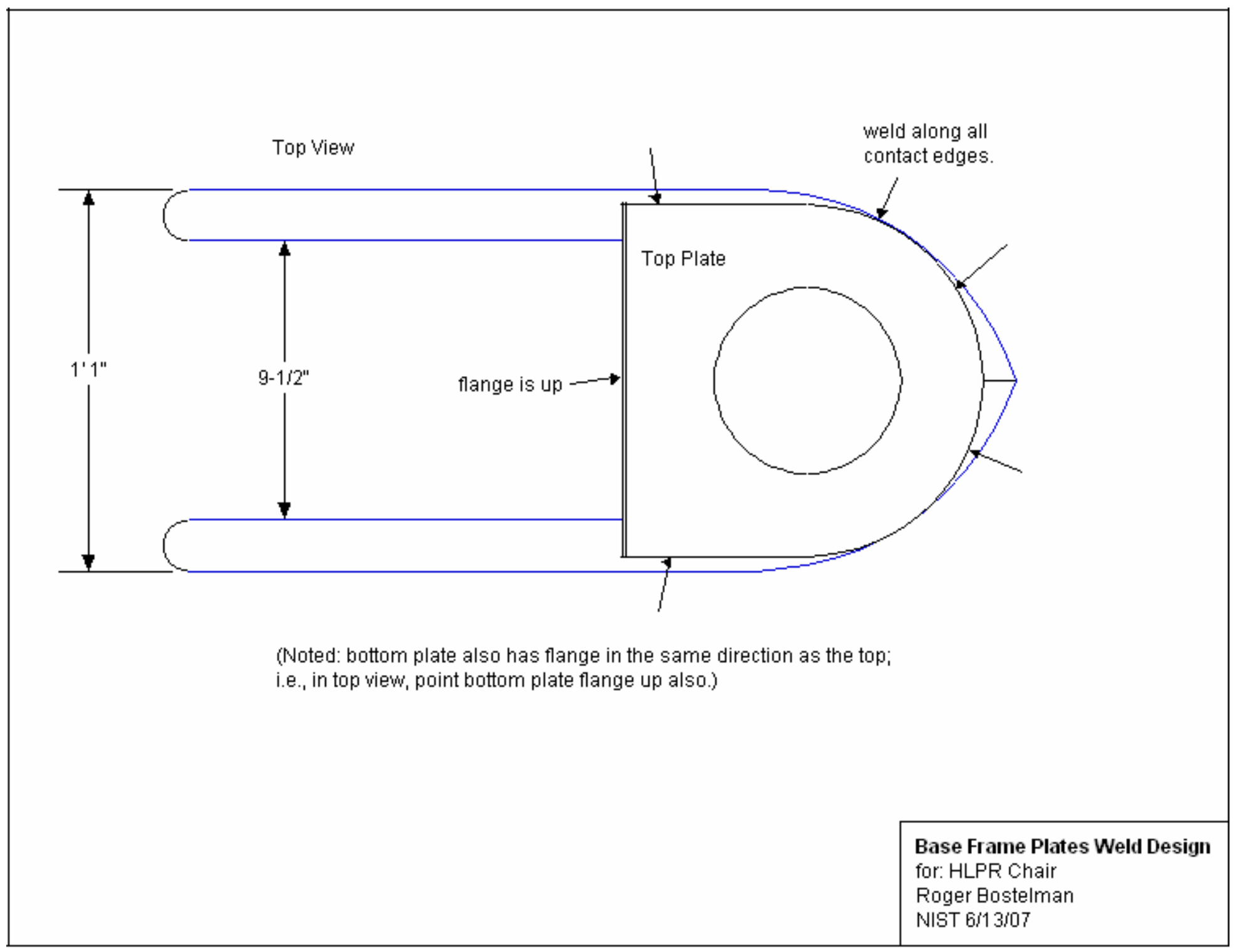




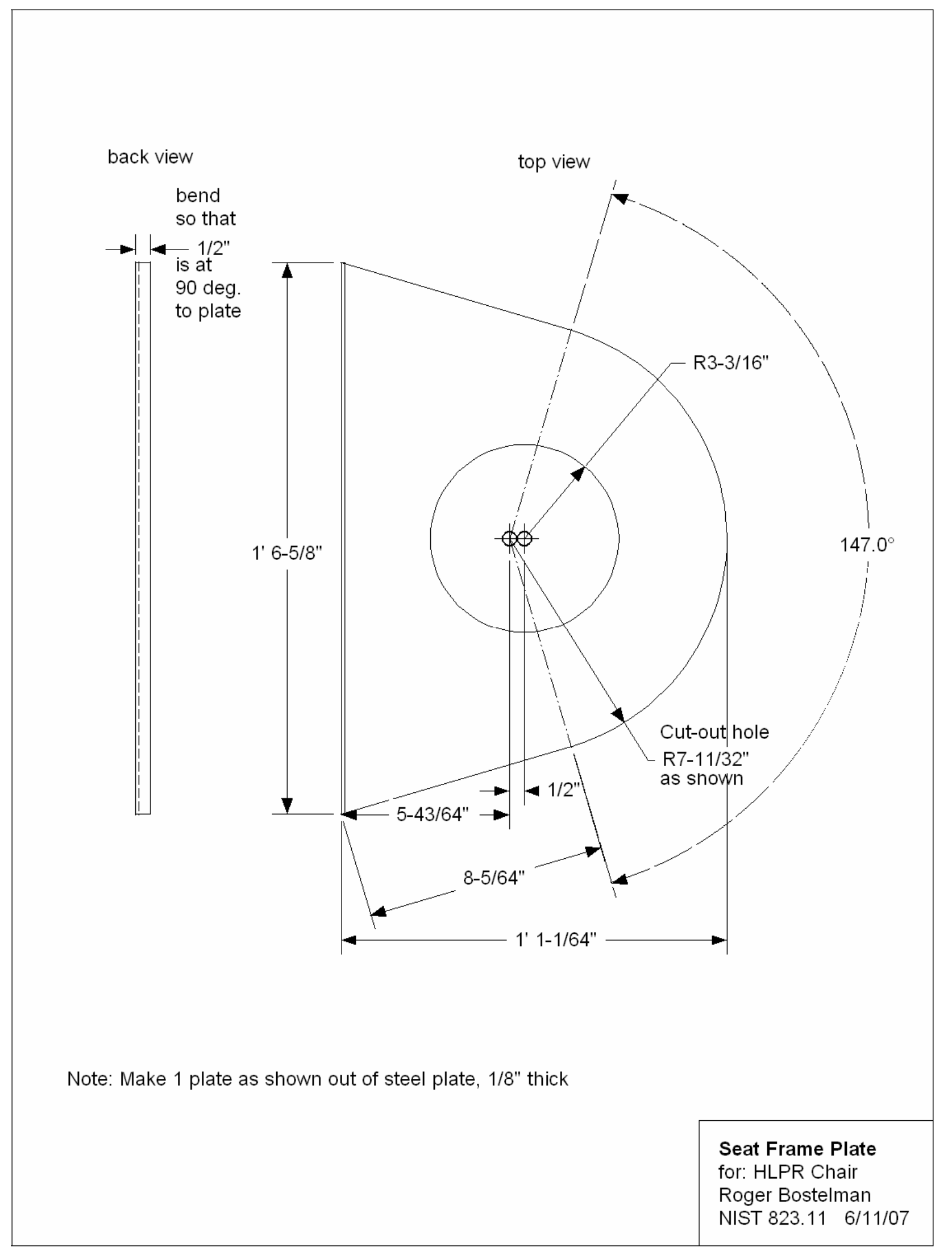




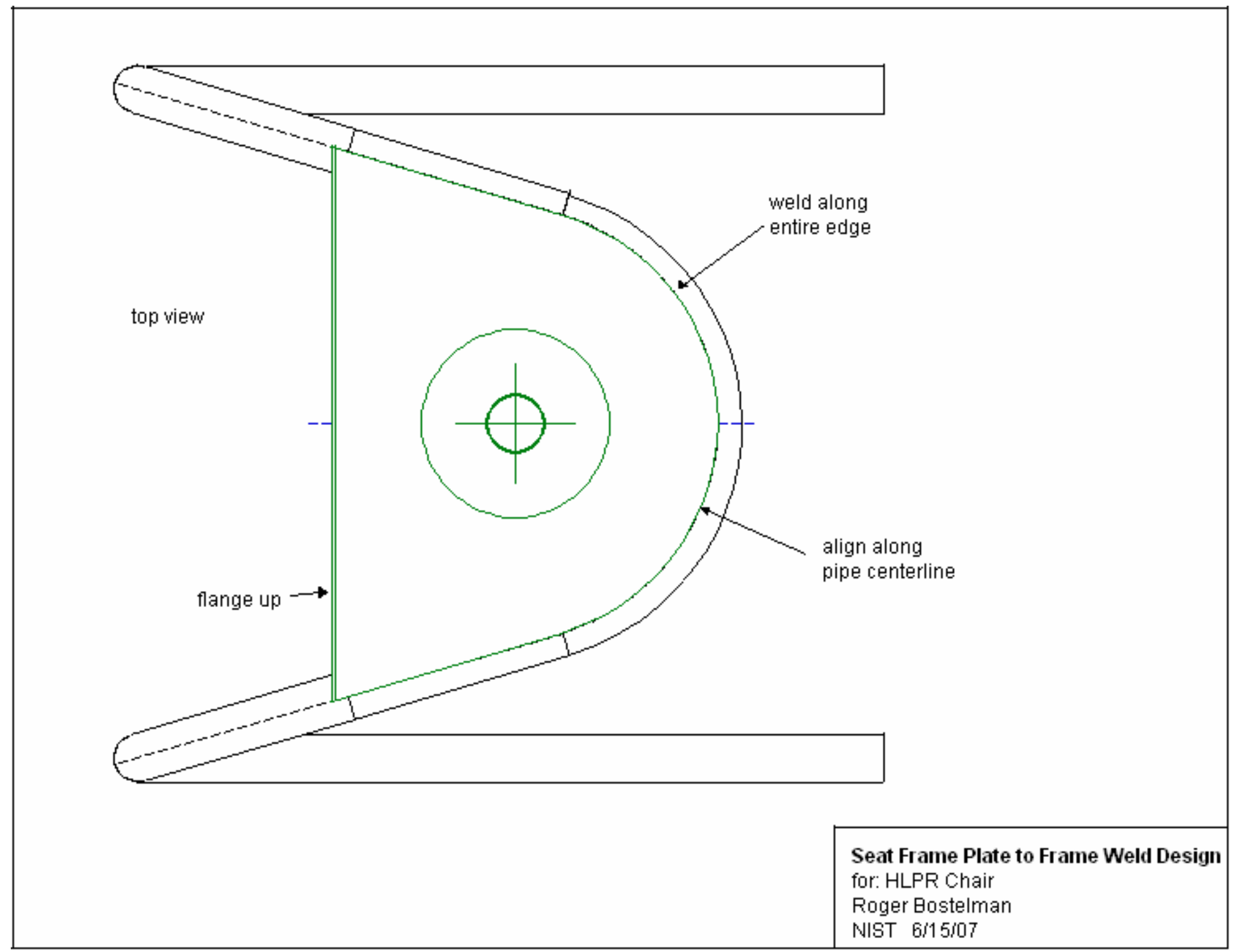




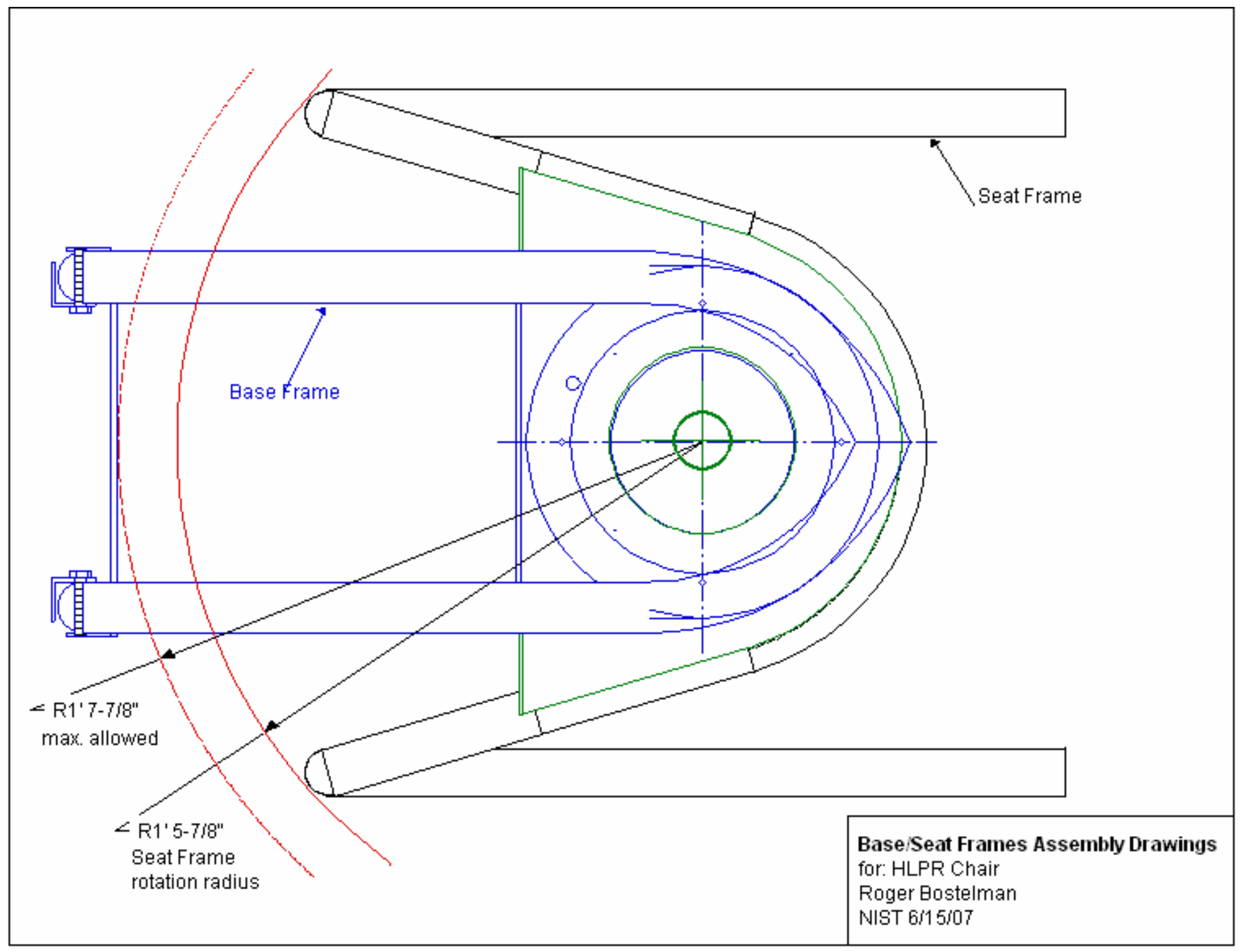




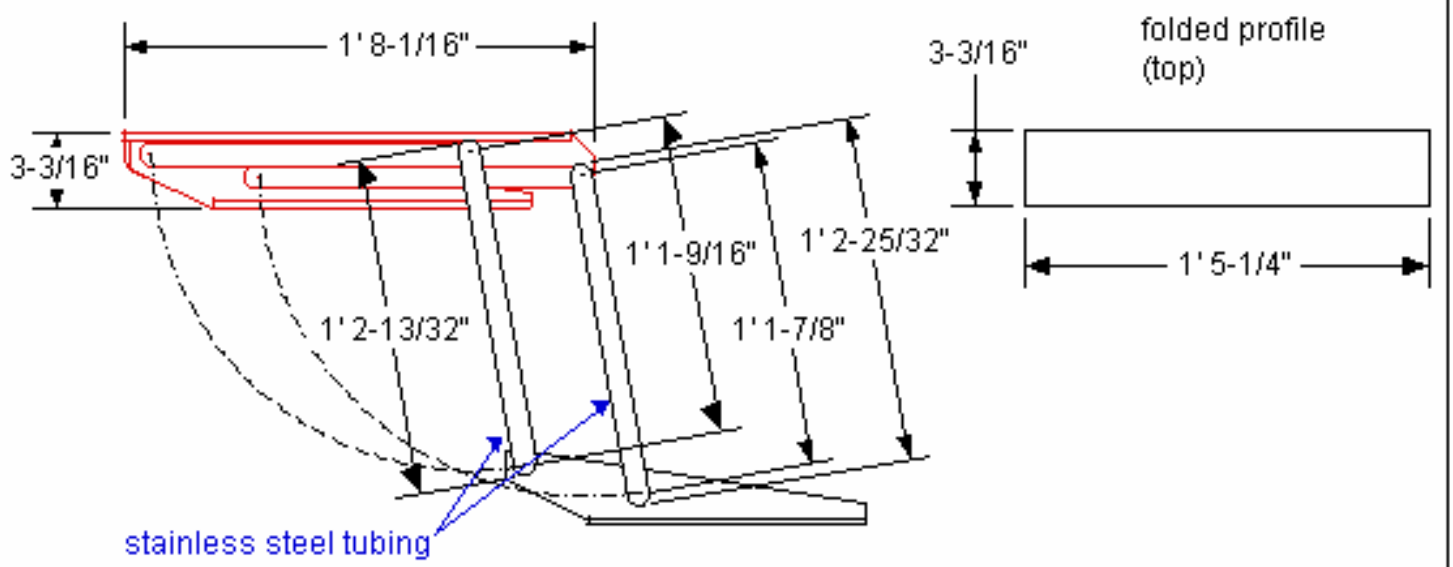

stainless steel tubes

- press flat 1" from both ends and drill 1/4" through holes as shown

- radius ends $7116 "$ and sand smooth to touch.
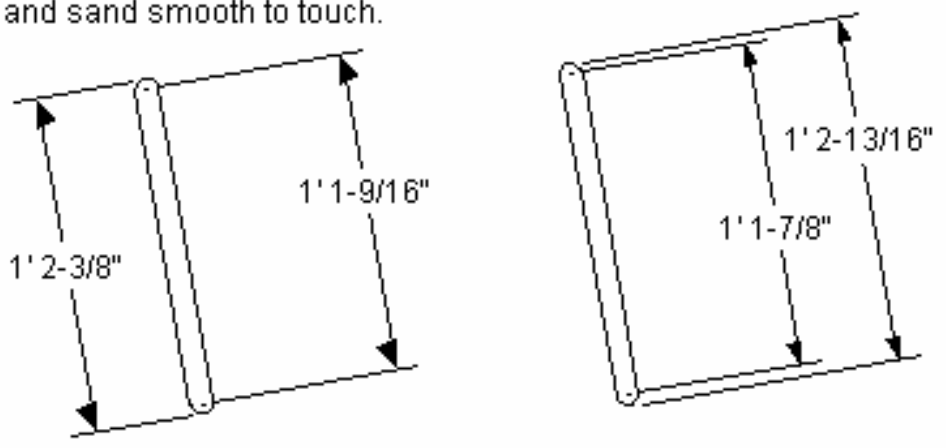

make 2 each

Footrest Assembly, Tubes

for: HLPR Chair 2

Roger Bostelman

NIST 823.11 3/14/07 
Design of the HLPR Chair

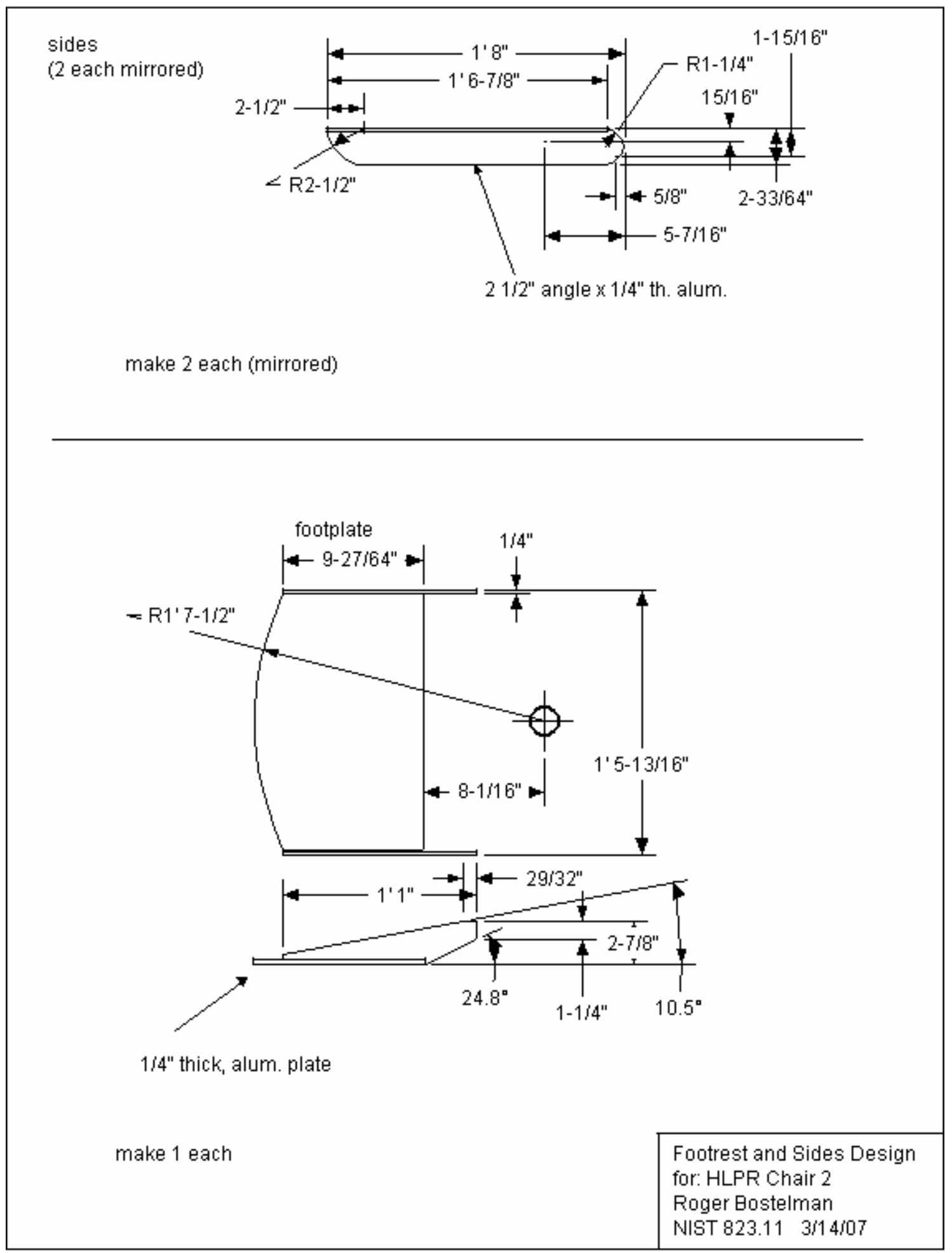




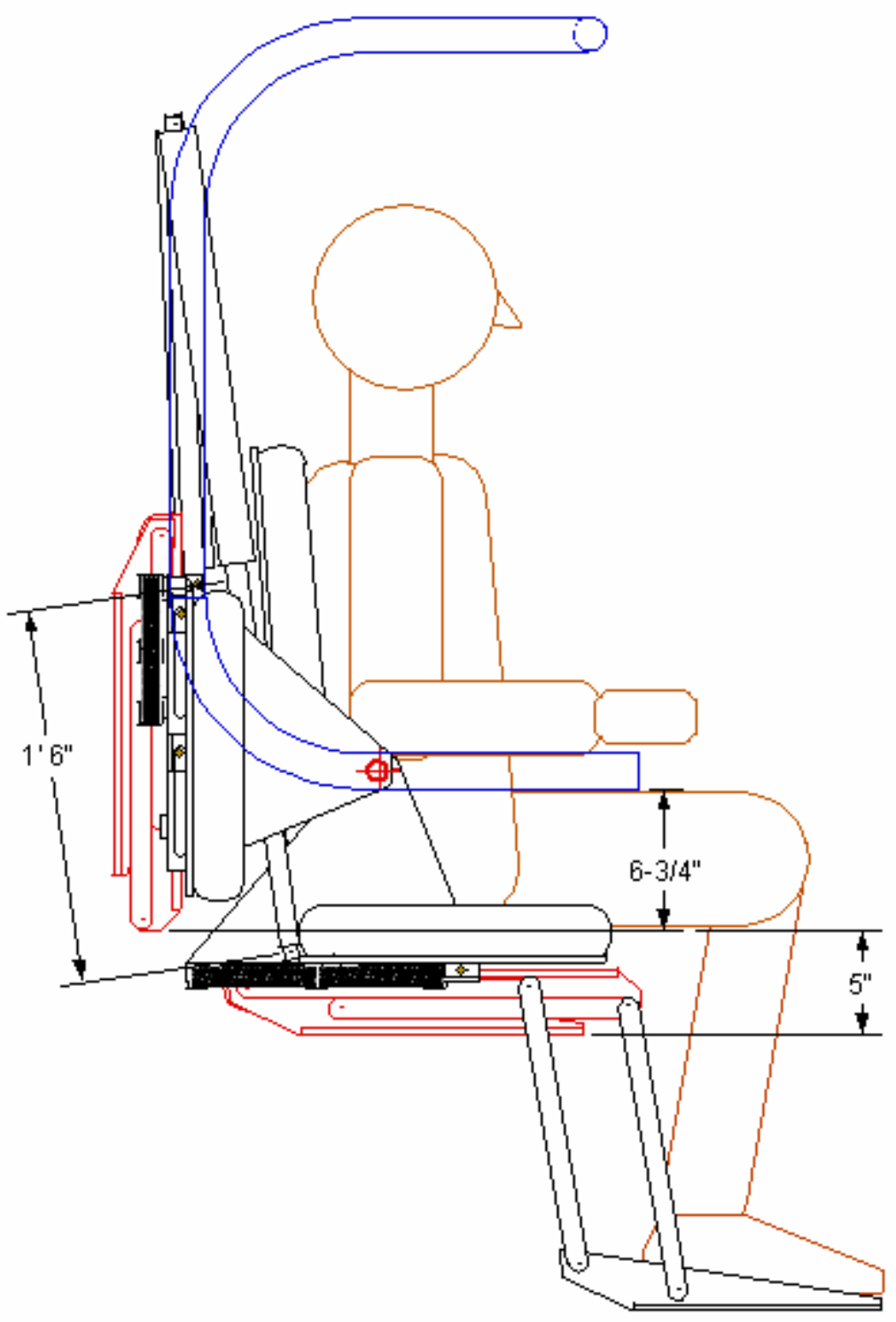

spring compresses from $6 "$ to $3.5^{\prime \prime}$ with 40 Lbs. so 2 will compress from $12^{\prime \prime}$ to $7^{\prime \prime}=2$ springs on each side $=80$ Lbs. $-F$ 


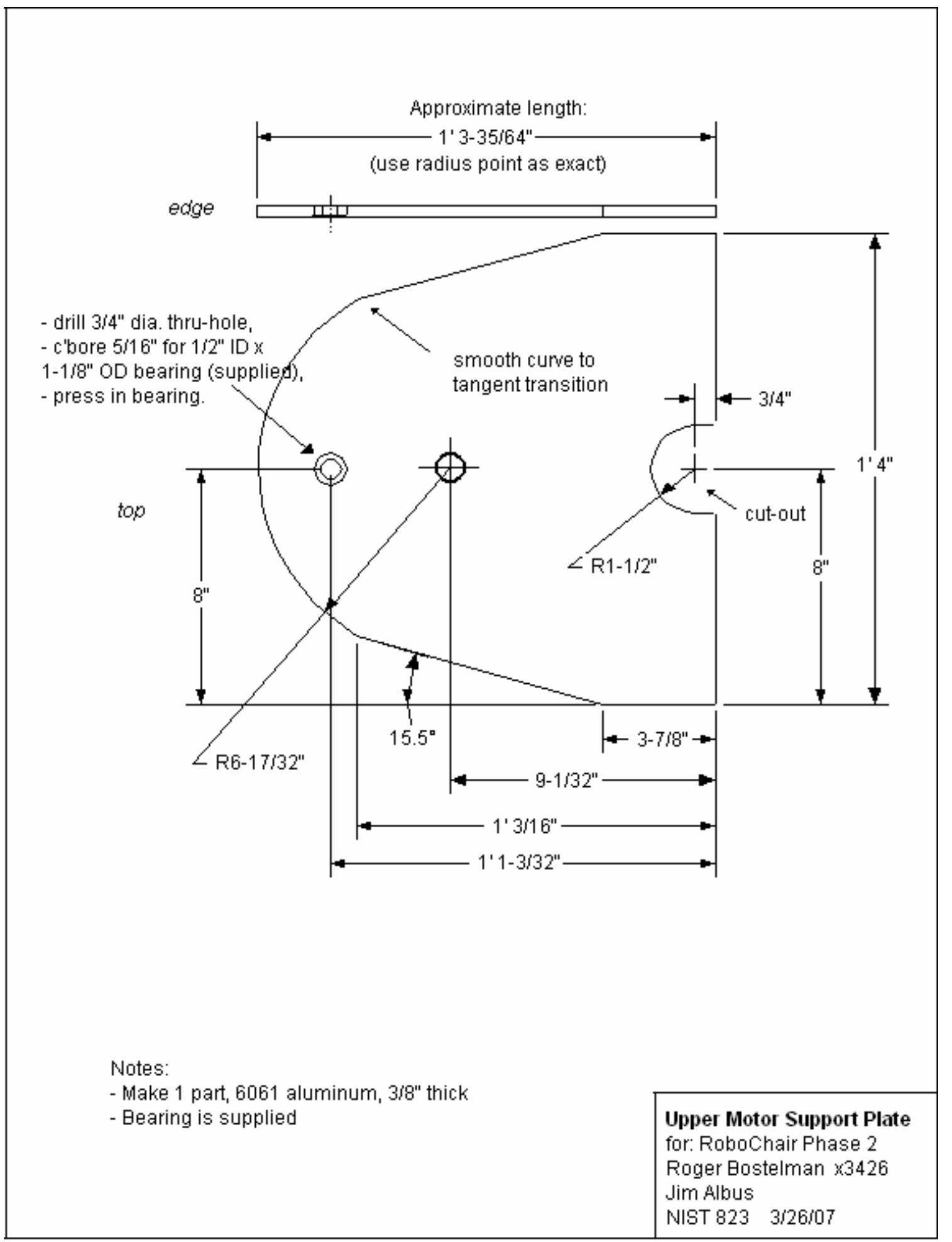




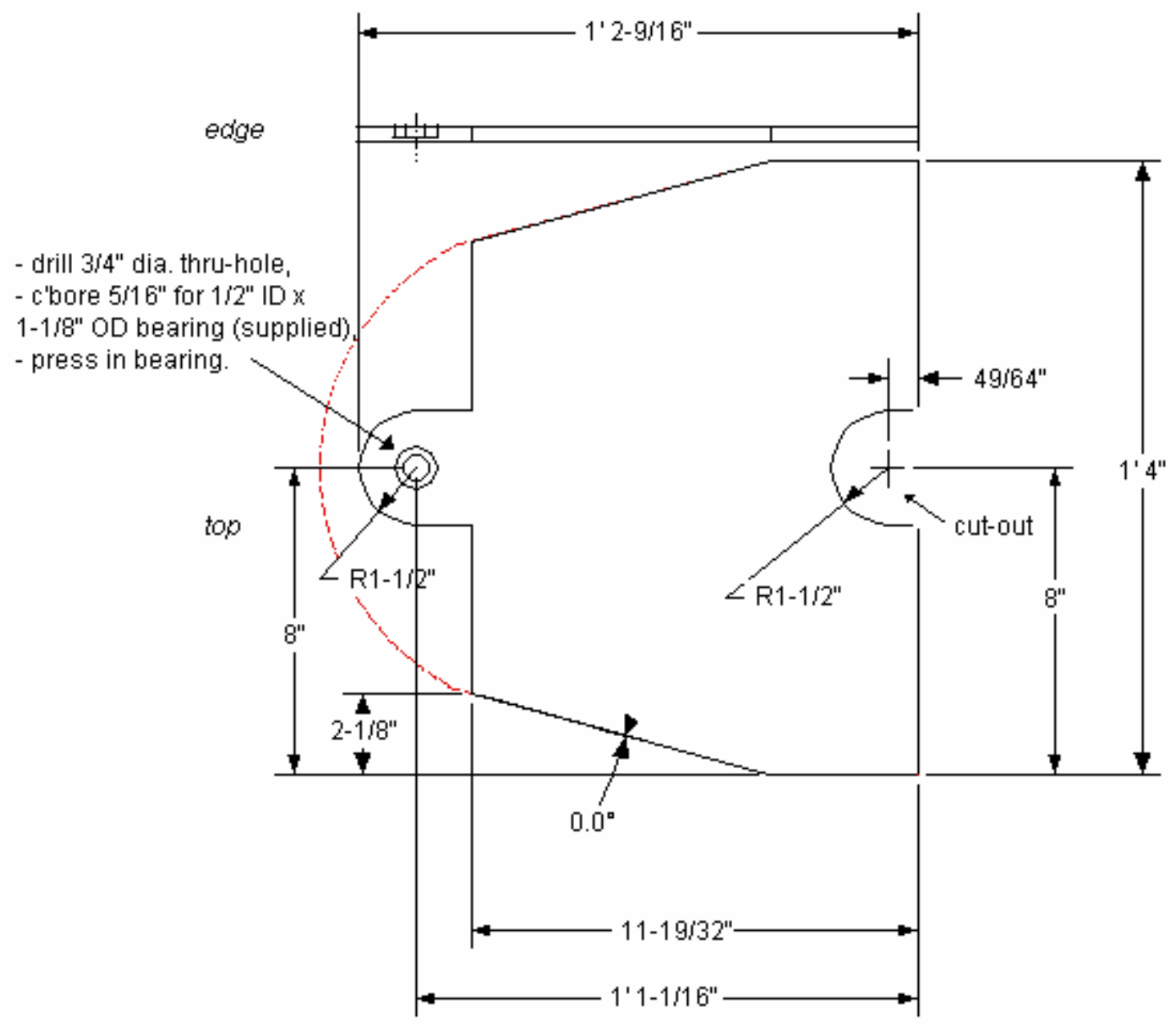

Notes:

- Make 1 part, 6061 aluminum, 3/8" thick

- Bearing is supplied

Lower Motor Support Plate

for: Robochair Phase 2

Roger Bostelman $\times 3426$

Jim Albus

NIST $823 \quad 3 / 26,07$ 


\section{Electrical Design}

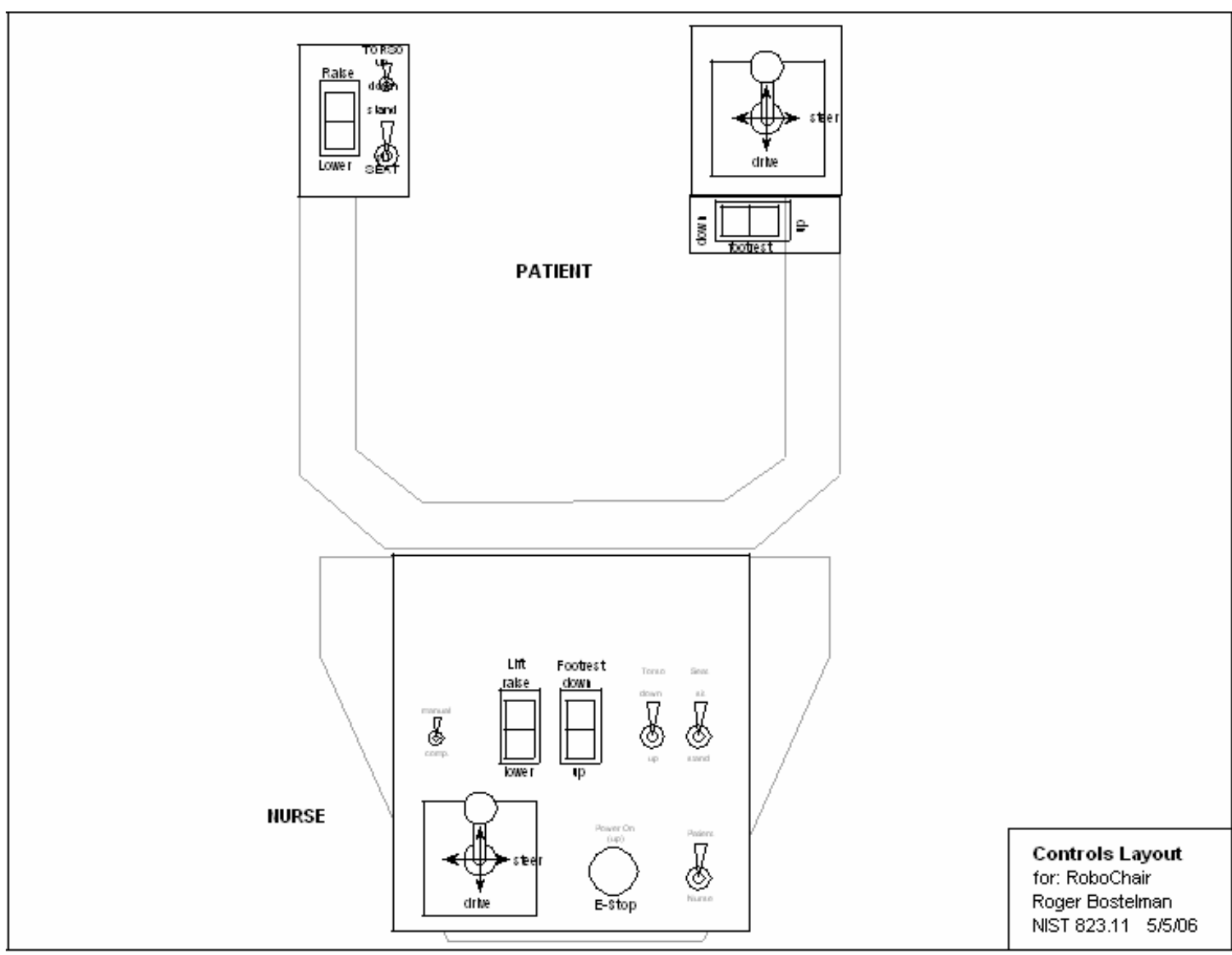


Design of the HLPR Chair

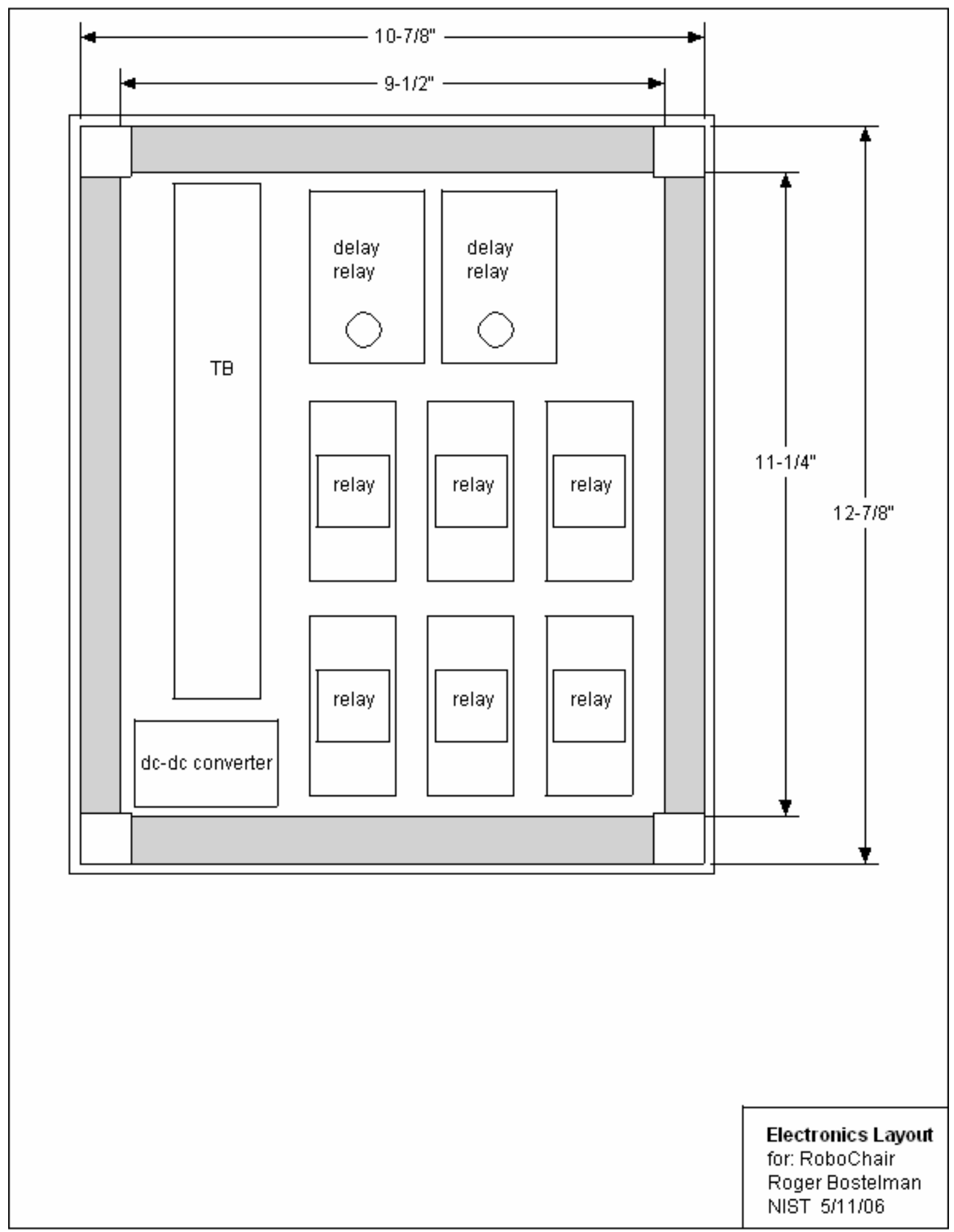


Design of the HLPR Chair

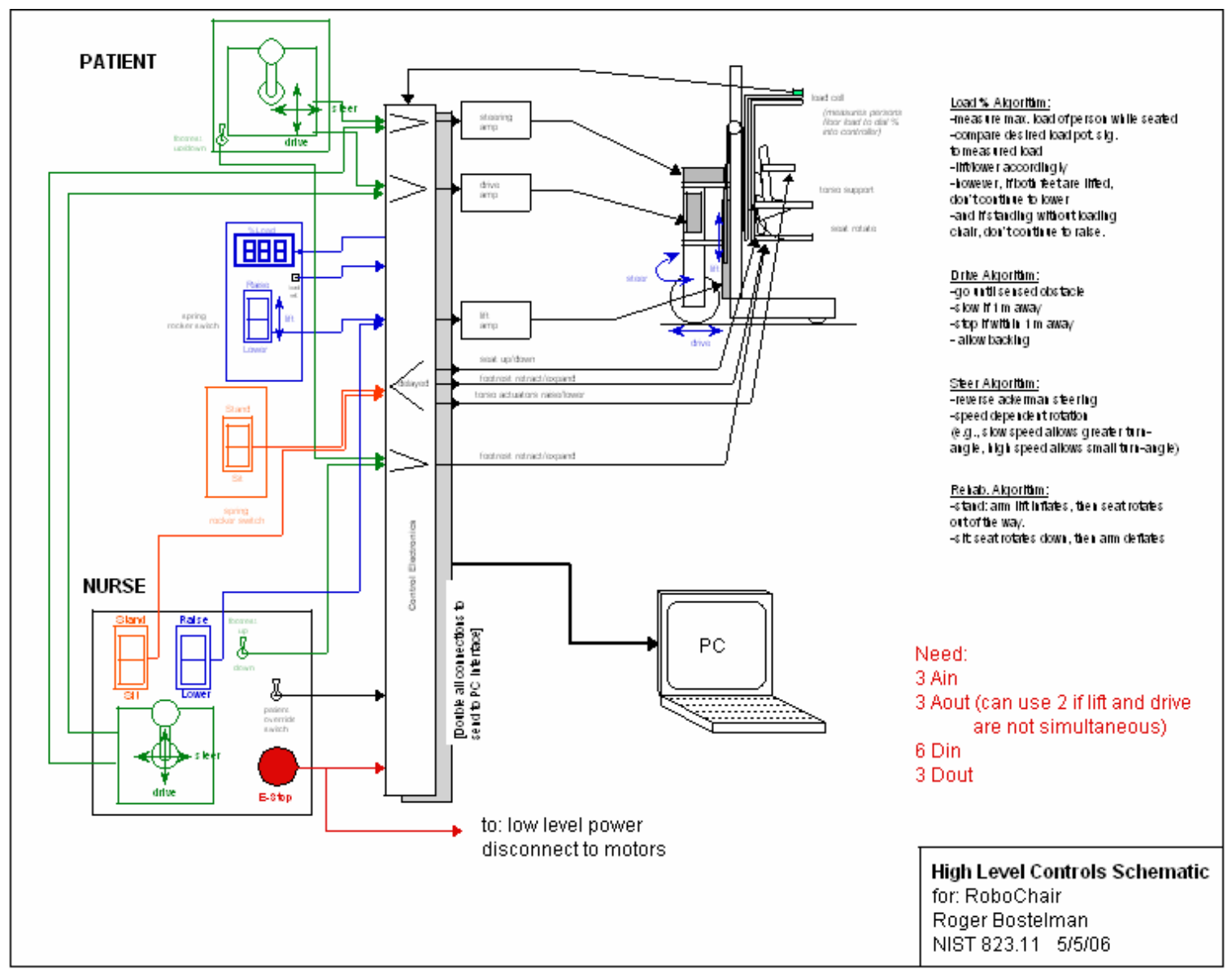




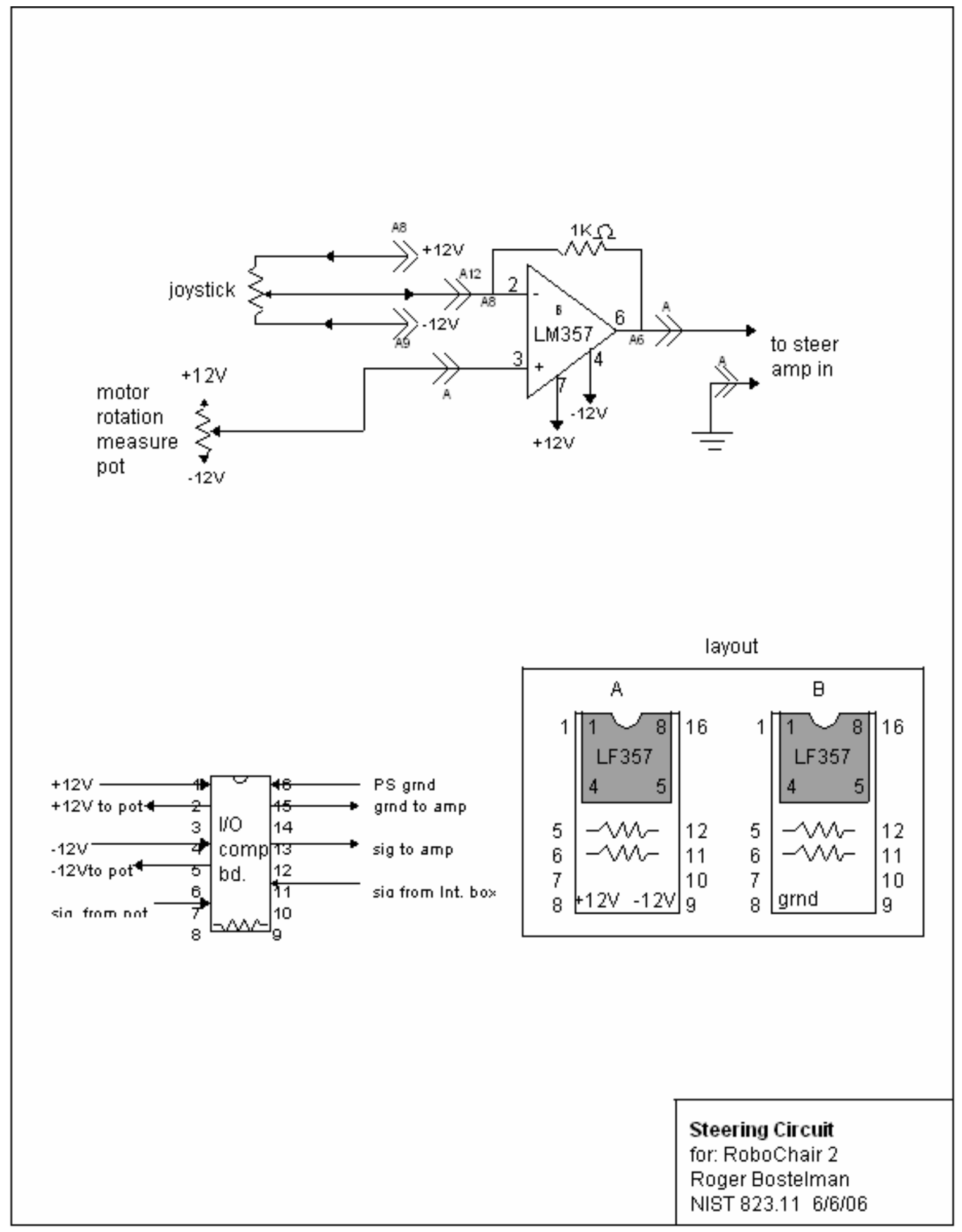




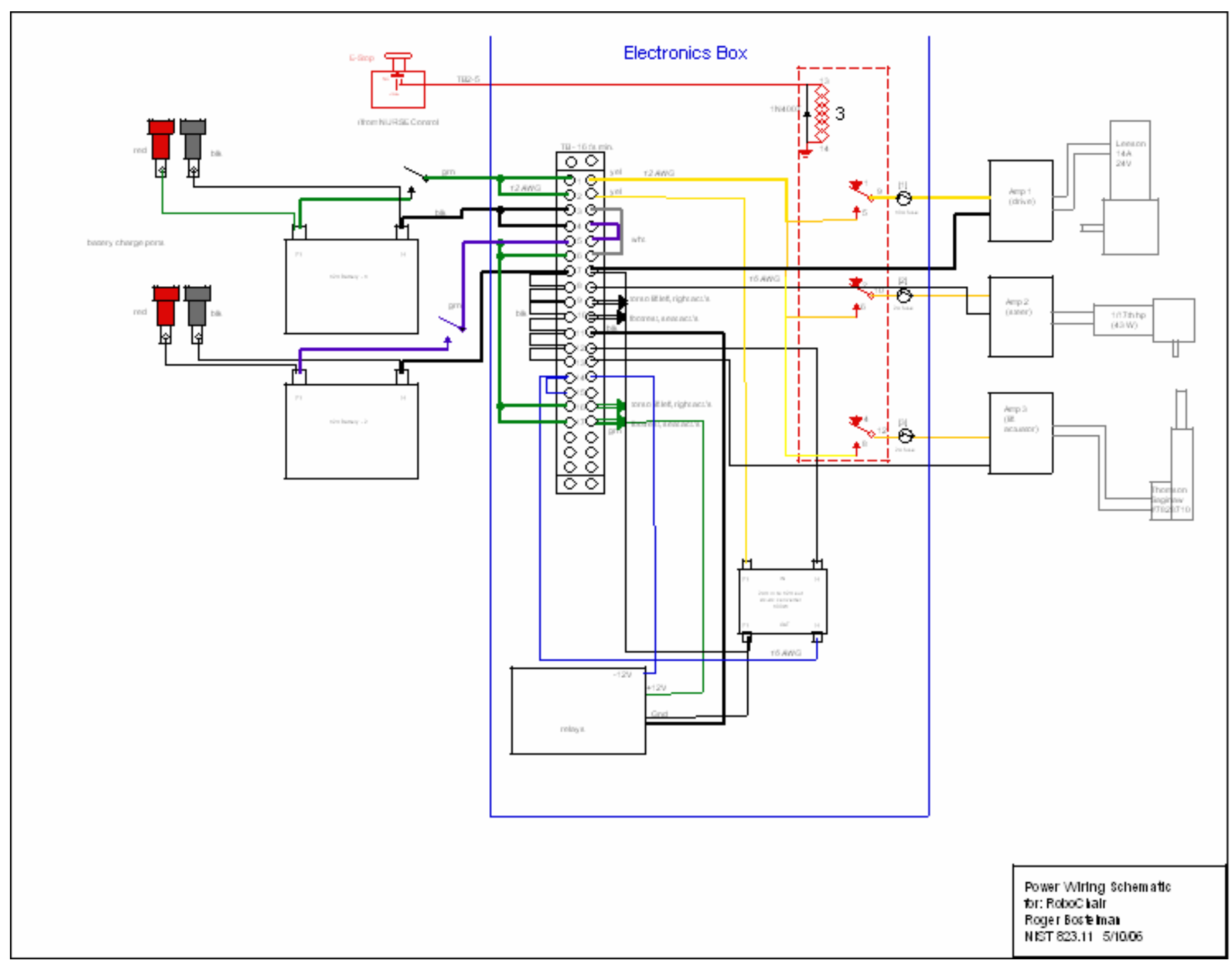




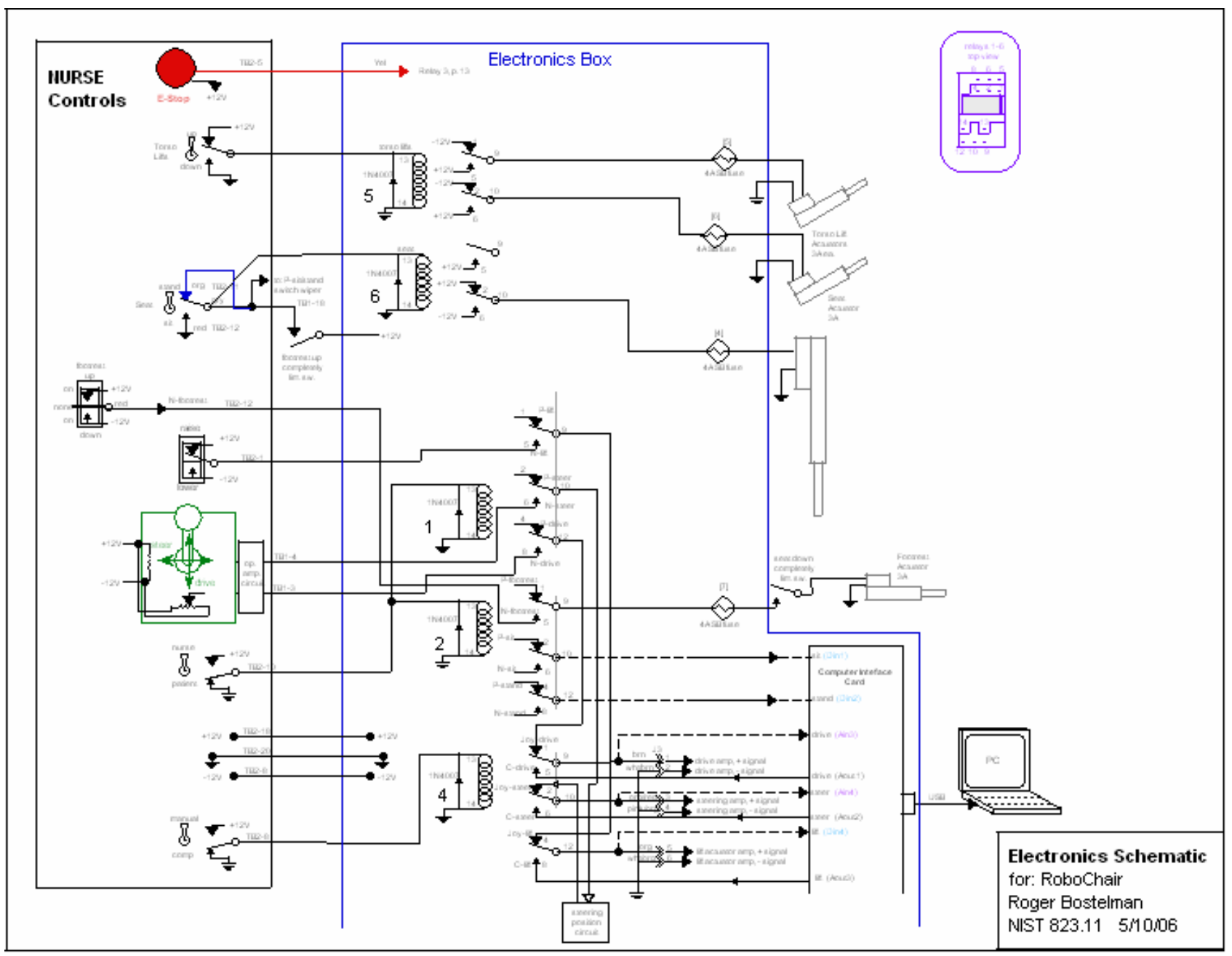




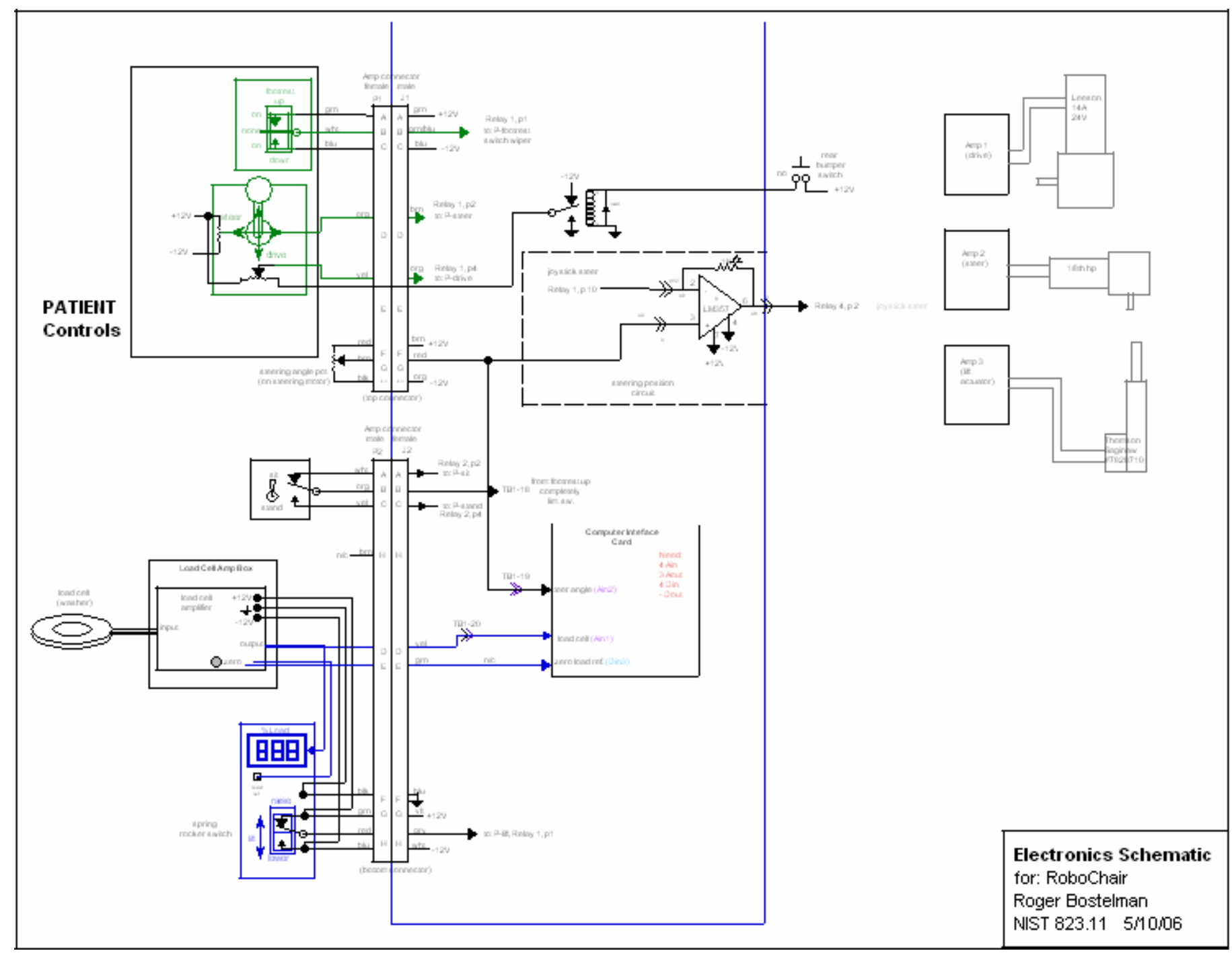




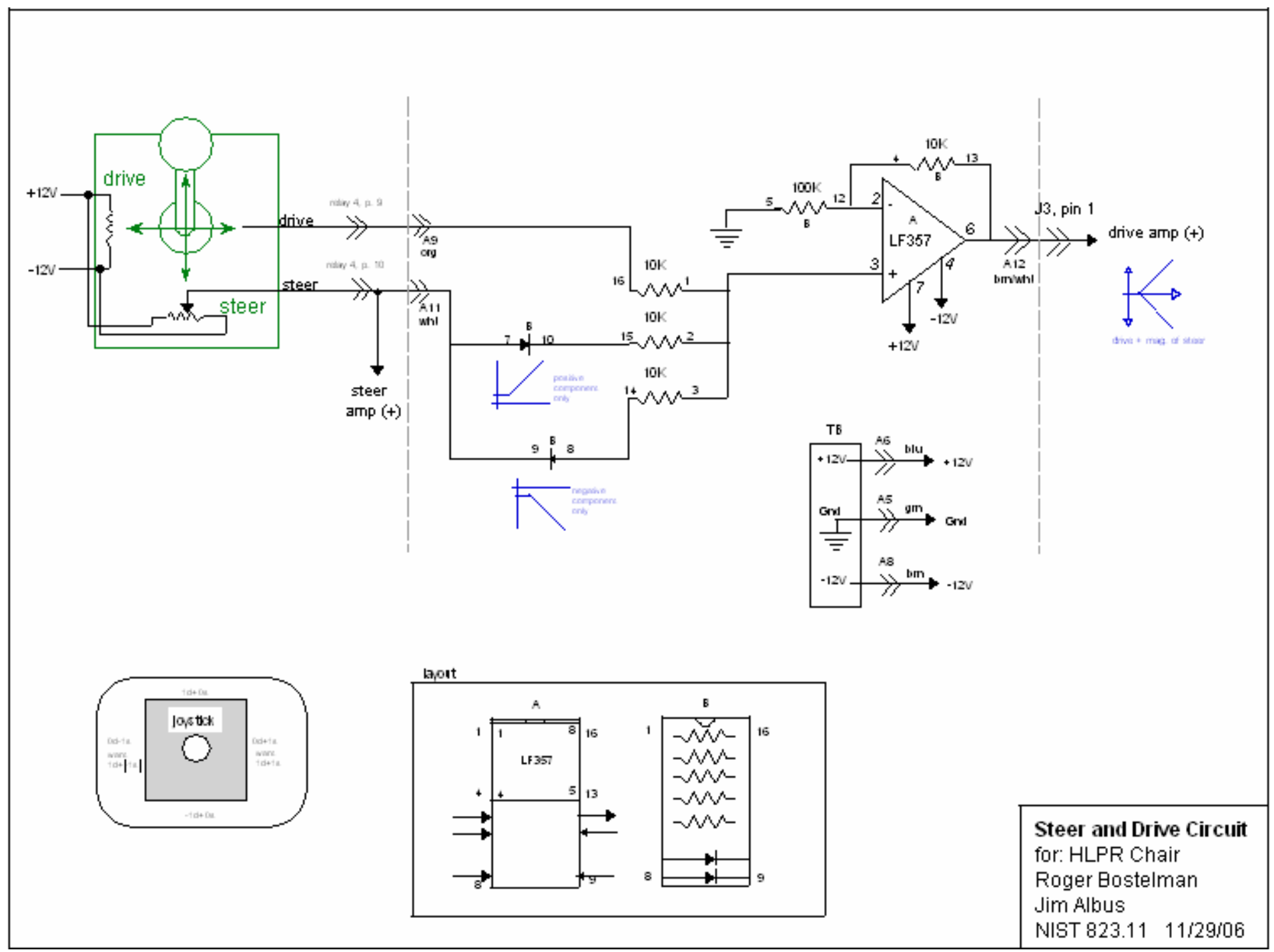


Design of the HLPR Chair

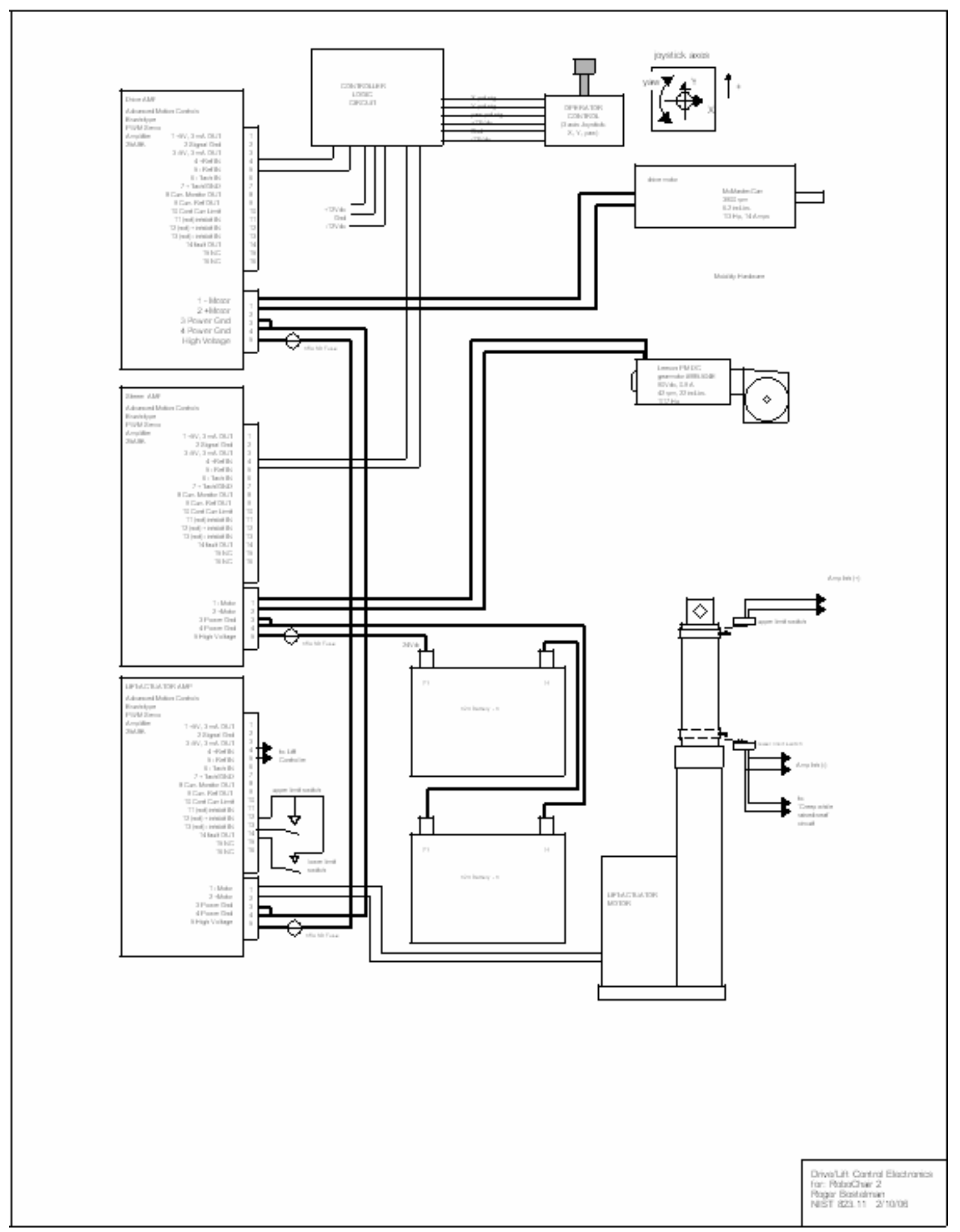




\section{Design of the HLPR Chair}

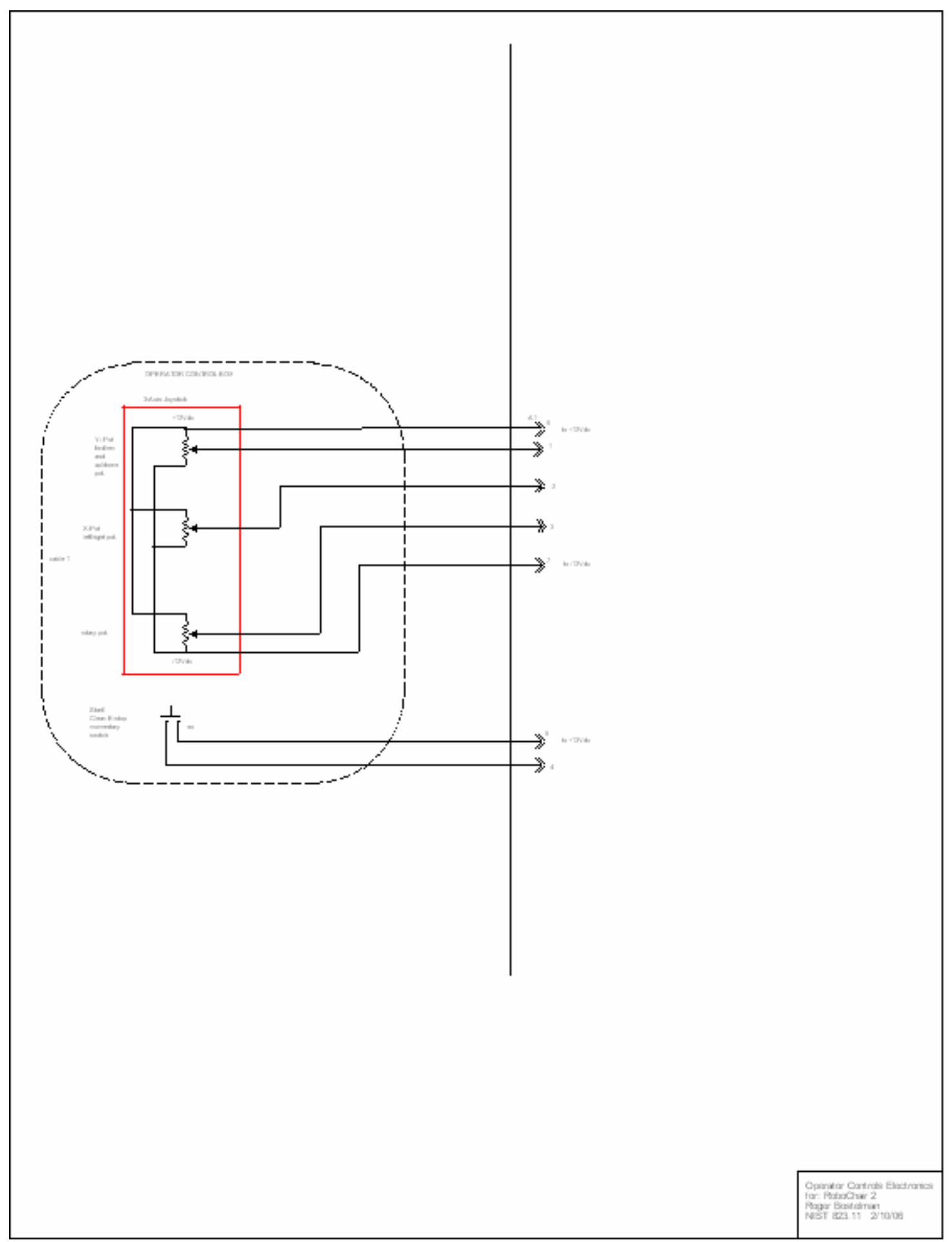


Design of the HLPR Chair

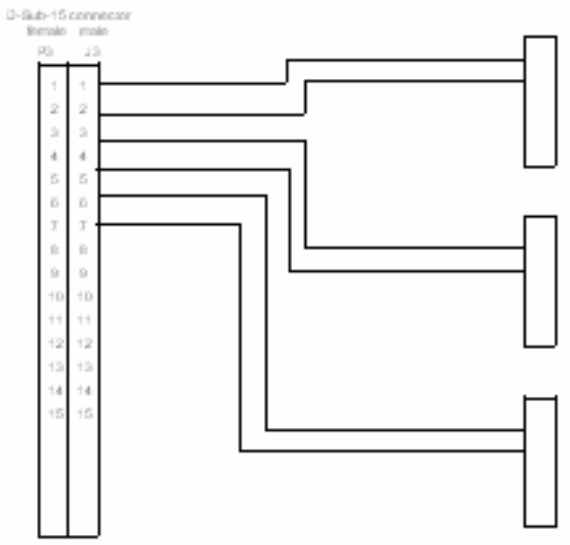

Connector Wiring

for: Robochair

Roger Bostelman

NIST $823.11 \quad 6 / 2 / 06$ 


\section{Towards Autonomous Control}

Refer to Photograph 8 for the following design drawings in this section.

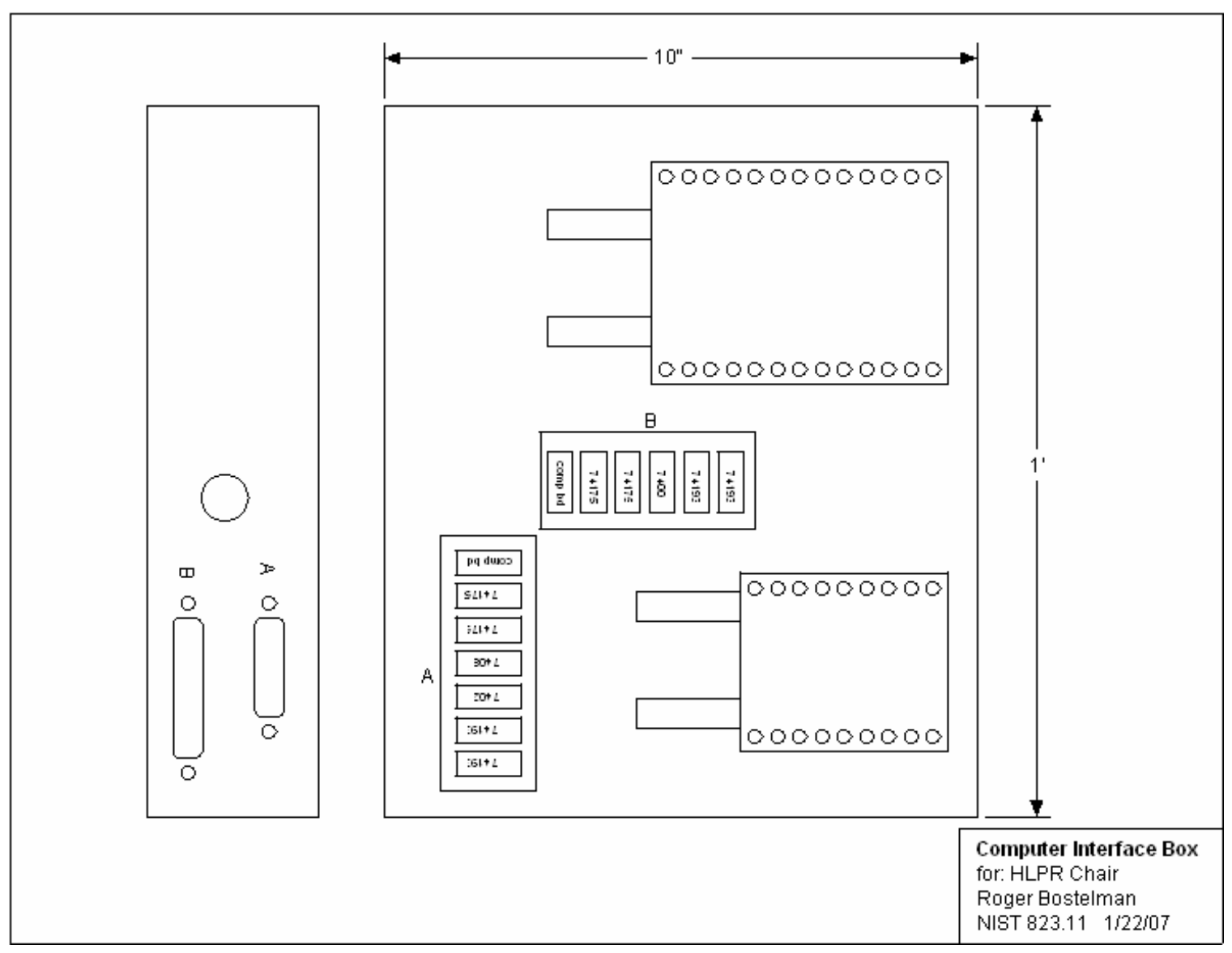




\section{Design of the HLPR Chair}

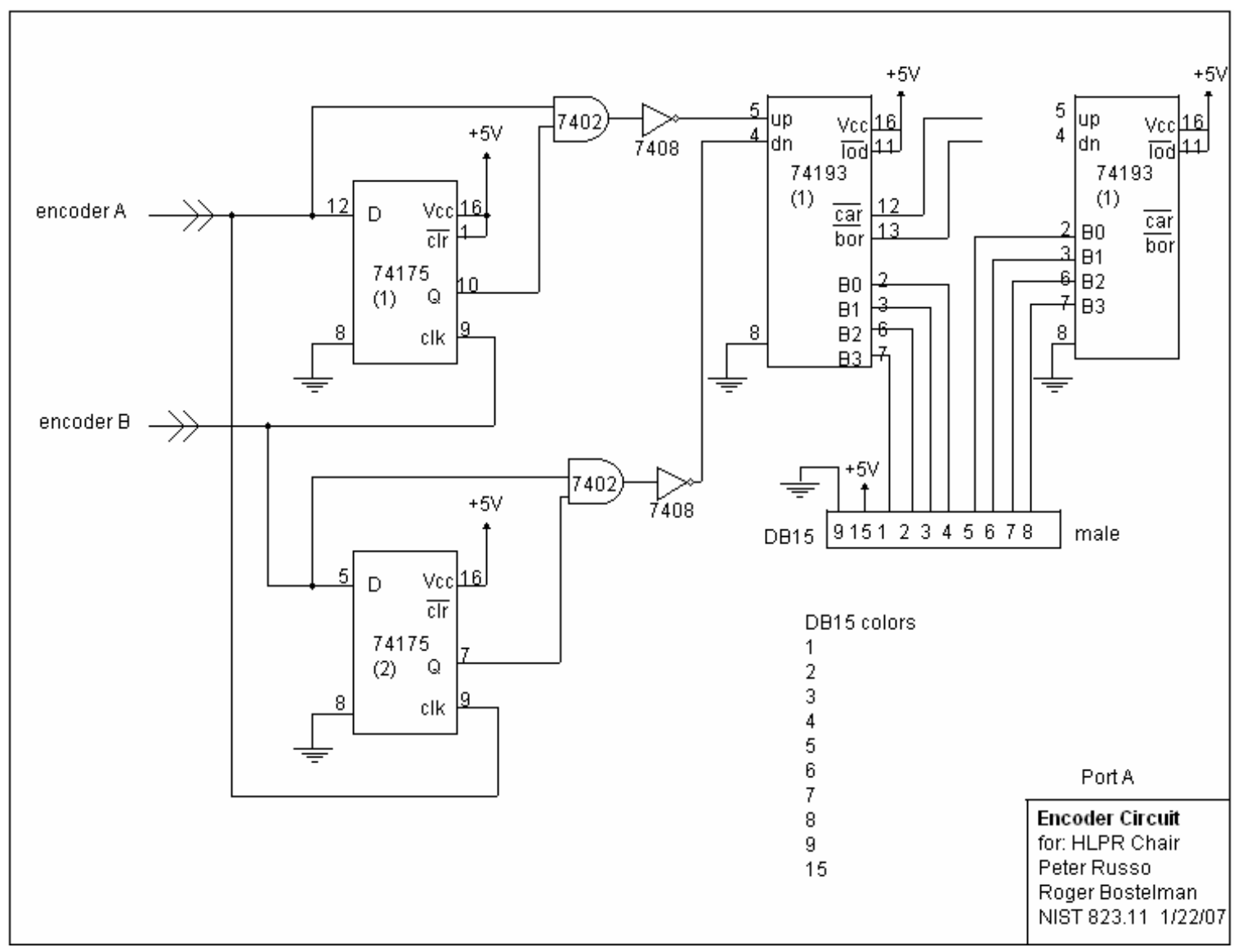




\section{Design of the HLPR Chair}
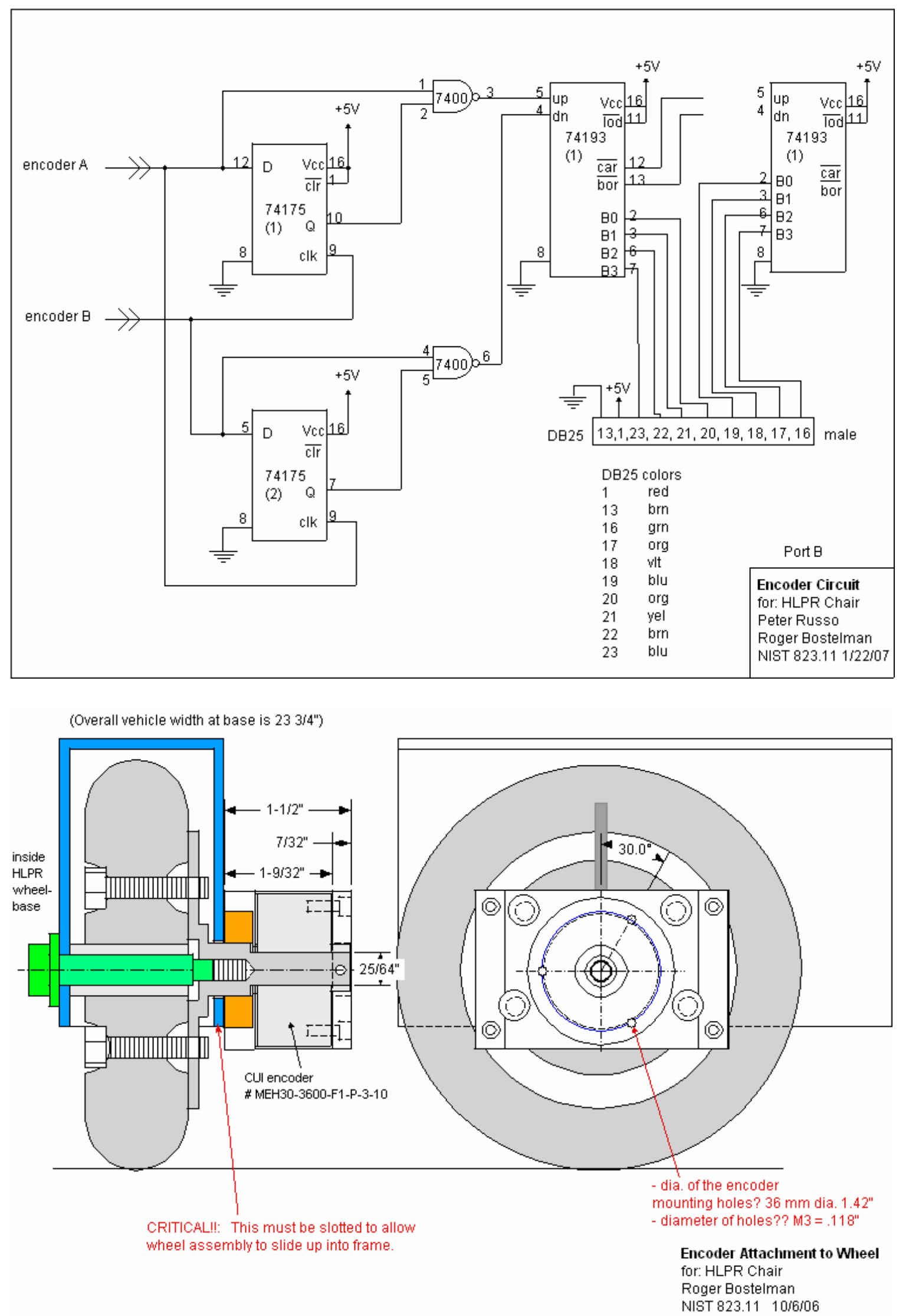


\section{Design of the HLPR Chair}

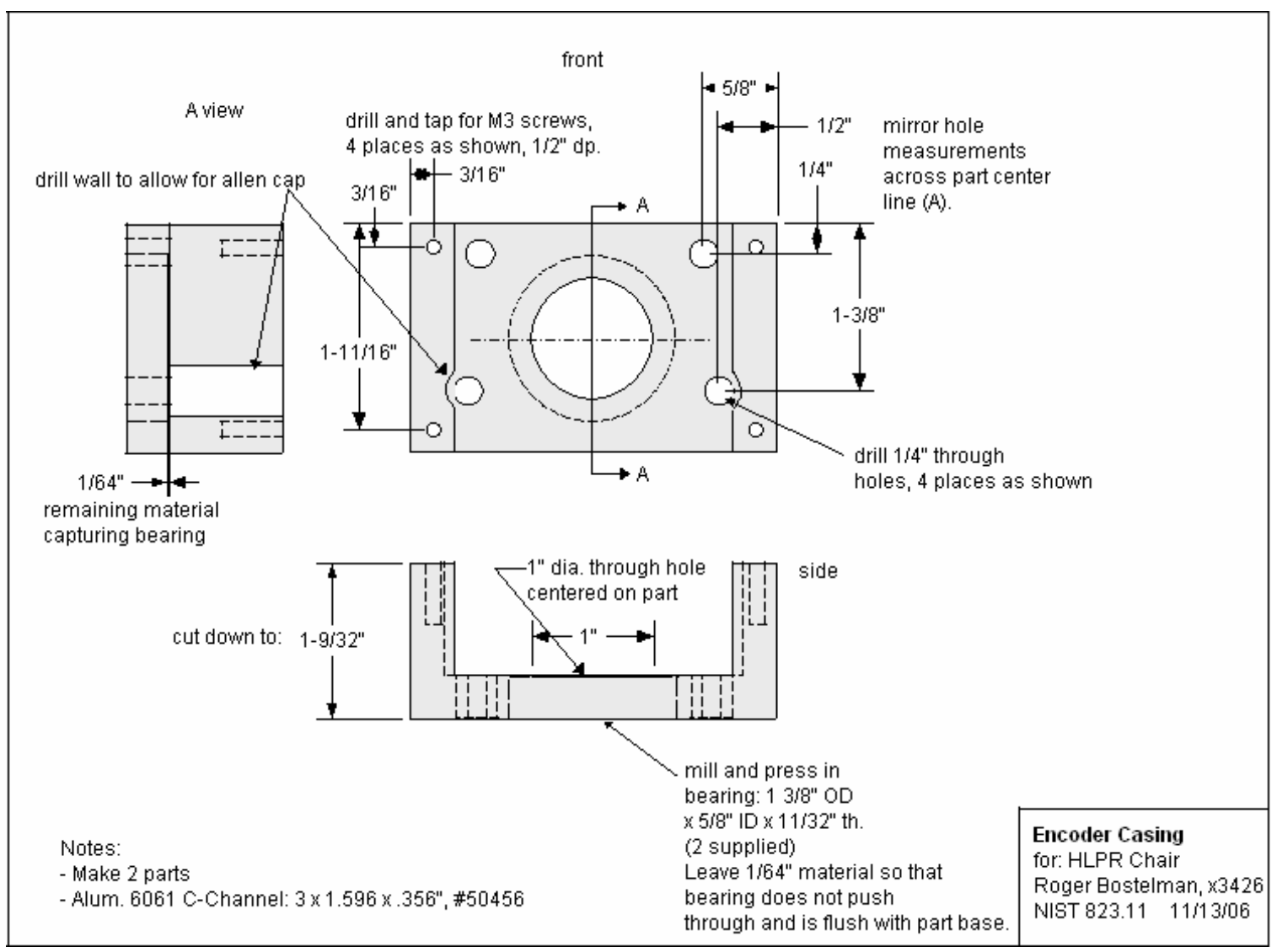




\section{Design of the HLPR Chair}

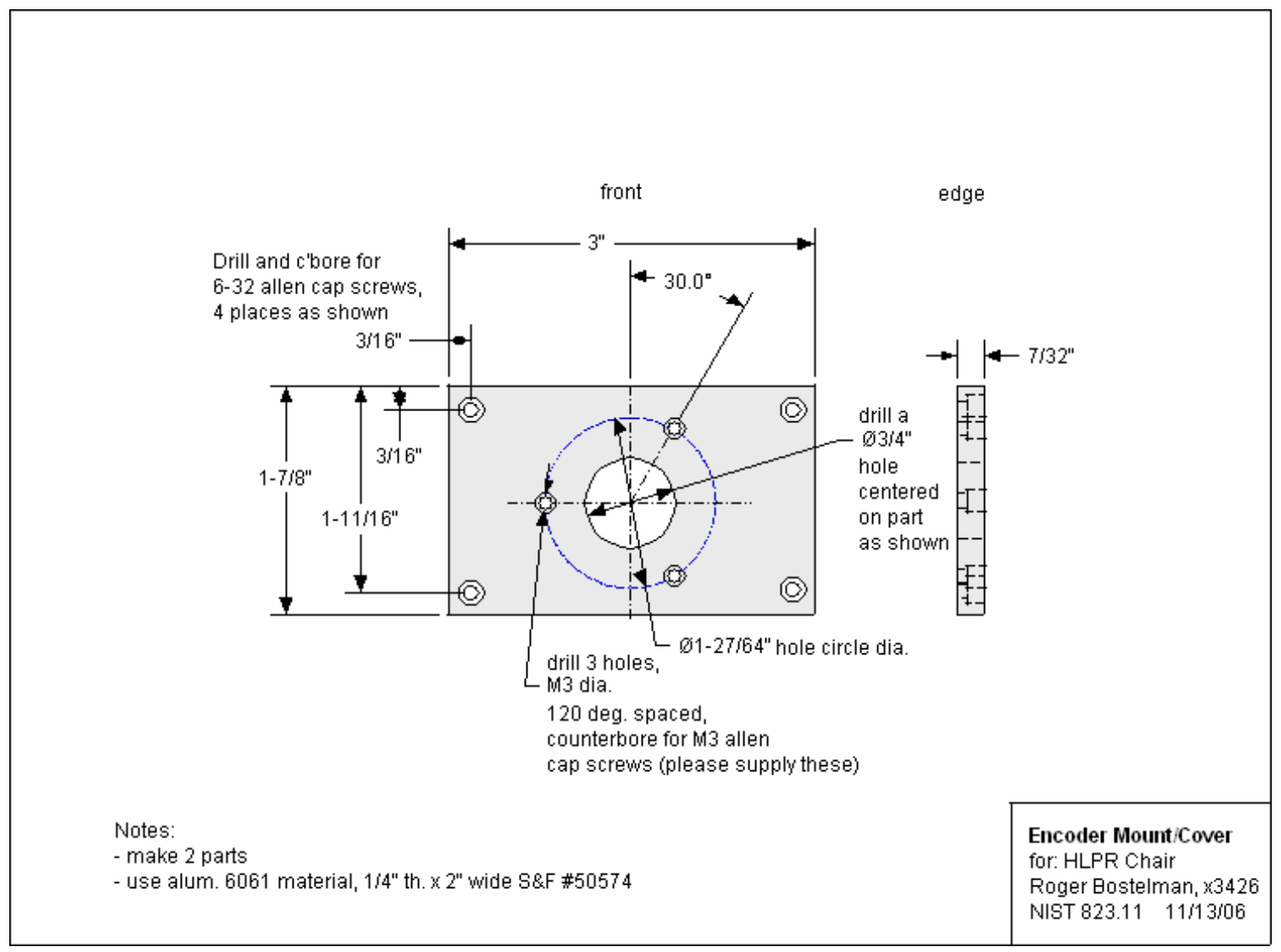




\section{Design of the HLPR Chair}

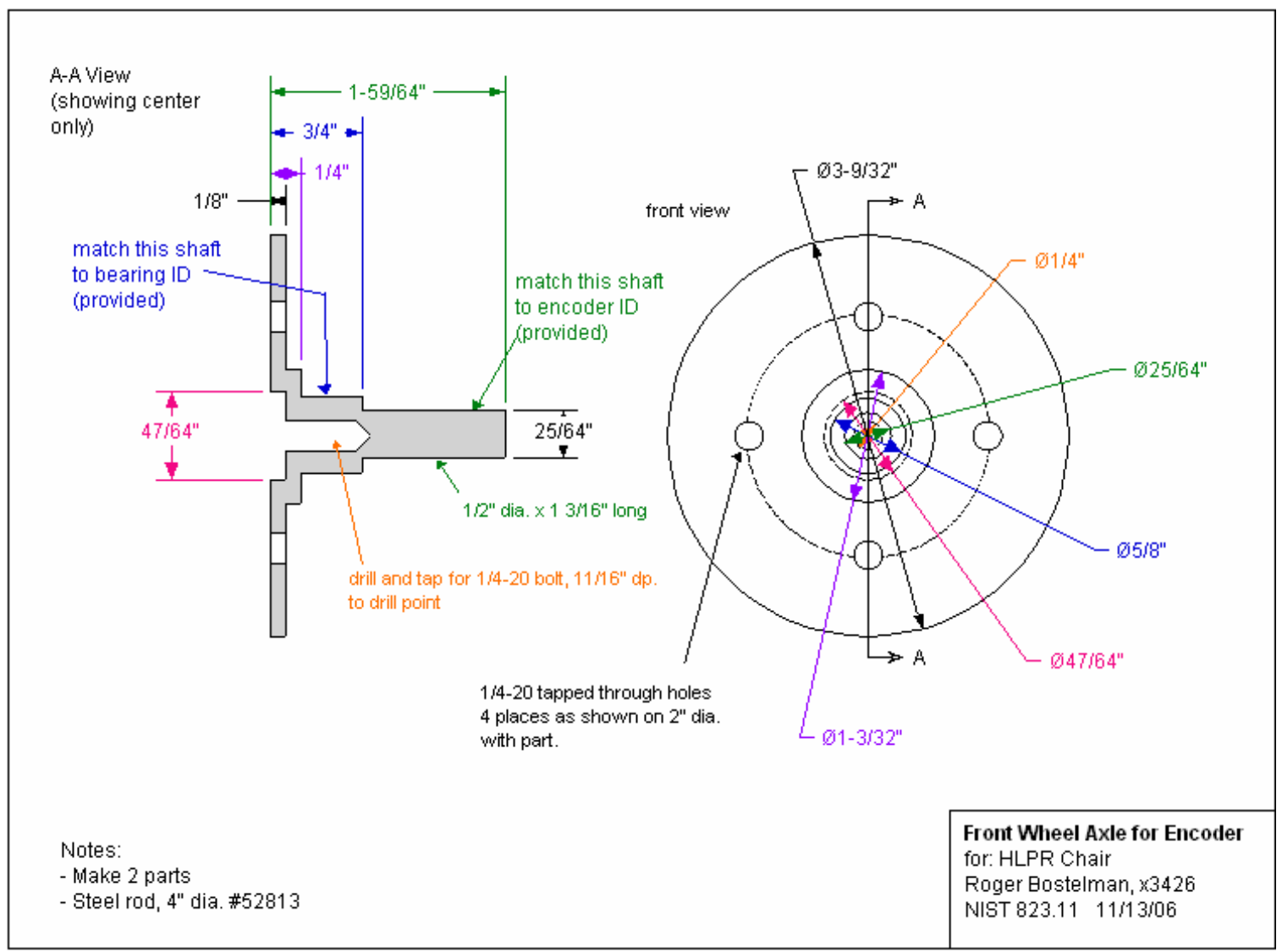




\section{Stability Testing}

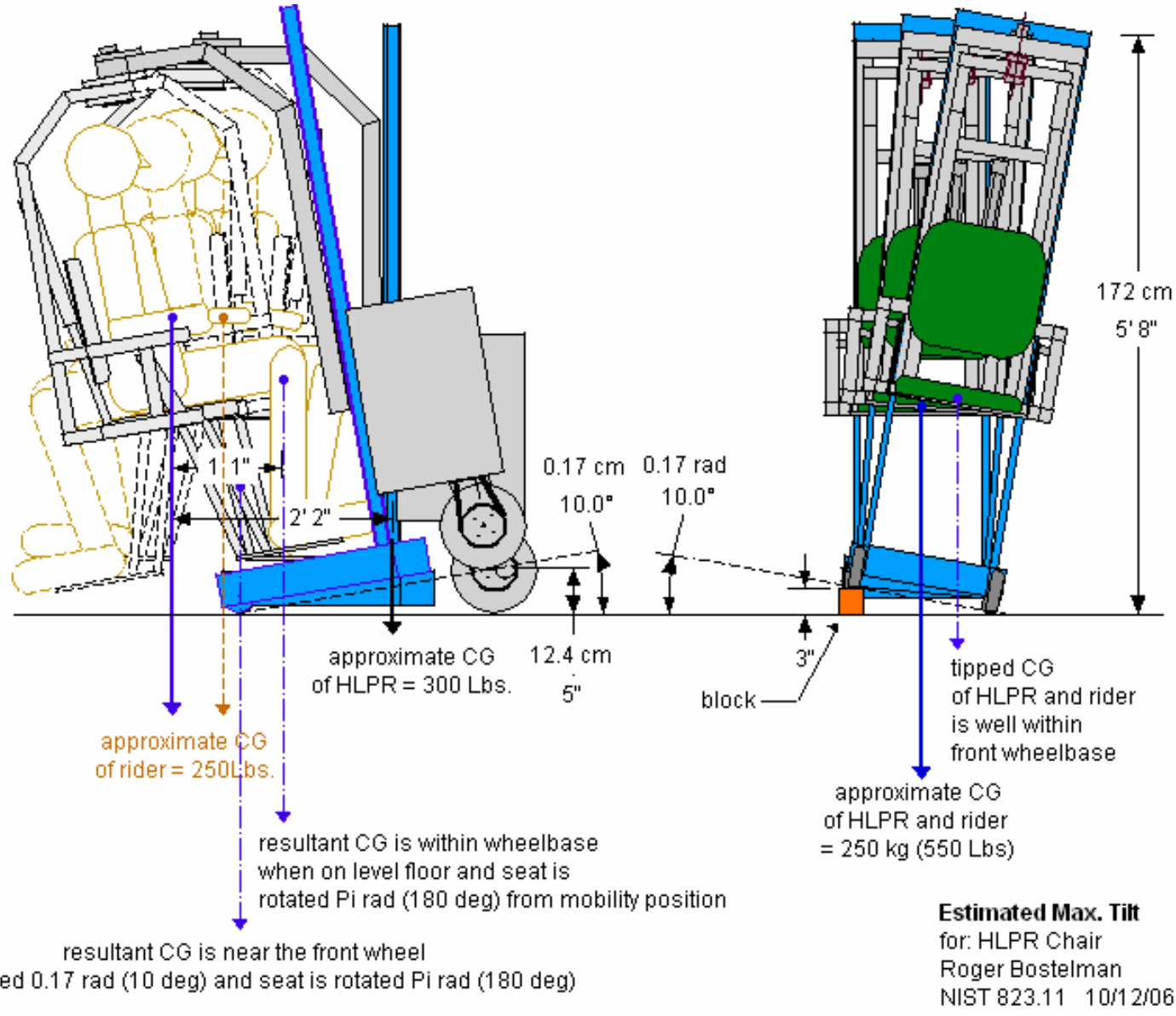




\section{Prototype Cost Estimate}

\begin{tabular}{|c|c|c|c|c|}
\hline Item & Manufacturer/Vendo & no. each & unit cost & cost \\
\hline Lift Actuator & & 1 & 286.00 & 286.00 \\
\hline Drive motor, 14A, PM & Leeson & 1 & 155.26 & 155.26 \\
\hline Steering motor, 1/8 hp & Leeson & 1 & 285.00 & 285.00 \\
\hline Amplifiers & Servo Systems & 3 & 295.00 & 885.00 \\
\hline Gear Reducers, couplings & McMaster Carr & 2 & 321.60 & 643.20 \\
\hline Lubricant & McMaster Carr & 1 & 27.70 & 27.70 \\
\hline Seat Actuator, 12" & McMaster Carr & 1 & 294.74 & 294.74 \\
\hline Footrest Actuator, 3" & Firgelli & 1 & 80.00 & 80.00 \\
\hline Torso Lift Actuator, 3" & Firgelli & 2 & 80.00 & 160.00 \\
\hline Arm pads - foam, vinyl & JoAnn Fabrics & 1 & 20.00 & 20.00 \\
\hline Seat, Backrest & & 1 & 50.00 & 50.00 \\
\hline Wheel, tire & McMaster Carr & 1 & 33.00 & 33.00 \\
\hline chain (unit $=$ per foot) & McMaster Carr & 3 & 3.47 & 10.41 \\
\hline Sprockets, 1.67, 5.06" & McMaster Carr & 1 & 38.33 & 38.33 \\
\hline Electrical boxes & Lowes & 3 & 13.00 & 39.00 \\
\hline Wire & & 1 & 100.00 & 100.00 \\
\hline Switches & & 4 & 40.00 & 160.00 \\
\hline Circuit Breakers & & 5 & 40.00 & 200.00 \\
\hline Joystick & & 2 & 300.00 & 600.00 \\
\hline Misc. Elect. Parts & & 1 & 100.00 & 100.00 \\
\hline Fork Lift frame & & 1 & 500.00 & 500.00 \\
\hline Seatbelt & & 2 & 119.99 & 239.98 \\
\hline Batteries, 12V, PC925 & Odyssey & 2 & 100.00 & 200.00 \\
\hline Battery, 12V, 10Ah & & 1 & 25.35 & 25.35 \\
\hline Shops work** & NIST & 1 & $5,000.00$ & $5,000.00$ \\
\hline \multirow[t]{2}{*}{ Misc. Parts - bolts, etc. } & & 1 & 200.00 & 200.00 \\
\hline & & total: & & $\$ 10,332.97$ \\
\hline
\end{tabular}

** Shop work for this prototype was dramatically reduced incorporating a redesigned seat and base frame through the use of bent tubing (see Modifications to Original Design section). The base frame was made from $5 \mathrm{~cm}$ (2 in) OD steel electrical conduit with a welded support bead and the seat frame was designed at NIST and procured from a pipe bending manufacturer. A $30 \mathrm{~cm}$ (12 in) diameter turntable bearing ring was used as the rotation device. The total for these components was approximately $\$ 400.00$ verses $\$ 5,000.00$. 